\title{
REMOVAL OF ARSENIC, CADMIUM AND LEAD FROM SYNTHETIC STORMWATER BY TWO LOW-COST ADSORBENTS: A KINETIC AND EQUILIBRIUM STUDY
}

\author{
by \\ Jason David \\ B. Eng., University of Guelph, 2012 \\ A thesis \\ presented to Ryerson University \\ in partial fulfillment of the \\ requirements for the degree of \\ Master of Applied Science \\ in the Program of \\ Environmental Applied Science and Management
}

Toronto, Ontario Canada, 2018

(C) Jason David, 2018 


\section{AUTHOR'S DECLERATION}

I hereby declare that I am the sole author of this thesis. This is a true copy of the thesis, including any required final revisions, as accepted by my examiners.

I authorize Ryerson University to lend this thesis to other institutions or individuals for the purpose of scholarly research I further authorize Ryerson University to reproduce this thesis by photocopying or by other means, in total or in part, at the request of other institutions or individuals for the purpose of scholarly research.

I understand that my thesis may be made electronically available to the public. 


\title{
REMOVAL OF ARSENIC, CADMIUM AND LEAD FROM SYNTHETIC STORMWATER BY TWO LOW-COST ADSORBENTS: A KINETIC AND EQUILIBRIUM STUDY
}

\author{
Master of Applied Science, 2018 \\ Jason David \\ Environmental Applied Science and Management \\ Ryerson University
}

\begin{abstract}
The adsorption isotherms and kinetics of two low cost adsorbents, Ladybug Sand and Greensand, were determined from multi-solute batch experiments using prepared synthetic stormwater containing arsenic, cadmium and lead. The adsorption equilibrium data were fit to the Langmuir, Freundlich and Henry isotherms using both nonlinear and linear regression techniques. Kinetic data were obtained at two different stormwater concentrations. The kinetic curves were fit to the pseudo-first-order, pseudo-second-order and homogenous surface diffusion model (HSDM). A solution to the HSDM was achieved using the user-oriented numeric solution proposed by Zhang et al. (2009). From the fitted kinetic models the reaction constants, $\mathrm{k}_{1}$ and $\mathrm{k}_{2}$, as well as the surface diffusion coefficient $\left(D_{s}\right)$ were determined. The maximum service lives of adsorbent columns comprised of Ladybug Sand or Greensand were calculated using the equilibrium column model (ECM) to evaluate the feasibility of the adsorbents for use in advanced stormwater treatment.
\end{abstract}




\section{ACKNOWLEDGEMENTS}

Firstly, I would like to thank my faculty supervisors Dr. Pushchak and Dr. Laursen who gave me the freedom to pursue this topic, provided me with valuable support and feedback, and were patient when things didn't work out. To my lab partners Aslam, Ramesh and Ryan, thank you for helping me out around the lab. I enjoyed our time working alongside each other. I would also like to thank Chris Bentley for lending a hand when needed. I wouldn't have been able to conduct my experiments without you. 


\section{TABLE OF CONTENTS}

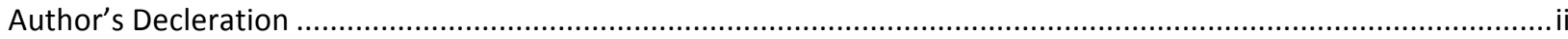

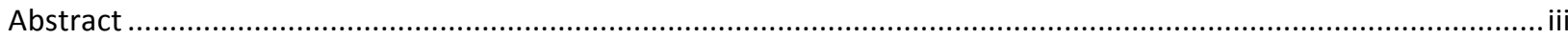

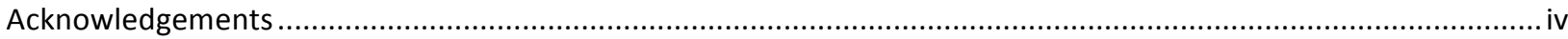

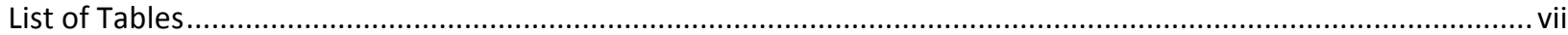

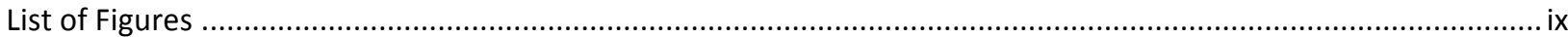

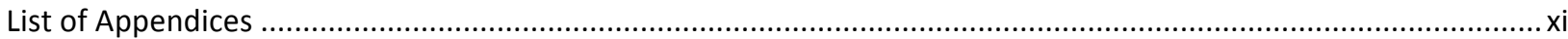

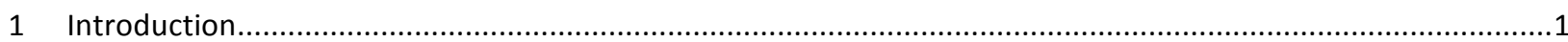

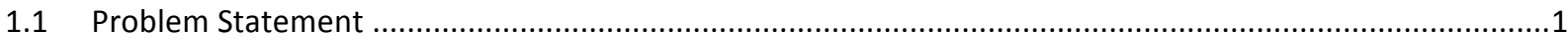

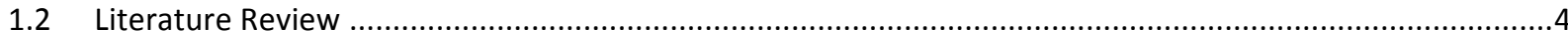

1.2.1 Advanced Stormwater Treatment: Adsorption .....................................................................

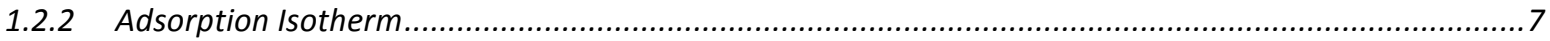

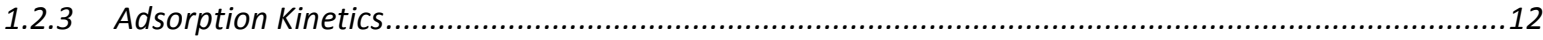

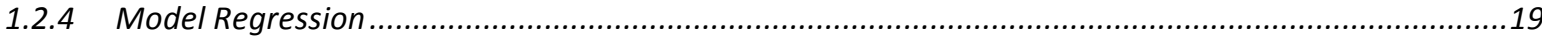

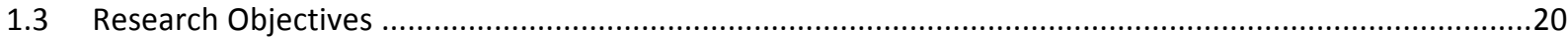

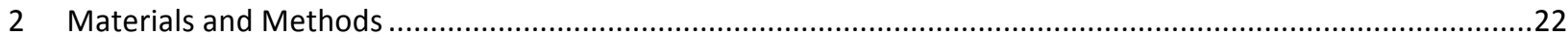

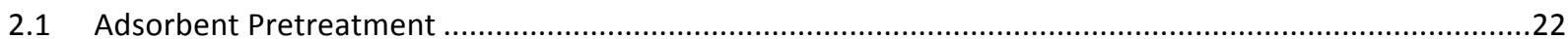

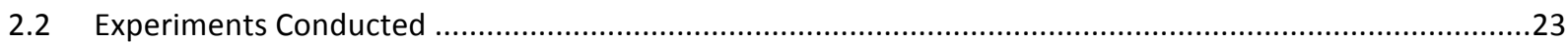

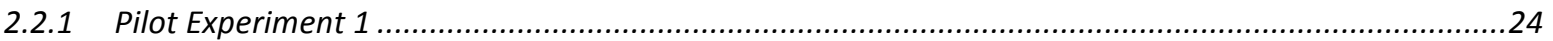

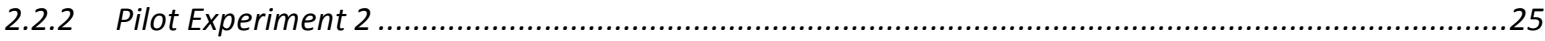

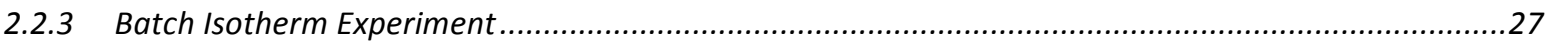

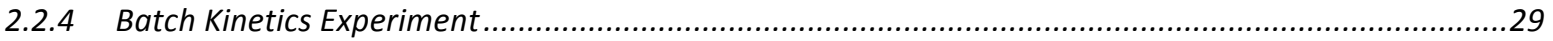

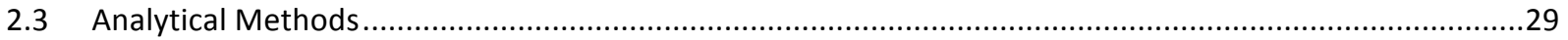




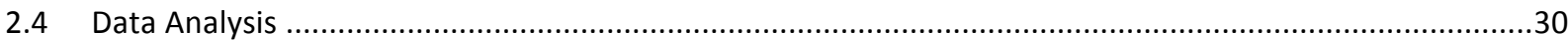

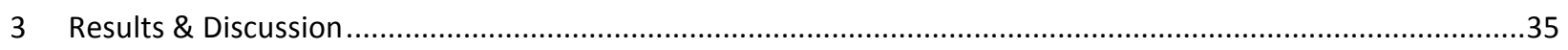

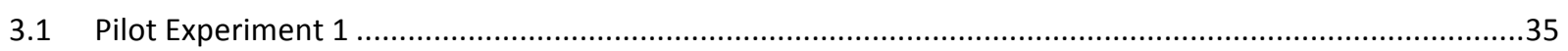

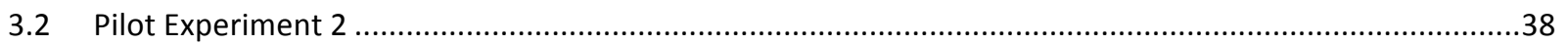

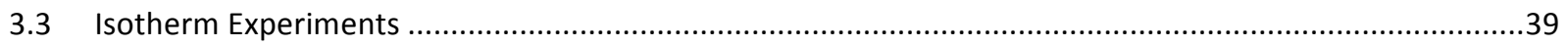

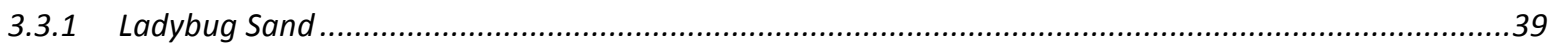

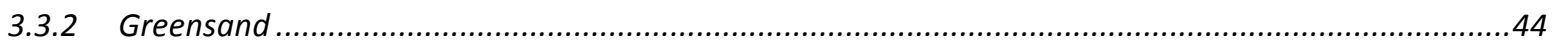

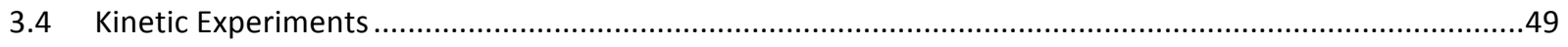

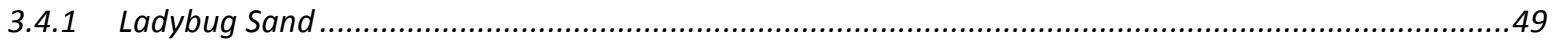

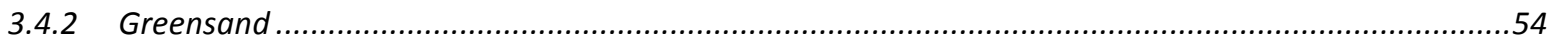

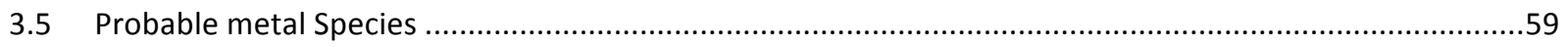

3.6 Feasibility of Adsorbent Column: Maximum Service Life ............................................................59

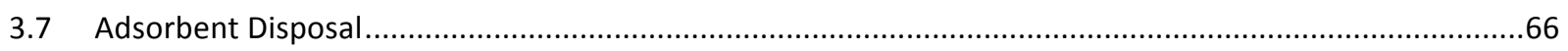

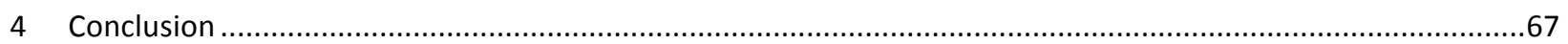

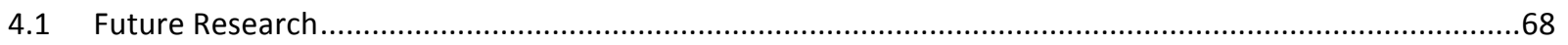

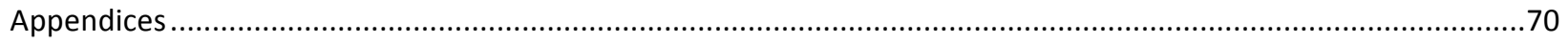

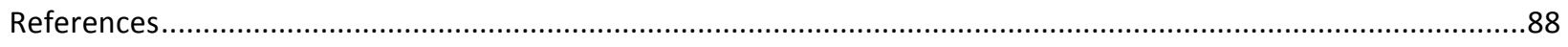

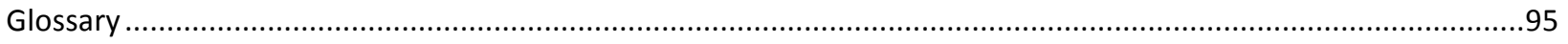




\section{LIST OF TABLES}

Table 1 - Nonlinear and linear isotherm equations, and linear plots .................................................................11

Table 2 - Nonlinear and linear reaction kinetic model equations, and linear plots ...............................................15

Table 3 - Summary of HSDM equations for a batch reactor..........................................................................

Table 4 - Limitations of linear Langmuir equations …......................................................................................

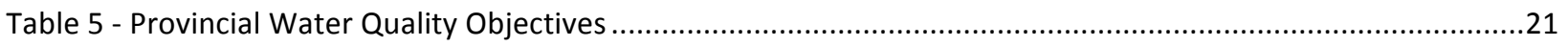

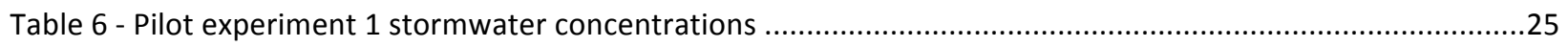

Table 7 - Pilot experiment 2 stormwater concentrations ........................................................................26

Table 8 - Minimum detection limits, PWQO, average concentration ranges, SWAMP EMC and concentration of synthetic stormwaters used in isotherm and kinetic experiments...........................................................28

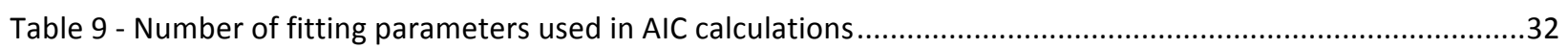

Table 10 - Parameters used in empirical equation that describes the HSDM solution for batch reactors, adapted from Zhang et al. (2009)

Table 11 - Concentration of $\mathrm{Cu}, \mathrm{Fe}, \mathrm{Zn}$ and As in Ladybug and Green sands as well as anoxic and oxic synthetic stormwaters from pilot experiment 1

Table 12 - Isotherm parameters derived from nonlinear regression of Ladybug Sand batch data.

Table 13 - Comparison of Langmuir isotherm parameters determined by nonlinear and linear regressions for Ladybug Sand batch data

Table 14 - Comparison of Freundlich isotherm parameters determined by nonlinear and linear regressions of Ladybug Sand batch data

Table 15 - Langmuir, Freundlich and Henry isotherm parameters and coefficient of determination of nonlinear regressions using Green sand batch data.

Table 16 - Langmuir isotherm parameters determined by nonlinear and linear regressions for Greensand batch data.

Table 17 - Freundlich isotherm parameters determined by nonlinear and linear regressions of Greensand batch equilibrium data. 
Table 18 - Reaction kinetic model parameters for Ladybug Sand

Table 19 - Comparison of reaction kinetic model parameters determined by nonlinear and linear regressions for Ladybug Sand..... .54

Table 20 - Kinetic model parameters for Greensand

Table 21 - Comparison of reaction kinetic model parameters determined by nonlinear and linear regressions for

Greensand.

Table 22 - Probable metal species in stormwater samples after 24 hours

Table 23 - Equilibrium adsorbent loadings for $\mathrm{As}, \mathrm{Cd}$ and $\mathrm{Pb}$ at 100, 2 and $40 \mu \mathrm{g} / \mathrm{L}$

Table 24 - Ladybug Sand and Greensand adsorption efficiencies

Table 25 - Ladybug Sand filter life expectancy in months as a function of drainage area and column diameter ......64

Table 26 -Greensand filter life expectancy in months as a function of drainage area and column diameter .65

Table 27 - Life expectancy of a Ladybug Sand filter at different influent arsenic concentrations. .66

Table 28 - Life expectancy of a Greensand filter at different influent arsenic concentrations ..............................66

Table 29 - SWAMP Average Event Mean Concentrations and Performance Data (SWAMP, 2015) ........................70

Table 30 - SWAMP Average Event Mean Concentrations and Performance Data (Continued) (SWAMP, 2015)........71

Table 31 - Spectral analysis of sands (ICP-ES) 


\section{LIST OF FIGURES}

Figure 1 - Example breakthrough curve where $\mathrm{C}=$ instantaneous effluent concentration and $\mathrm{C}_{\mathrm{o}}=$ inlet concentration.

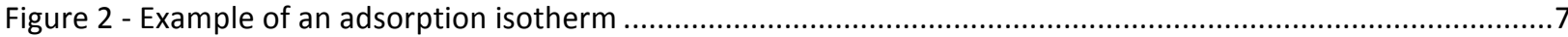

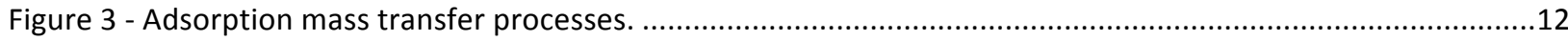

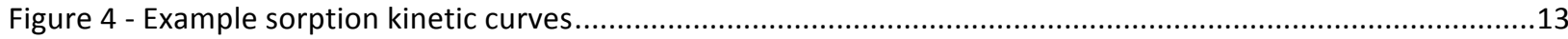

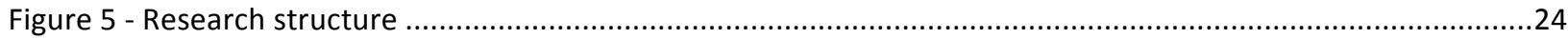

Figure 6 -Pilot experiment 1: water phase concentrations of As over 48-hour sampling period for (a) Ladybug Sand and (b) Greensand .35

Figure 7 - Pilot experiment 1: water phase concentrations of Cu over 48-hour sampling period for (a) Ladybug Sand and (b) Greensand .36

Figure 8 - Pilot experiment 1: water phase concentrations of Fe over 48-sampling period for (a) Ladybug Sand and

(b) Greensand .36

Figure 9 - Pilot experiment 1: water phase concentrations of Zn over 48-hour sampling period for (a) Ladybug Sand and (b) Greensand

Figure 10 - Water phase concentration of $\mathrm{As}, \mathrm{Cd}$ and $\mathrm{Pb}$ in (a) Ladybug Sand samples and (b) Greensand samples 38

Figure 11 - Ladybug Sand batch equilibrium data and best-fit isotherms.

Figure 12 - Greensand batch equilibrium data and best-fit isotherms .48

Figure 13 - Ladybug Sand kinetic data and kinetic models derived from nonlinear regression....... .53

Figure 14 - Greensand kinetic data and kinetic models derived from nonlinear regression .58

Figure 15 - Linear regression plots for arsenic equilibrium data .74

Figure 16 - Linear regression plots for cadmium data. .76

Figure 17 - Linear regression plots for lead equilibrium data .78

Figure 18 - (a) Pseudo-first-order and (b) pseudo-second-order models applied to arsenic kinetic batch data........79

Figure 19 - (a) Pseudo-first-order and (b) pseudo-second-order models applied to cadmium kinetic batch data....80

Figure 20 - (a) Pseudo-first-order and (b) pseudo-second-order models applied to lead kinetic batch data. .81 
Figure 21 - (a) Pseudo-first-order and (b) pseudo-second-order models applied to arsenic kinetic batch data........82

Figure 22 - (a) Pseudo-first-order and (b) pseudo-second-order models applied to Lead kinetic batch data. ..........83

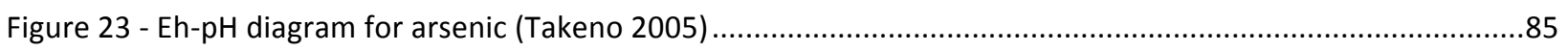

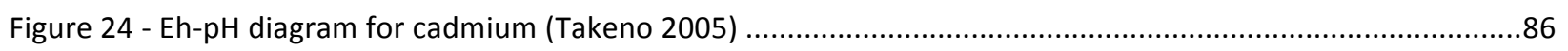

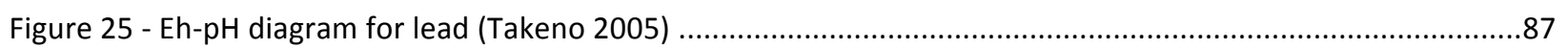




\section{LIST OF APPENDICES}

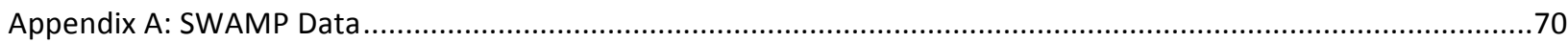

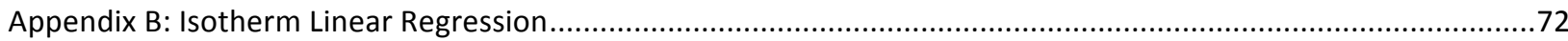

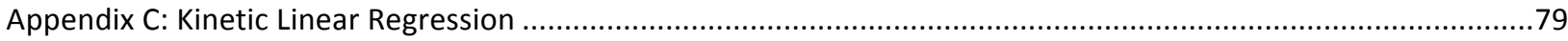

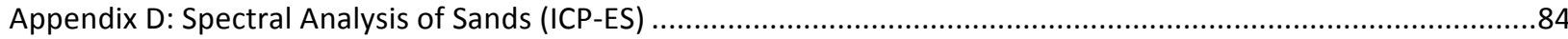

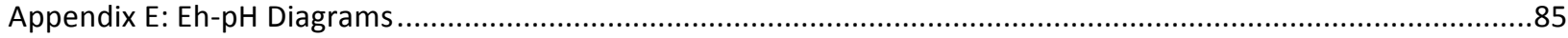




\section{INTRODUCTION}

\subsection{PROBLEM STATEMENT}

As communities urbanize, their landscape surfaces become more impermeable. This process alters the natural hydrologic cycle, increasing the proportion of precipitation converted into runoff and decreasing the amount of water infiltrated into the ground and evapotranspirated. These hydrologic changes can impact groundwater levels and stream baseflow, cause increased flooding and erosion, and degrade sediment and water quality (Ministry of the Environment 2003; Bradford and Gharabaghi 2004).

The impact of urban runoff on the quality of receiving water bodies can be substantial. According to the 2004 Water Quality Report to U.S. Congress, urban runoff was one of the top ten contributors to water quality degradation of rivers, streams, lakes, ponds, reservoirs, bays and estuaries assessed within the United States (EPA 2009).

To mitigate the impacts of urban runoff, a variety of stormwater treatment best management practices (BMP) have been developed. Historically, stormwater treatment BMPs have been implemented in accordance with design guidelines that dictate storage requirements that provide a presumed total suspended solids (TSS) removal efficiency (Clark and Pitt 2012). This is currently the case with the design guidelines provided by the Ontario Ministry of the Environment and Climate Change (Ministry of the Environment 2003). The problem of relying on a removal efficiency performance criterion is that, although it may ensure a large percentage of the TSS is removed, it can not ensure discharge concentrations are within an acceptable range (Bradford and Gharabaghi 2004). This was found to be the case for a number of stormwater 
BMPs analyzed by the Toronto and Region Conservation Authority (TRCA) as part of the Stormwater Management Assessment and Performance (SWAMP) program, a study conducted in 2005 that assessed the long-term performance of ten stormwater management facilities in Ontario (Toronto and Region Conservation Authority 2005). Despite meeting significant reductions in TSS, the BMPs' mean effluent concentrations of several pollutants were above receiving water quality objectives (i.e. the provincial water quality objectives or PWQO). Furthermore, TRCA (2005) went on to summarize that:

- TSS removal efficiencies were often greater than the removal efficiencies of other pollutants that readily bind to sediment

- Roughly 65 to $85 \%$ of TSS effluent particles fell within the clay size range $(<4$ microns). [Therefore] further reduction in observed effluent TSS concentrations may not be practically achievable by simply expanding the volume storage in the facilities

- Meeting stringent receiving water quality objectives for these pollutants is clearly not an 'achievable' goal for facilities that depend primarily on gravity settling for water quality treatment

(Toronto and Region Conservation Authority 2005)

The contaminants that were identified by the SWAMP program as having mean effluent concentrations above the PWQO, the provincial surface water quality standard, were copper, zinc, iron, lead, cadmium, chloride, phosphorus and Escherichia coli. Reported event mean concentrations from the SWAMP program can be found in Appendix A.

With increasing concerns regarding water quality degradation, some regulatory agencies have moved towards using specified stormwater discharge limits (Clark and Pitt 2012). As 
concluded by the TRCA (2005), if stormwater permits were to include effluent concentration limits, the use of gravity-settling BMP (e.g. stormwater ponds) alone would not be sufficient to meet strict permit requirements, and additional treatment methods would have to be employed. This is a significant problem considering that in Ontario, stormwater ponds are the most prevalent stormwater treatment BMP (Ministry of the Environment 2003). In the Greater Toronto Area alone, there are an estimated 1500 stormwater ponds (Koumoulas 2015). Furthermore, the colloidal and dissolved pollutants that are not effectively removed by these ponds tend to be the most mobile and bioavailable, and therefore exhibit high levels of toxicity (Tuccillo 2006; Vollertsen, Lange, Pedersen, Hallager, and Brink-kjær 2009; Wium-Andersen et al. 2012). 


\subsection{LITERATURE REVIEW}

\subsubsection{ADVANCED STORMWATER TREATMENT: ADSORPTION}

One promising approach for removing the colloidal and dissolved contaminants in stormwater pond effluent is the use of adsorption (Genç-Fuhrman et al. 2007). Adsorption is a surface phenomenon that involves the movement of a substance from a bulk phase (e.g. liquid) to the surface of a receiving phase (usually a solid particle) (Gupta et al. 2009; Worch 2012). When referring to adsorption, it is customary to refer to the substance that is subject to transfer as the adsorbate and the receiving phase as the adsorbent (Worch 2012). Adsorption can involve physical or chemical interactions. Physisorption, or physical adsorption, involves the physical attraction (i.e. usually van der Waals forces) between the adsorbate and adsorbent (Gupta et al. 2009). Chemisorption, or chemical adsorption, involves the chemical bonding of the adsorbate and adsorbent (Gupta et al. 2009). Of the two types of adsorption, chemisorption is typically stronger and less prone to desorption (Gupta et al. 2009).

Adsorbents can be used in either batch or fixed-bed (i.e. flow-through) reactors. Hereafter, the term adsorption column or filter will be used interchangeably with fixed-bed reactor. In batch reactors the adsorbent is typically dispersed in a large volume of liquid and needs to be separated from the liquid phase before the liquid is discharged (Worch 2012). Due to the nature of the batch reactor, smaller sized sorbents can be used (Worch 2012). Conversely, in a fixed-bed reactor, the liquid filters through the voids in a adsorbent column, typically requiring larger sized sorbents to ensure adequate hydraulic conductivity (Worch 2012). Fixed-bed adsorbers are of more practical use in a stormwater context because they don't require an 
additional step to separate the adsorbent from the liquid or constant agitation to keep the adsorbent dispersed. Thus, only fixed-bed adsorber or adsorption filter design will be discussed.

Predicting the breakthrough behavior of an adsorption filter is essential to its design (Cooney 1999; Worch 2012). By predicting the breakthrough behavior, the time at which the effluent becomes intolerably degraded can be determined. A filter's breakthrough behavior can be described by the change in effluent concentration (often expressed as a ratio of the inlet concentration) over time or volume of effluent (Worch 2012). This is represented graphically as a breakthrough curve (BTC). An example of a BTC is provided in Figure 1.

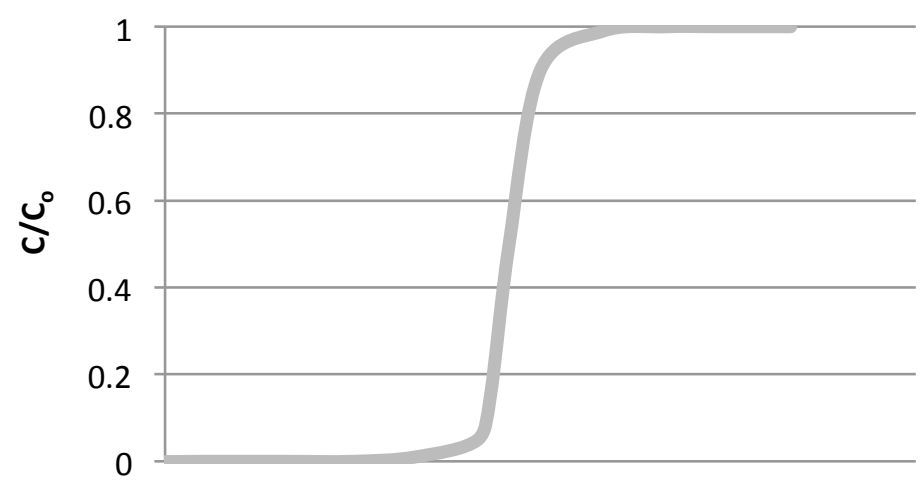

Effluent Volume or Time

Figure 1 - Example breakthrough curve where $C=$ instantaneous effluent concentration and $C_{o}$ $=$ inlet concentration.

There are two main methods by which breakthrough behavior can be predicted: scale-up methods and breakthrough curve (BTC) models (Cooney 1999; Worch 2012). Scale-up methods are strictly empirical in nature, and utilize various scaling factors to design lab-scale sorption filters, which attempt to mimic actual mass transfer conditions (Worch 2012). Common scale-up 
methods include rapid small-scale column testing (RSSCT), the length of unused bed (LUB) approach, the empty-bed contact time (EBCT) approach and the bed depth-service time (BDST) approach (Cooney 1999). Hydraulic similarity between lab-scale and full-scale conditions is integral to the accuracy of these methods (Worch 2012). Conversely, BTC models are theoretical mathematical models. Consequently, these models can be applied more widely (Worch 2012). Due to the wide scale applicability of BTC models, these models will be the focus of the following discussion.

The three components of most BTC models are (1) the differential mass balance equation, (2) adsorption isotherm(s) and (3) adsorption mass transfer equations (Worch 2008). The differential mass balance equation for an adsorption column or fixed-bed reactor, as presented in Cooney (1999), is,

$$
v \epsilon S(C)_{z}-v \epsilon S(C)_{z+\Delta Z}+\epsilon S \Delta Z\left(\frac{\partial C}{\partial t}\right)+(1-\epsilon) S \Delta Z\left(\frac{\partial q}{\partial t}\right)=0
$$

where $v$ is the average axial velocity flowing in the void space, $\epsilon$ is the void fraction of the column bed, $\mathrm{S}$ is the cross-sectional area of the column, $\mathrm{C}$ is concentration, $\mathrm{Z}$ is the axial distance and $\mathrm{q}$ is adsorbent loading. The flow (Q) is related to the average axial velocity $(v)$ by the equation $Q=v \epsilon S$. Dividing by $\epsilon S \Delta Z$, taking the limit as $\Delta Z \rightarrow 0$ and rearranging, the equation becomes,

$$
v \epsilon\left(\frac{\partial C}{\partial Z}\right)+\epsilon\left(\frac{\partial C}{\partial t}\right)+(1-\epsilon)\left(\frac{\partial q}{\partial t}\right)=0
$$

The first term of Eq. 2 represents the flow of solute into and out of the system; the second term represents the accumulation of solute within the interstitial space; and the third term represents the rate of adsorption of the solute onto the adsorbent. It should be noted that axial 
dispersion has been neglected, which can affect the flow of solute into and out of the system. Neglecting dispersion is often appropriate when the fluid phase is a liquid, except at extremely low flow rates (Cooney 1999). Furthermore, if the adsorber is designed to eliminate maldistribution and dead volume, dispersion is typically negated (Knaebel 2007).

\subsubsection{ADSORPTION ISOTHERM}

An adsorption isotherm is a mathematical equation that describes the relationship between a solute's adsorbent loading $\left(\mathrm{q}_{\mathrm{e}}\right)$ and water phase concentration $\left(\mathrm{C}_{\mathrm{e}}\right)$ at equilibrium (Limousin et al. 2007). The term isotherm implies that the equation is valid only for a given temperature (Worch 2012). An example of an adsorption isotherm is provided in Figure 2.

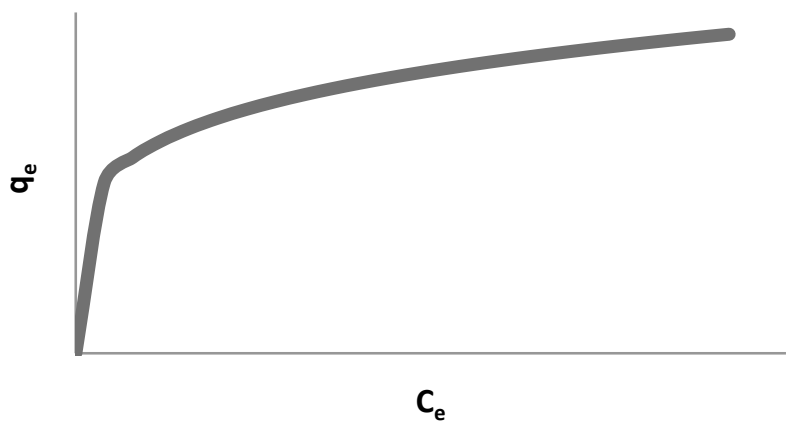

Figure 2 - Example of an adsorption isotherm

To determine an adsorption isotherm, the equilibrium adsorbent loading has to be determined at different concentrations. A common technique used to determine the equilibrium adsorbent loading is the bottle-point method, or batch method (Cooney 1999; Worch 2012). This method is used in many sorption equilibrium studies (Genç-Fuhrman et al. 2007; Arias and Sen 2009; Vollertsen, Lange, Pedersen, Hallager, Bruus, et al. 2009; Vijayakumar et al. 2012; Wium- 
Andersen et al. 2012; Reddy et al. 2014) and is the recommended approach by Ali \& Gupta (2006) for the characterization of low-cost sorbents. To conduct batch adsorption equilibrium experiments, a volume of water with a known concentration of solute(s), and a known mass of adsorbent, is added to a batch reactor (i.e. a bottle or other type of container), which is then shaken or stirred until equilibrium is reached (Worch 2012). The amount adsorbed to the adsorbent can be calculated using the following mass balance equation,

$$
q=\frac{V}{M}\left(C_{o}-C\right) \quad E q .3
$$

where $\mathrm{q}$ is the adsorbent loading, $\mathrm{C}_{\mathrm{o}}$ is the initial solute concentration, $\mathrm{C}$ is the instantaneous solute concentration, $\mathrm{V}$ is the volume of solution, and $\mathrm{M}$ is the mass of adsorbent (Worch 2012; Reddy et al. 2014).

There is no universal isotherm that can describe all adsorbate-adsorbent systems (Worch 2012). Therefore, to accurately describe the various sorption relationships, many isotherm equations have been developed (Worch 2012). The isotherm equations vary in the number of parameters used. Although increasing the number of parameters typically improves the quality of data fitting, when applying the isotherm to sorption models, using an isotherm equation with the lowest number of parameters is recommended to minimize complexity (Worch 2012).

The simplest isotherm equations are the horizontal and linear isotherms. The horizontal (or irreversible) isotherm is concentration independent, and is typical of very high solute concentrations when sorption saturation (i.e. when sorption capacity does not change with increasing solute concentration) is reached (Worch 2012). The horizontal isotherm can be described by Eq. 4 . 


$$
q_{e}=\text { constant }
$$

Eq. 4

Conversely, the linear, or Henry isotherm is typical of very low concentrations (Worch 2012). The Henry isotherm describes a sorption relationship whereby equilibrium solute concentration and sorption capacity are linearly related and is expressed by the equation,

$$
q_{e}=K_{H} C_{e}
$$

Eq. 5

where $K_{H}$ is the Henry isotherm constant (Worch 2012).

Two of the most commonly used and widely applicable isotherms are the Langmuir and Freundlich isotherms (Cooney 1999; Ho 2004a; Worch 2012). These isotherms involve two fitting parameters. The Langmuir isotherm is described by the equation,

$$
q_{e}=\frac{q_{m} b C_{e}}{1+b C_{e}}
$$

Eq. 6

where $\mathrm{q}_{\mathrm{m}}$ is the adsorbent loading at saturation, and $\mathrm{b}$ is the Langmuir adsorption coefficient (Bolster and Hornberger 2007). At low concentrations the Langmuir equation reduces to the linear Henry equation and at high concentrations it reduces to the horizontal isotherm equation (Worch 2012). The Langmuir isotherm was derived based on the following assumptions: each adsorption site can bind to only one adsorbate molecule and every adsorption site has the same energy of adsorption (i.e. bond strength) (Cooney 1999). The Langmuir isotherm has been extensively applied to liquid-solid-phase adsorption systems (Ho 2004a), including the sorption 
of metal solutes (Echeverría et al. 1998; Ho 2006; Argun et al. 2007; Arias and Sen 2009; WiumAndersen et al. 2012; Sukpreabprom et al. 2014).

The Freundlich isotherm can be described by the equation (Worch 2012),

$$
q_{e}=K C_{e}^{1 / n}
$$

Eq. 7

where $\mathrm{K}$ and $\mathrm{n}$ are isotherm parameters. The parameter $\mathrm{K}$ is an indication of the strength of adsorption (Worch 2012). The larger the K value, the greater the adsorption capacity (Worch 2012). The exponent $n$ determines the curvature of the isotherm (Worch 2012). When $n=1$ the isotherm is linear. When $1 / \mathrm{n}<1$ the isotherm will exhibit high adsorbent loadings at low concentrations, whereas when $1 / \mathrm{n}>1$ the opposite is true (Worch 2012). Therefore, a $1 / \mathrm{n}>1$ is unfavorable. The Freundlich isotherm was the first model to describe multilayer adsorption, with non-homogenous adsorption sites (Foo and Hameed 2010). The Freundlich equation assumes that $\mathrm{q}_{\mathrm{e}}$ can increase indefinitely with increasing values of $\mathrm{C}_{\mathrm{e}}$ (Cooney 1999). In reality this is impossible; therefore, the Freundlich isotherm typically fails to fit experimental data at very high $\mathrm{C}_{\mathrm{e}}$ values (Cooney 1999) and is best used to describe the medium concentration range (Worch 2012). In the context of wastewater treatment, solutions are typically dilute enough that $C_{e}$ values should be below the Freundlich isotherm breaking point (Cooney 1999). 
A summary of the isotherm equations and their linearized forms are provided in Table 1.

Table 1 - Nonlinear and linear isotherm equations, and linear plots

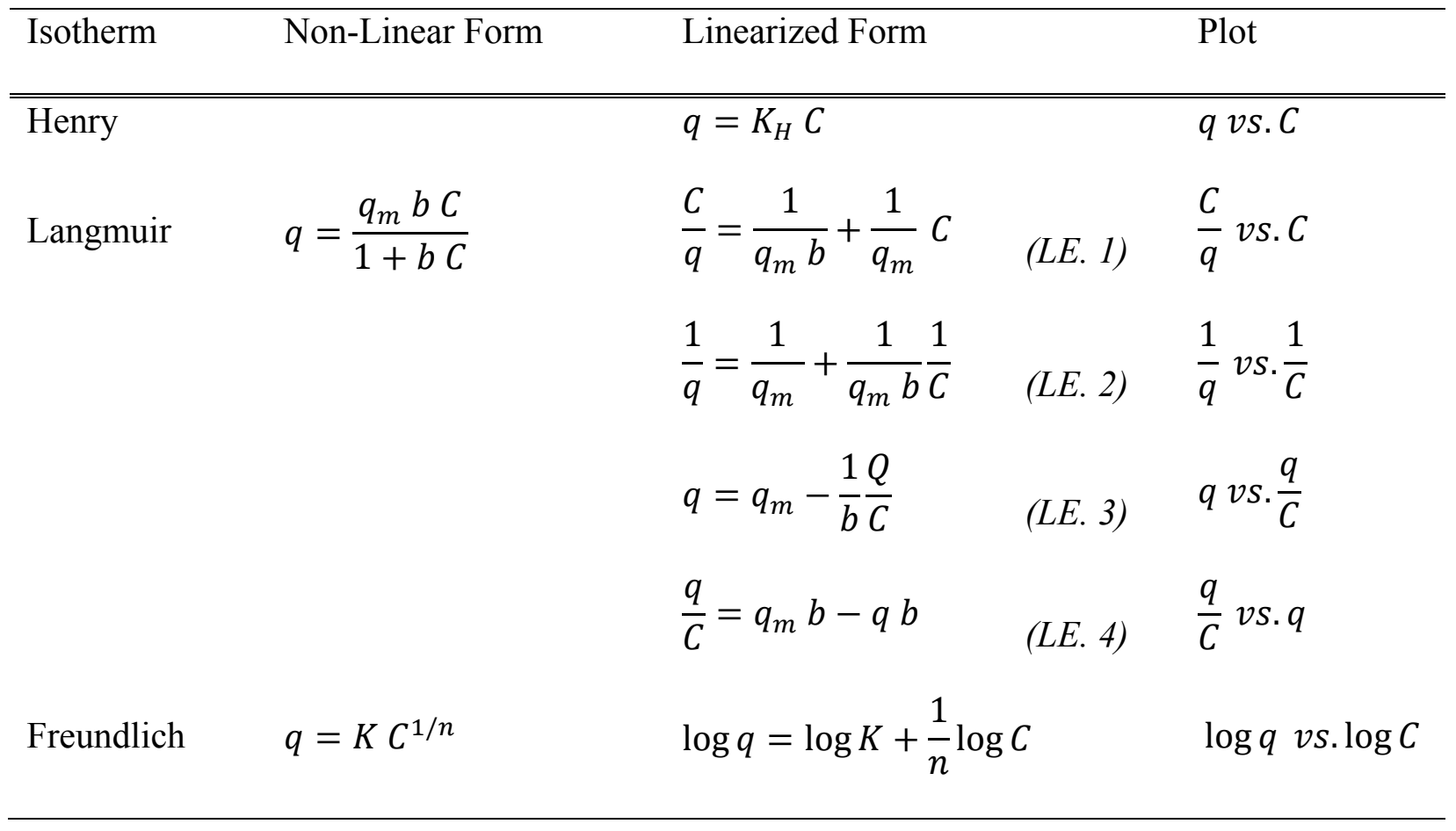

For single-solute systems, two-parameter isotherms are typically sufficient to fit the data (Cooney 1999). If the two-parameter isotherms do not accurately describe experimental data, the concentration range may be too large (Worch 2012). If this occurs, a three-parameter isotherm can be used, or a subset of the total concentration range can be used to fit the two-parameter isotherm (Worch 2012). Some three-parameter isotherms include the Langmuir-Freundlich, the Redlich-Peterson, and the Tóth (Worch 2012). A comprehensive list of adsorption isotherm equations in their non-linear and linear forms are provided in Foo \& Hameed (2010). 


\subsubsection{ADSORPTION KINETICS}

The BTC models predominately differ based on how they treat the rate of adsorption $\left(\frac{\partial q}{\partial t}\right)$

(Weber and Chakravorti 1974). To describe the rate of adsorption various mass transfer models have been developed. Each model has an adsorption rate equation that assumes a rate limiting adsorption mechanism(s). There are four stages of adsorption: (1) the transport of the adsorbate in the bulk solution, (2) the diffusion of the adsorbate across the liquid-film surrounding the adsorbent, (3) the intraparticle diffusion of the adsorbate either through pore or surface diffusion and (4) the attachment (adsorption) or detachment (desorption) of the adsorbent to the surface of the adsorbent (Plazinski et al. 2009).

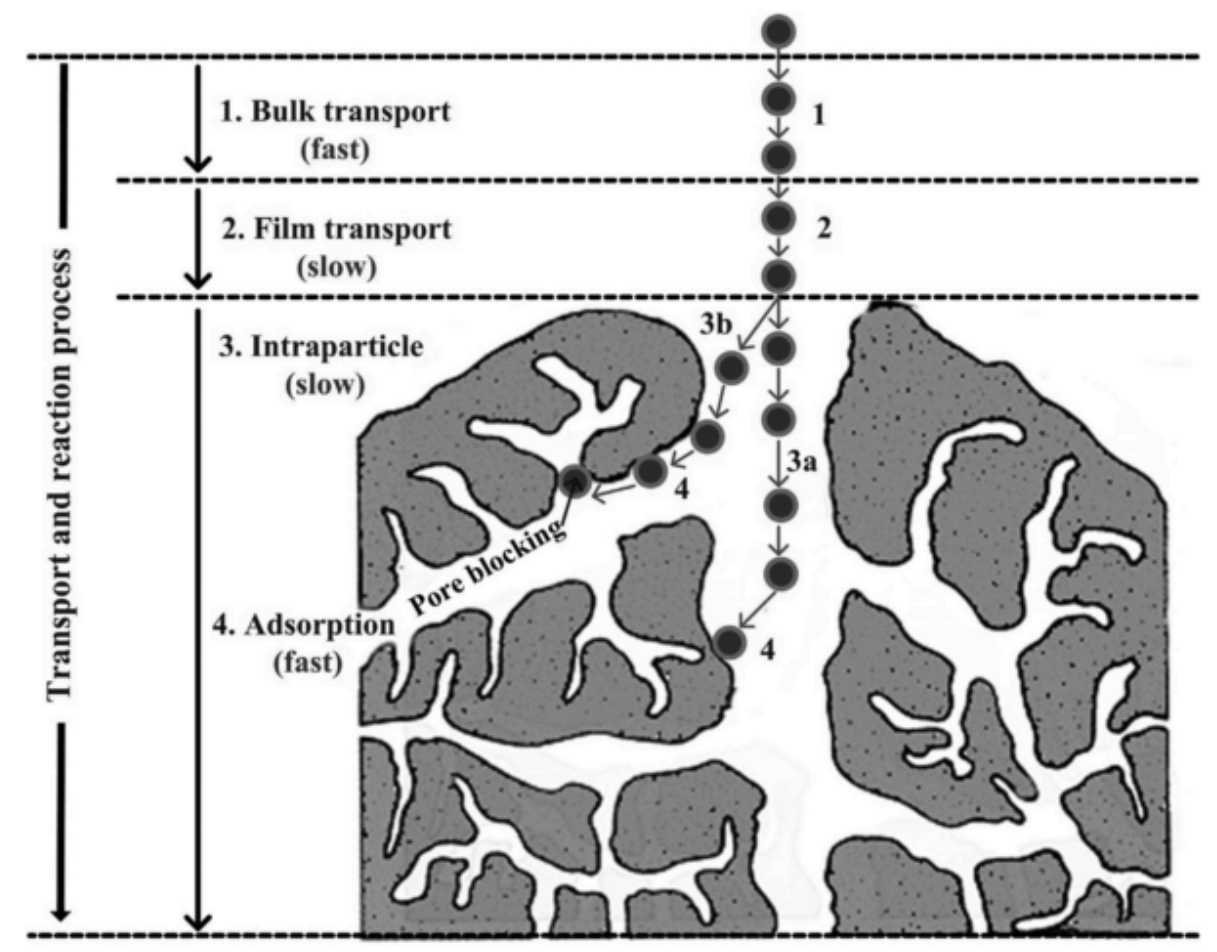

Figure 3 - Adsorption mass transfer processes.

Image taken from (Tran et al. 2017) and originally adapted from (Weber and Smith 1987) 
To apply the mass transfer equations to BTC models the kinetic coefficients must be determined. These coefficients can be determined by fitting the kinetic models to experimentally-determined kinetic curves which can be obtained from batch reactor experiments (Worch 2012). Kinetic curves can be expressed as the liquid phase solute concentration or adsorbent loading as a function of time. Examples of both curves are provided in Figure 4.
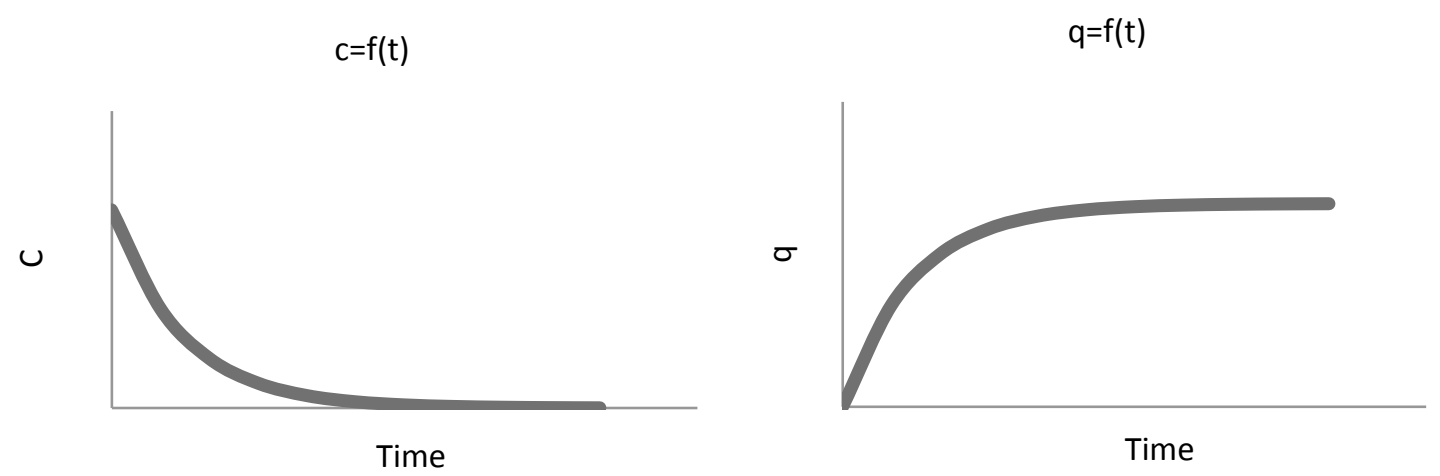

Figure 4 - Example sorption kinetic curves

In general, the mass transfer models can be categorized into two groups: reaction and diffusion (Ho et al. 2000; Qiu et al. 2009). Reaction models assume step (4), the adsorption reaction, is the rate-limiting step, whereas diffusion models assume steps (2) and/or (3) are rate limiting. Some diffusion models consider only one mechanism, while others consider several. For practical purposes, diffusion models that consider all three diffusion processes (i.e. film, pore and surface) are seldom used due to their complexity (Worch 2012). 


\section{Reaction Models}

Reaction kinetic models have been widely used to describe the adsorption kinetics of many solutes such metals, dyes and organics from aqueous solutions (Ho 2004b). Two commonly applied reaction models are the pseudo-first-order and pseudo-second-order models (Ho and McKay 1998). These models are based on adsorbent loading or adsorption capacity. The term 'pseudo' is used to distinguish these models from reaction models based on solute concentration (Ho 2004b; Qiu et al. 2009).

The pseudo-first-order and pseudo-second order equations are (Qiu et al. 2009),

$$
\begin{array}{ll}
\frac{d q}{d t}=k_{1}\left(q_{e}-q\right) & E q .8 \\
\frac{d q}{d t}=k_{2}\left(q_{e}-q\right)^{2} & E q .9
\end{array}
$$

where $\mathrm{k}_{1}$ and $\mathrm{k}_{2}$ are the pseudo-first-order and pseudo-second-order rate constants, respectively.

Integrating the pseudo-first-order equation with the initial conditions $q=0$ and $t=0$, provides Eq. 10 .

$$
q=q_{e}\left(1-e^{-k_{1} t}\right)
$$

This nonlinear equation can be rewritten in the linearized form as Eq. 11.

$$
\ln \frac{\left(q_{e}-q_{t}\right)}{q_{e}}=-k_{1} t
$$

Likewise, integrating the pseudo-second-order equation, under the same initial conditions, provides Eq. 12. 


$$
q=\frac{k_{2} q_{e}^{2} t}{1+k_{2} q_{e} t}
$$

This equation can be rearranged into the commonly used (Simonin 2016) linearized pseudo-second-order equation (Eq. 13).

$$
\frac{t}{q_{t}}=\frac{1}{k_{2} q_{e}{ }^{2}}+\frac{1}{q_{e}} t
$$

Ho and McKay (1999) provide an extensive list of studies that have characterized the reaction kinetics of adsorbate-adsorbent systems as $1^{\text {st }}$ or $2^{\text {nd }}$ order. The derivation of these models can be found in Azizian (2004).

A summary of the nonlinear and commonly used linear forms of the reaction kinetic model equations is provided in Table 2 .

Table 2 - Nonlinear and linear reaction kinetic model equations, and linear plots

\begin{tabular}{llll}
\hline Kinetic Model & Nonlinear Form & Linearized Form & Plot \\
\hline Pseudo-First-Order & $q=q_{e}\left(1-e^{-k_{1} t}\right)$ & $\ln \frac{\left(q_{e}-q_{t}\right)}{q_{e}}=-k_{1} t$ & $\ln \frac{\left(q_{e}-q_{t}\right)}{q_{e}}$ vs.t \\
Pseudo-Second-Order & $q=\frac{k_{2} q_{e}^{2} t}{1+k_{2} q_{e} t}$ & $\frac{t}{q_{t}}=\frac{1}{k_{2} q_{e}{ }^{2}}+\frac{1}{q_{e}} t$ & $\frac{t}{q_{t}}$ vs.t
\end{tabular}

\section{Homogenous Surface Diffusion Model (HSDM)}

One commonly used diffusion model is the homogeneous surface diffusion model (HSDM) (Worch 2012). This model has been used successfully to predict the adsorption dynamics in fixed-bed reactors for many adsorption systems (Hand et al. 1983). The HSDM 
model considers surface diffusion as the sole intraparticle mass transport mechanism (Worch 2012). Film diffusion can be considered in conjunction with the HSDM, in which case the model becomes the pore and surface diffusion model (PSDM). Typically, the surface diffusion flux is greater than the pore diffusion flux for strongly adsorbed solutes (Hand et al. 1983). Therefore, it is reasonable to estimate the total intraparticle mass transport considering only surface diffusion in many cases (Hand et al. 1983).

The HSDM assumes the adsorbent is a homogenous spherical particle and that the surface diffusive flux can be described by Fick's law (Hand et al. 1983; Zhang et al. 2009). Assuming the surface diffusion coefficient is constant, the adsorption rate equation derived from the intraparticle mass balance can be described by the equation (Worch 2012),

$$
\frac{\partial q}{\partial t}=D_{s}\left(\frac{\partial^{2} q}{\partial r^{2}}+\frac{2}{r} \frac{\partial q}{\partial r}\right) \quad E q .14
$$

where $r$ is the radius of the particle and $D_{s}$ is the surface diffusion coefficient. If the particle is a sphere then the average adsorbent loading ( $\left.\mathrm{q}_{\mathrm{ave}}\right)$ in the particle is (Zhang et al. 2009),

$$
q_{\text {ave }}=\frac{3}{\pi r_{p}^{3}} \int_{0}^{r_{p}} 4 q \pi r^{2} d r \quad \text { Eq. } 15
$$

The mass balance is dependent on the reactor being considered. The differential mass balance for a batch reactor is

$$
m_{A} \frac{d q_{\text {ave }}}{d t}=-V_{L} \frac{d c}{d t} \quad \text { Eq. } 16
$$


where $\mathrm{m}_{\mathrm{A}}$ is the mass of the adsorbent and $\mathrm{V}_{\mathrm{L}}$ is volume of liquid. Integrating with the initial conditions $\mathrm{c}(\mathrm{t}=0)=\mathrm{c}_{\mathrm{o}}$ and $\mathrm{q}_{\mathrm{ave}}(\mathrm{t}=0)=0$ gives the following equation,

$$
q_{\text {ave }}(t)=\frac{V_{L}}{m_{A}}\left[c_{o}-c(t)\right] \quad E q .17
$$

Table 3 - Summary of HSDM equations for a batch reactor

\begin{tabular}{|c|c|}
\hline Equation & Role \\
\hline$m_{A} \frac{d q_{\text {ave }}}{d t}=-V_{L} \frac{d c}{d t}$ & Mass balance for a batch reactor \\
\hline$q_{\text {ave }}=\frac{3}{\pi r_{p}^{3}} \int_{0}^{r_{p}} 4 q \pi r^{2} d r$ & Average adsorbent loading \\
\hline$\frac{\partial q}{\partial t}=D_{s}\left(\frac{\partial^{2} q}{\partial r^{2}}+\frac{2}{r} \frac{\partial q}{\partial r}\right)$ & Diffusion rate equation for a spherical particle \\
\hline$q(r, 0)=0$ & Initial condition \\
\hline$\frac{\partial q}{\partial t}=0, r=0$ & Boundary conditions for the centre of particle \\
\hline$D_{s} \rho \frac{\partial q}{\partial r}=k_{f}\left(C_{b}-C_{s}\right)$ & Boundary condition for continuity of flux at $r=r_{p}$ \\
\hline$q_{e}=K C_{e}^{1 / n}$ & Freundlich isotherm \\
\hline
\end{tabular}

Table adapted from (Roy et al. 1993)

The HSDM depends on a system of differential equations (presented in Table 3) and therefore analytical solutions are only available for limited cases, specifically, for adsorbent systems that follow a linear adsorption isotherm (Worch 2012). However, approximations of the 
solutions can be obtained using numerical methods. To make the process of obtaining numerical solutions easier, simplified user-orientated solutions have been developed by adsorption researchers (e.g. Hand et al., 1983; Zhang et al., 2009).

When empirically determining diffusion mass transfer coefficients (i.e. by fitting kinetic models to experimental data) there are some important factors to consider. The film diffusion coefficient is highly dependent on hydrodynamic conditions, and consequently must be determined under the same hydrodynamic conditions in which the filter is expected to operate (Worch 2012). Therefore, a film diffusion coefficient determined from batch experiments is not transferable to fixed-bed column design (Cooney 1999). Film diffusion coefficients are typically determined from breakthrough tests using small scale flow-through reactors (Cooney 1999). They can also be estimated from empirical equations (Hand et al. 1983). To the contrary, the intraparticle diffusion coefficients are independent of hydrodynamic conditions (Worch 2012). These coefficients can be determined using the kinetic data obtained from batch experiments, and are theoretically independent of stirrer or shaker speed (Worch 2012). To minimize the effects of film diffusion when using batch experiments, high stirrer or shaker speeds can be used (Worch 2012). According to Ho et al. (2000), using agitation will typically result in film diffusion being rate controlling only for the first few minutes. To test if the reactor agitation is adequate to eliminate film diffusion resistance, multiple batch experiments can be conducted at varying mixing intensities (Hand et al. 1983). Film diffusion resistance has been eliminated once an increase in mixing intensity does not result in a change in the kinetic data (Hand et al. 1983). Experiments have shown that adsorption rates do not change at agitation speeds above a few hundred rpm (Cooney 1999). 


\subsubsection{MODEL REGRESSION}

Linear regression is widely used in adsorption equilibrium and kinetic studies as a means of fitting isotherm and adsorption kinetic models. This regression technique is attractive because it is easy to do. However, it can produce unsatisfactory results (El-Khaiary and Malash 2011). Some of the limitations of applying the various linear Langmuir equations are provided in Table 4.

Table 4 - Limitations of linear Langmuir equations

\begin{tabular}{|c|c|c|}
\hline Equation & Equation Form & Limitations \\
\hline $\begin{array}{l}\text { LE } 1 \\
\text { (Hanes-Woolf) }\end{array}$ & $\frac{C}{q}=\frac{1}{q_{m} b}+\frac{1}{q_{m}} C$ & $\begin{array}{l}\text { Because } \mathrm{x}(\mathrm{C}) \text { and } \mathrm{y}(\mathrm{C} / \mathrm{q}) \text { are not independent the } \\
\text { correlation between } \mathrm{x} \text { and } \mathrm{y} \text { is overestimated, i.e., equation } \\
\text { may provide good fits to data that do not conform to the } \\
\text { Langmuir model. }\end{array}$ \\
\hline $\begin{array}{l}\text { LE } 2 \\
\text { (Lineweaver-Burke) }\end{array}$ & $\frac{1}{q}=\frac{1}{q_{m}}+\frac{1}{q_{m} b} \frac{1}{C}$ & $\begin{array}{l}\text { Transformation leads to clumping of data points near origin } \\
\text { - extremely sensitive to variability at low values of } q \text { (high } \\
\text { values of } 1 / \mathrm{q}) \text {. } \\
\text { Abscissa is not error free; } \mathrm{x}(\mathrm{q} / \mathrm{c}) \text { and } \mathrm{y}(\mathrm{q}) \text { data are not }\end{array}$ \\
\hline $\begin{array}{l}\text { LE } 3 \\
\text { (Eadie-Hofstee) }\end{array}$ & $q=q_{m}-\frac{1}{b} \frac{Q}{C}$ & $\begin{array}{l}\text { independent. In this case, correlation between } \mathrm{x} \text { and } \mathrm{y} \text { is } \\
\text { underestimated, i.e., equation may provide poor fit to data } \\
\text { that do conform to the Langmuir model. }\end{array}$ \\
\hline $\begin{array}{l}\text { LE } 4 \\
\text { (Scatchard) }\end{array}$ & $\frac{q}{C}=q_{m} b-q b$ & $\begin{array}{l}X(q) \text { and } y(q / c) \text { are not independent. In this case, } \\
\text { correlation between } x \text { and } y \text { is underestimated, i.e., equation } \\
\text { may provide poor fits to data that do not conform to the } \\
\text { Langmuir model }\end{array}$ \\
\hline
\end{tabular}

Adapted from (Bolster and Hornberger 2007) 
A more statistically robust alternative to linear regression is nonlinear regression. Nonlinear regression uses an algorithm to minimize an objective or error function. The error function measures the difference between the observed and calculated data (Bolster and Hornberger 2007). Common error functions include the chi-square statistic $\left(\mathrm{X}^{2}\right)$, the sum-ofsquared errors (SSE), the average relative error (ARE), the sum of the absolute errors (SAE) and the hybrid fractional error function (HYBRID) (Amrhar et al. 2015). These regression techniques were used to fit the isotherm and kinetic models presented in the previous sections to the experimental data produced from this study.

\subsection{RESEARCH OBJECTIVES}

The purpose of this study was to characterize two low cost, locally available adsorbents, specifically LadybugBag Agg Sand and Greensand. Of specific interest is the potential use of these adsorbents to treat effluent from gravity-settling based stormwater treatment BMPs (such as stormwater ponds and wetlands) to meet PWQO. The PWQO levels are presented in Table 5. The contaminants used in this study were the metals identified in the SWAMP report as having mean effluent concentrations above PWQO, specifically, copper, zinc, iron, cadmium and lead. Arsenic was also included due to its relevance in stormwater and high toxicity $(\mathrm{Wu}$ and Zhou 2009). This is the first study to investigate Ladybug Sand and Greensand with the combination of metals identified. 
Table 5 - Provincial Water Quality Objectives

\begin{tabular}{ll}
\hline Metal & \multicolumn{1}{c}{$\mathrm{PWQO}^{\mathrm{a}}$} \\
\hline Copper $(\mathrm{Cu})$ & $1 \mu \mathrm{g} / \mathrm{L}\left(<20 \mathrm{mg} / \mathrm{L} \mathrm{CaCO}_{3}\right)$ \\
& $5 \mu \mathrm{g} / \mathrm{L}\left(>20 \mathrm{mg} / \mathrm{L} \mathrm{CaCO}_{3}\right)$ \\
Zinc $(\mathrm{Zn})$ & $20 \mu \mathrm{g} / \mathrm{L}$ \\
Iron $(\mathrm{Fe})$ & $300 \mu \mathrm{g} / \mathrm{L}$ \\
& $0.1 \mu \mathrm{g} / \mathrm{L}(<100 \mathrm{mg} / \mathrm{L} \mathrm{CaCO} 3)$ \\
Cadmium $(\mathrm{Cd})$ & $0.5 \mu \mathrm{g} / \mathrm{L}(>100 \mathrm{mg} / \mathrm{L} \mathrm{CaCO} 3)$ \\
& $1 \mu \mathrm{g} / \mathrm{L}(<30 \mathrm{mg} / \mathrm{L} \mathrm{CaCO} 3)$ \\
& $2 \mu \mathrm{g} / \mathrm{L}(30-80 \mathrm{mg} / \mathrm{L} \mathrm{CaCO} 3)$ \\
Lead $(\mathrm{Pb})$ & $5 \mu \mathrm{g} / \mathrm{L}(>80 \mathrm{mg} / \mathrm{L} \mathrm{CaCO} 3)$ \\
& $\mathrm{NA}{ }^{\mathrm{b}}$ \\
Arsenic $(\mathrm{As})$ & \\
\hline Note: ${ }^{a}$ 1 $\mu \mathrm{g} / l=1$ ppb & \\
Note: ${ }^{b}$ The PWQO does not include arsenic
\end{tabular}

To characterize the adsorbents, multi-solute adsorption isotherm and adsorption kinetic experiments were conducted. The equilibrium experimental data was fit to the Langmuir, Freundlich and Henry isotherms. The kinetic experimental data was fit to the pseudo-first-order, pseudo-second-order and HSDM kinetic models. With the adsorption isotherms and mass transfer coefficients determined from these experiments, BTC models can be used to design pilot-scale studies, interpret the results of these studies, investigate multistage adsorber configurations, and estimate preliminary costs of adsorption columns (Hand et al. 1983). 


\section{MATERIALS AND METHODS}

\subsection{ADSORBENT PRETREATMENT}

The two sorbents selected for analysis were: LadyBugBag aggregate (hereafter Ladybug Sand) and Greensand. These sorbents were selected because of their relatively low cost and availability. Ladybug Sand is a general-purpose aggregate that can be purchased from a hardware store. Greensand is an engineered material comprised of a manganese base and was developed for the removal of iron, manganese and hydrogen sulfide (Hungerford \& Terry Inc. 2003).

Prior to conducting the experiments, these sands were sieved to get a rough indication of the grain size distribution so that a grain size with sufficient quantity could be selected. In accordance with the AASHTO T 88 method (American Association of State Highway and Transportation Officials 2013), sieving was discontinued when less than $0.5 \%$ by weight was passed in 60 seconds of sieving. The sand retained between sieve numbers 20 and 40 (i.e. between $420-841 \mu \mathrm{m}$ in diameter) was used in the experiments.

To remove fine particulates and organic precursors, the sands were pretreated in accordance with the protocol for characterizing low cost adsorbents as defined in Ali \& Gupta (2006). First, the sands were repeatedly washed with milli-Q water until the washing water ran clear. The sands were then dried in an oven at $100^{\circ} \mathrm{C}$ for 2 hours. The sands were then placed in an oven at $550^{\circ} \mathrm{C}$ for 24 hours to carbonize any organic precursors. To remove adhered organic matter the sands were fully submerged in 3\% hydrogen peroxide and placed in an oven at $60^{\circ} \mathrm{C}$ for 24 hours. To remove the hydrogen peroxide, the sands were washed three times with milli-Q water

and then dried in an oven at $100^{\circ} \mathrm{C}$ for 2 hour. Finally the sands were placed in an oven at $500^{\circ} \mathrm{C}$ for 6 hours. 
The bulk densities of the sands were measured by weighing $10 \mathrm{~mL}$ of sand in a graduated cylinder.

\subsection{EXPERIMENTS CONDUCTED}

In total, four experiments were performed. A brief description of each experiment is provided below. The procedures followed are provided in more detail in subsequent sections.

Pilot Experiment 1 evaluated the adsorbents' effectiveness of removing arsenic, copper, iron and zinc and investigated the effects of oxygen saturation on adsorption. Upon receiving the data from the first pilot experiment, it was evident that the adsorbents were ineffective at removing copper, iron and zinc. These metals were subsequently dropped from the proceeding experiments and cadmium and lead were added for investigation.

Pilot Experiment 2 obtained preliminary data on the adsorbents' effectiveness at removing arsenic, cadmium and lead. Once it was determined that the adsorbents were capable of removing the metals, adsorption isotherm and kinetic experiments were conducted.

Finally, the batch adsorption isotherm experiments determined the adsorption isotherms and the batch adsorption kinetic experiments determined the adsorption kinetics. A schematic of the research structure is provided in Figure 5. 


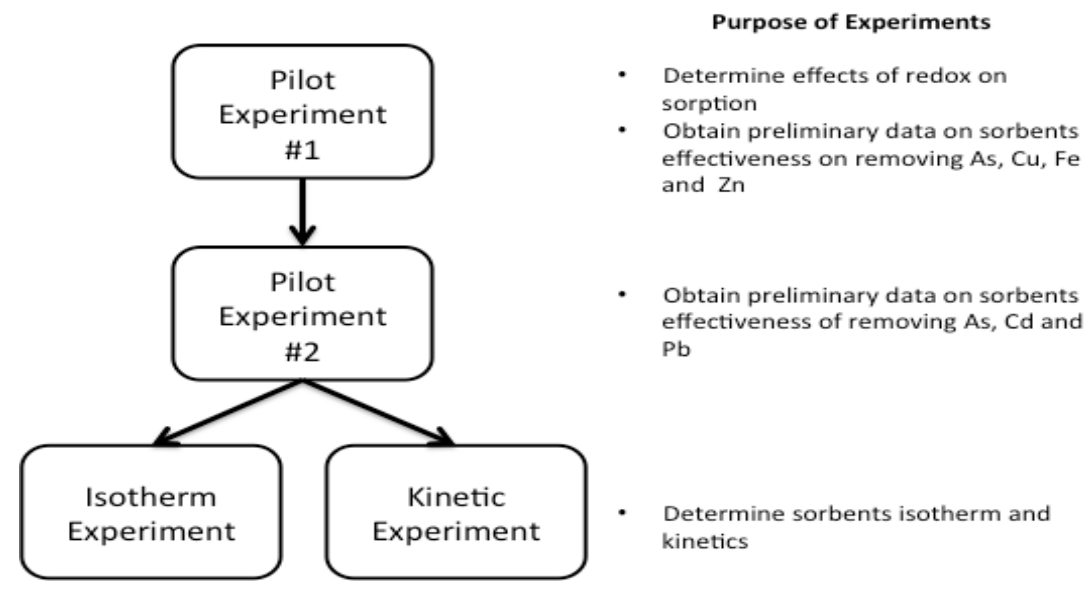

Figure 5 - Research structure

\subsubsection{PILOT EXPERIMENT 1}

The first pilot study was conducted to determine if Ladybug Sand and Greensand were capable of removing arsenic, copper, iron and zinc, and to investigate the effects of oxygen saturation on adsorption. Metal stock solutions were created by dissolving the metals, in their solid elemental form, in either nitric or hydrochloric acid, then diluting with milli-Q water. All glassware used was washed with detergent and then rinsed with dilute $10 \%(\mathrm{v} / \mathrm{v})$ hydrochloric acid and ultrapure milli-Q water. Metal stocks were used to create synthetic stormwater with defined metals concentrations. Two volumes of synthetic stormwater were made in separate $2 \mathrm{~L}$ bottles. One of these bottles was sparged with $\mathrm{N}_{2}$ for 5 minutes to create anoxic water. Due to dilution errors made while preparing the synthetic stormwaters, the two stormwaters tested (i.e. anoxic and oxic) ended up being different concentrations when they should have been the same. However, for the purposes of this investigation the results obtained were still useful. The stormwater concentrations used in the pilot experiment are presented in Table 6 . The $\mathrm{pH}$ of the synthetic stormwater was not controlled during the experiment. 
Table 6 - Pilot experiment 1 stormwater concentrations

Concentration (ppb)

Stormwater

\begin{tabular}{llll}
\hline $\mathrm{As}$ & $\mathrm{Cu}$ & $\mathrm{Fe}$ & $\mathrm{Zn}$
\end{tabular}

\begin{tabular}{llccc}
\hline \hline Anoxic & 11.1 & 23.4 & 66 & 127.8 \\
Aerobic & 22.4 & 44.6 & 32 & 194.9 \\
\hline
\end{tabular}

To test the removal efficacy of the sands, batch reactor kinetic experiments were conducted. Glass BOD bottles (60 mL volume) with $50 \mathrm{~mL}$ of stormwater and $1 \mathrm{~g}+/-0.001 \mathrm{~g}$ of sand were used. BOD bottles were gravity filled from the synthetic stormwater stocks (anoxic and oxic) immediately after sparging, using a Tygon tube inserted into the bottom of the BOD bottle. Ground glass stoppers inserted immediately after filling to prevent air intrusion, and were taped into place. These bottles were shaken on an orbital shaker table at $60 \mathrm{rpm}$. One sample of each stormwater (anoxic or oxic) and sand type was collected at 30 minutes, 1 hour, 3 hours, 24 hours and 48 hours. To obtain the samples, the bottles were placed on the desk for a few minutes to allow the sand to settle and then the supernatant was collected in $50 \mathrm{~mL}$ polypropylene conical centrifuge tubes and then stored in the fridge. One sample of each sand was also collected and dried so that their chemical composition could be determined. The $\mathrm{pH}$ of the synthetic stormwater was not controlled, and the experiment was conducted at room temperature.

\subsubsection{PILOT EXPERIMENT 2}

Analysis of the sand revealed that the materials contained high quantities of copper, iron and zinc (Table 11 in section 3.1) and therefore did not effectively these metals from the stormwater when present at low concentrations $(<200 \mathrm{ppb})$. Furthermore, it was determined that oxic conditions 
were more conducive than anoxic conditions for the removal of arsenic, the only metal effectively removed. As a result, two new metals, cadmium and lead, were selected for future analysis due to their low concentrations in the adsorbents, and due to their relevance as stormwater contaminants.

Pilot experiment 2 was conducted to test if the sands were able to remove arsenic, cadmium and lead from water. The same procedure used in pilot experiment 1 was followed, except the metal stock solutions used to make the new synthetic stormwater were prepared according to EPA method 7010 , the method for graphite furnace atomic adsorption spectrophotometry, and were prepared to a concentration of $1000 \mathrm{mg}$ of metal per liter. To prepare the arsenic stock, $0.132 \mathrm{~g}$ of arsenic trioxide, $\mathrm{As}_{2} \mathrm{O}_{3}$, was dissolved in $10 \mathrm{~mL}$ of milli-Q water with $0.4 \mathrm{~g}$ of $\mathrm{NaOH}$, then acidified with $2 \mathrm{~mL}$ of $\mathrm{HNO}_{3}$ and diluted to $100 \mathrm{~mL}$. To prepare the cadmium stock, $0.1 \mathrm{~g}$ of cadmium metal was dissolved in $2 \mathrm{~mL}$ of $1: 1 \mathrm{HNO}_{3}$ and diluted to $100 \mathrm{~mL}$. To prepare the lead stock $0.1599 \mathrm{~g}$ of $\mathrm{Pb}\left(\mathrm{NO}_{3}\right)_{2}$ was dissolved in milli-Q water and 1 $\mathrm{mL}$ of $\mathrm{HNO}_{3}$ and diluted to $100 \mathrm{~mL}$. The metal concentrations in the synthetic stormwater used are provided in Table 7 . The $\mathrm{pH}$ of the synthetic stormwater was not controlled and the experiments were conducted at room temperature.

Table 7 - Pilot experiment 2 stormwater concentrations

Metal Concentration (ppb)

\begin{tabular}{cc}
\hline \hline As & 17.4 \\
$\mathrm{Cd}$ & 10.79 \\
$\mathrm{~Pb}$ & 13.7 \\
\hline
\end{tabular}


As with the first pilot experiment, these concentrations were selected to be representative of outflow concentrations from stormwater management facilities based on the EMC data presented in the SWAMP report.

\subsubsection{BATCH ISOTHERM EXPERIMENT}

The adsorption isotherms were determined through batch experiments using $50 \mathrm{~mL}$

polypropylene conical centrifuge tubes. Each tube contained $45 \mathrm{~mL}$ of synthetic stormwater and $1+/-0.001 \mathrm{~g}$ of sand. The reactors were placed on a reciprocating shaker table operating at 250 rpm and allowed to equilibrate for 48 hours. All of the batch isotherm experiments were conducted at room temperature. A blank sample, with no sand, was evaluated using the highest stormwater concentration (SW8) so that any potential adsorption of the metals onto the reactor vessel wall could be quantified.

The metal stock solutions from pilot experiment 2 were used to prepare the synthetic stormwater for the batch isotherm experiments. Eight stormwater solutions were tested. The concentrations of the eight stormwater solutions used are provided in Table 8. Due to a dilution error the arsenic concentrations were ten times higher than desired. Duplicate trails of each stormwater were conducted, for a total of 16 trials for each adsorbent. The $\mathrm{pH}$ of the synthetic stormwater was not controlled during the experiment. 
Table 8 - Minimum detection limits, PWQO, average concentration ranges, SWAMP EMC and concentration of synthetic stormwaters used in isotherm and kinetic experiments.

\begin{tabular}{|c|c|c|c|}
\hline & As $(\mu \mathrm{g} / \mathrm{L})$ & $\mathrm{Cd}(\mu \mathrm{g} / \mathrm{L})$ & $\mathrm{Pb}(\mu \mathrm{g} / \mathrm{L})$ \\
\hline $\mathrm{MDL}^{\mathrm{a}}$ & 0.5 & 0.05 & 0.2 \\
\hline PWQO & $4^{\mathrm{b}}$ & $0.1-0.5$ & $1-5$ \\
\hline $\mathrm{ACR}^{\mathrm{c}}$ & $1-210^{\mathrm{d}}$ & $1-24^{\mathrm{e}}$ & $38-55^{\mathrm{e}}$ \\
\hline SWAMP EMC & NA & $0.1-1.7$ & $<\mathrm{dl}-4.9$ \\
\hline SW 1 & 447 & 12 & 24 \\
\hline SW 2 & 870 & 24 & 54 \\
\hline SW 3 & 1780 & 45 & 103 \\
\hline SW 4 & 3384 & 88 & 208 \\
\hline SW 5 & 6800 & 179 & 431 \\
\hline SW 6 & 13471 & 344 & 824 \\
\hline SW 7 & 26516 & 653 & 1590 \\
\hline SW 8 & 44465 & 982 & 2455 \\
\hline \multicolumn{4}{|c|}{$\begin{array}{l}{ }^{a} M D L=\text { minimum detection limit } \\
{ }^{b} \text { this is the Danish emission limit value (DELV) (Genç-Fuhrman et al. 2007). An objective for arsenic is no } \\
\text { provided in the PWQO. } \\
{ }^{c} \text { ACR }=\text { average concentration range } \\
{ }^{d} \text { Value from Genç-Fuhrman et al. (2007) } \\
{ }^{e} \text { Values are from the Ontario Stormwater Management Planning and Design Manual (2003) }\end{array}$} \\
\hline
\end{tabular}

After 48 hours of shaking, the tubes containing Greensand were visibly cloudy. To remove the suspended sediment in these tubes, the supernatant was filtered through $8 \mu \mathrm{m}$, grade 40, Whatman filter paper. The Ladybug tubes remained clear after 48 hours and therefore the supernatant was directly collected. The final samples were collected in $50 \mathrm{~mL}$ polypropylene tubes and stored at $4{ }^{\circ} \mathrm{C}$ prior to analysis. 


\subsubsection{BATCH KINETICS EXPERIMENT}

The adsorption kinetics experiment was also conducted in $50 \mathrm{~mL}$ polypropylene conical centrifuge tubes. Each reactor contained $45 \mathrm{~mL}$ of stormwater and $1+/-0.001 \mathrm{~g}$ of sand. These reactors were shaken on the reciprocating tables used in the adsorption isotherm experiment. Kinetic curves were determined for stormwaters 5 and 8 (see Table 8 for concentrations). Stormwaters 5 and 8 were selected because it was assumed that these concentrations would be sufficiently high to establish kinetic curves over a 24-hour period, and differed by a factor of $>5$ for each element, so that the potential effects of concentration on kinetics might be observed. Two centrifuge tubes of each stormwater and sand were removed from the shaker table and decanted at 15 minutes, 30 minutes, 1 hour, 3 hours, 6 hours and 24 hours, for a total of 24 samples. The supernatant samples from the Greensand samples were filtered through $8 \mu \mathrm{m}$, grade 40, Whatman filter paper to remove suspended sediment. The Ladybug Sand samples were not filtered, as they did not contain any visible suspended sediment. The samples were stored in 50 $\mathrm{mL}$ polypropylene tubes at $4^{\circ} \mathrm{C}$ prior to analysis.

\subsection{ANALYTICAL METHODS}

All samples were sent to the Bureau Veritas Minerals lab in Vancouver for analysis. Water samples were analyzed for cations using ICP-MS. Sand samples were analyzed using a multiacid digestion and ICP-ES. The ICP-MS detection limits for $\mathrm{As}, \mathrm{Cd}, \mathrm{Cu}, \mathrm{Fe}, \mathrm{Pb}$ and $\mathrm{Zn}$ were 0.5 ppb, $0.05 \mathrm{ppb}, 0.1 \mathrm{ppb}, 10 \mathrm{ppb}, 0.1 \mathrm{ppb}$ and $0.5 \mathrm{ppb}$, respectively. 


\subsection{DATA ANALYSIS}

The batch data derived from the isotherm and kinetic experiments were fit to a variety of isotherms and kinetic models. The isotherms and kinetic models were evaluated using both nonlinear and linear regression techniques.

To perform the non-linear regressions, Excel's Solver Add-in was used. Using the Solver's GRG (Generalized Reduced Gradient) solving algorithm, isotherm parameters were found that minimized the sum-of-squared errors (SSE). The sum-of-squared errors, as defined by Bolster \& Hornberger (Bolster and Hornberger 2007), is described by equation Eq. 18.

$$
S S E=\sum\left(q_{\text {exp }}-q_{\text {cal }}\right)^{2} \quad \text { Eq. } 18
$$

Where $\mathrm{q}_{\mathrm{exp}}$ is the experimental adsorbent loading and $\mathrm{q}_{\mathrm{cal}}$ is the calculated adsorbent loading.

To perform the linear regression, the linearized isotherm and kinetic model equations and corresponding plots, provided in Table 1 (section 1.2.2) and Table 2 (section 1.2.3) respectively, were used. When fitting the Henry isotherm, only the linear (i.e. lowest) part of the concentration range was considered.

The fit of the isotherm and kinetic models were determined using the coefficient of determination $\left(\mathrm{R}^{2}\right)$. The coefficient of determination was calculated using the equation (Eq. 19) from Boulinguiez et al. (2008).

$$
R^{2}=\frac{\sum\left(q_{c a l}-q_{m, \text { exp }}\right)^{2}}{\sum\left(q_{c a l}-q_{m, \exp }\right)^{2}+\sum\left(q_{c a l}-q_{\text {exp }}\right)^{2}} \quad \text { Eq. } 19
$$

Where, $\mathrm{q}_{\mathrm{m} \text {,exp }}$ is the mean experimental adsorbent loading. 
The Akaike's Information Criteria (AIC) was also used to evaluate the fit of the different models. The AIC was developed to overcome some of the shortfalls of using the coefficient of determination to compare models with different numbers of data points or degrees of freedom (Bolster and Hornberger 2007; El-Khaiary and Malash 2011). A model with more data points and more fitting parameters will typically be a better fit, which may not be statistically justified (Bolster and Hornberger 2007; El-Khaiary and Malash 2011). The AIC, as presented in ElKhaiary \& Malash (2011), is

$$
A I C=N \ln \left(\frac{S S E}{N}\right)+2 N_{p}+\frac{2 N_{p}\left(N_{p}+1\right)}{N-N_{p}-1} \quad \text { Eq. } 20
$$

where $\mathrm{N}$ is the number of data points, $\mathrm{N}_{\mathrm{p}}$ is the number of fitting parameters. This equation is valid when the number of data points is greater than the number of fitting parameters by three or more (Bolster and Hornberger 2007). The model with the lowest AIC is considered to be the best of the those considered (Bolster and Hornberger 2007). A summary of the number of degrees of freedom (or fitting parameters) used in the AIC calculations for the various models considered are provided in Table 9. 


\begin{tabular}{lc} 
Table 9 - Number of fitting parameters used in AIC calculations \\
\hline Model & $\mathrm{N}_{\mathrm{p}}$ \\
\hline Langmuir Isotherm & 2 \\
Freundlich Isotherm & 2 \\
Henry Isotherm & 1 \\
Pseudo-First-Order & 2 \\
Pseudo-Second-Order & 2 \\
HSDM & 1
\end{tabular}

\section{Homogenous Surface Diffusion Model (HSDM)}

The homogenous surface model (HSDM) was solved using the user-oriented solution developed by Zhang et al. (2009). This solution is an extension of the solution developed by Hand et al. (1983). The user-oriented solution works by calculating the dimensionless concentration $\bar{C}$ using Eq. 21 (Hand et al. 1983).

$$
\bar{C}=A_{0}+A_{1}(\ln \bar{t})+A_{2}(\ln \bar{t})^{2}+A_{3}(\ln \bar{t})^{3}
$$

Where, $\mathrm{A}_{0}, \mathrm{~A}_{1}, \mathrm{~A}_{2}$ and $\mathrm{A}_{3}$ are empirically determined constants, and $\bar{t}$ is dimensionless time. The empirical constants were selected from a table provided by Zhang et al. (2009). These constants are dependent on the Freundlich parameter 1/n, and the ratio of equilibrium concentration to initial concentration $\left(\mathrm{C}_{\mathrm{e}} / \mathrm{C}_{\mathrm{o}}\right)$. The dimensionless time was calculated using Eq. 22.

$$
\bar{t}=D_{s} \frac{t}{r_{p}^{2}}
$$


The empirical equation for dimensionless concentration (Eq. 21) was optimized by finding the surface diffusion coefficient $\left(\mathrm{D}_{\mathrm{s}}\right)$ that minimizes the objective function $(\mathrm{OF})$, which is described by equation Eq. 23 .

$$
O F=\sqrt{\frac{\sum_{i=1}^{n}\left(\frac{\bar{C}_{\text {data }, i}-\bar{C}_{\text {model }, i}}{\bar{C}_{\text {data }, i}}\right)^{2}}{n-1}}
$$

where $\bar{C}_{\text {model }}$ is calculated using the empirical equation (Eq. 21) and $\bar{C}_{\text {data }}$ was calculated using Eq. 24,

$$
\bar{C}_{\text {data }}=\frac{C(t)-C_{e}}{C_{o}-C_{e}}
$$

where $\mathrm{C}(\mathrm{t})$ is the concentration at time $\mathrm{t}, \mathrm{C}_{\mathrm{e}}$ is the equilibrium concentration and $\mathrm{C}_{\mathrm{o}}$ is the initial concentration. The empirical constants used in the calculations are provided in Table 10 
Table 10 - Parameters used in empirical equation that describes the HSDM solution for batch reactors, adapted from Zhang et al. (2009)

\begin{tabular}{|c|c|c|c|c|c|c|c|}
\hline \multirow{2}{*}{$\begin{array}{l}\text { Freundlich } \\
(1 / n)\end{array}$} & \multirow{2}{*}{$\mathrm{C}_{\mathrm{e}} / \mathrm{C}_{\mathrm{o}}$} & \multicolumn{4}{|c|}{$\bar{C}=A_{0}+A_{1}(\ln \bar{t})+A_{2}(\ln \bar{t})^{2}+A_{3}(\ln \bar{t})^{3}$} & \multicolumn{2}{|c|}{$\begin{array}{l}\text { Equation Valid for } \\
\text { following } \bar{t} \text { range }\end{array}$} \\
\hline & & $\mathrm{A}_{0}$ & $\mathrm{~A}_{1}$ & $\mathrm{~A}_{2}$ & $\mathrm{~A}_{3}$ & Lower & Upper \\
\hline \multirow[t]{6}{*}{0.3} & 0.001 & $8.48276 \times 10^{-1}$ & $4.69793 \times 10^{-1}$ & $7.59594 \times 10^{-2}$ & $2.81270 \times 10^{-3}$ & $1.10 \times 10^{-4}$ & $2.20 \times 10^{-2}$ \\
\hline & 0.2 & $9.58145 \times 10^{-2}$ & $1.78899 \times 10^{-1}$ & $9.53563 \times 10^{-2}$ & $7.66911 \times 10^{-3}$ & $5.40 \times 10^{-4}$ & $3.00 \times 10^{-1}$ \\
\hline & 0.4 & $4.94239 \times 10^{-2}$ & $1.34897 \times 10^{-1}$ & $9.69648 \times 10^{-2}$ & $8.73526 \times 10^{-3}$ & $9.90 \times 10^{-4}$ & $3.00 \times 10^{-1}$ \\
\hline & 0.5 & $2.19306 \times 10^{-2}$ & $1.01747 \times 10^{-1}$ & $9.01030 \times 10^{-2}$ & $8.32783 \times 10^{-3}$ & $9.90 \times 10^{-4}$ & $3.00 \times 10^{-1}$ \\
\hline & 0.8 & $-3.88441 \times 10^{-2}$ & $2.56893 \times 10^{-2}$ & $7.29750 \times 10^{-2}$ & $7.20863 \times 10^{-3}$ & $9.90 \times 10^{-4}$ & $3.00 \times 10^{-1}$ \\
\hline & 0.9 & $-5.34998 \times 10^{-2}$ & $6.64081 \times 10^{-3}$ & $6.85331 \times 10^{-2}$ & $6.90873 \times 10^{-3}$ & $9.90 \times 10^{-4}$ & $3.00 \times 10^{-1}$ \\
\hline \multirow[t]{2}{*}{0.4} & 0.01 & $2.94919 \times 10^{-1}$ & $2.17595 \times 10^{-1}$ & $4.53972 \times 10^{-2}$ & $1.63889 \times 10^{-3}$ & $1.65 \times 10^{-4}$ & $7.45 \times 10^{-2}$ \\
\hline & 0.1 & $1.19490 \times 10^{-1}$ & $1.71903 \times 10^{-1}$ & $7.02191 \times 10^{-2}$ & $4.60326 \times 10^{-3}$ & $1.55 \times 10^{-4}$ & $2.30 \times 10^{-1}$ \\
\hline
\end{tabular}

Once the optimized $\bar{C}_{\text {model }}$ was determined the concentration at time (t) was calculated by rearranging equation Eq. 24.

$$
C(t)=\bar{C}_{\text {model }}\left(C_{o}-C_{e}\right)+C_{e} \quad E q .25
$$

The adsorbent loading was then calculated from the mass balance (Eq. 3) and the SSE, coefficient of determination $\left(\mathrm{R}^{2}\right)$ and AIC were calculated using equations Eq. 18, Eq. 19 and Eq. 20 respectively. 


\section{RESULTS \& DISCUSSION}

\subsection{PILOT EXPERIMENT 1}

An individual metal was selected for further investigation if its concentration was reduced over the 48-hour sampling period, and if it did not exhibit significant amounts of desorption during that time. Of the four metals tested, arsenic was the only metal effectively reduced by both sands, specifically under oxic conditions. Under anoxic conditions, arsenic exhibited high levels of desorption (Figure 6). Although some amount of desorption from the Ladybug Sand did occur under oxic conditions (Figure 6a), the arsenic concentration never went above its initial level. Conversely under anoxic conditions, the Ladybug Sand released more arsenic than it adsorbed, and the Greensand started releasing arsenic right away. Furthermore, the arsenic in the Greensand samples did not drop below the initial level until after 3 hours. In strongly reducing environments (i.e. low oxygen saturation) the preferential arsenic species is solid arsenic (Takeno 2005). This may account for the release of arsenic from both sands in anoxic conditions.

(a) Ladybug Sand

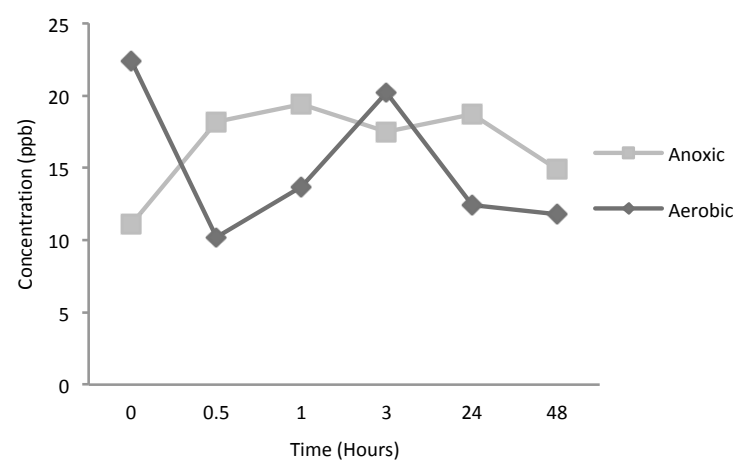

(b) Greensand

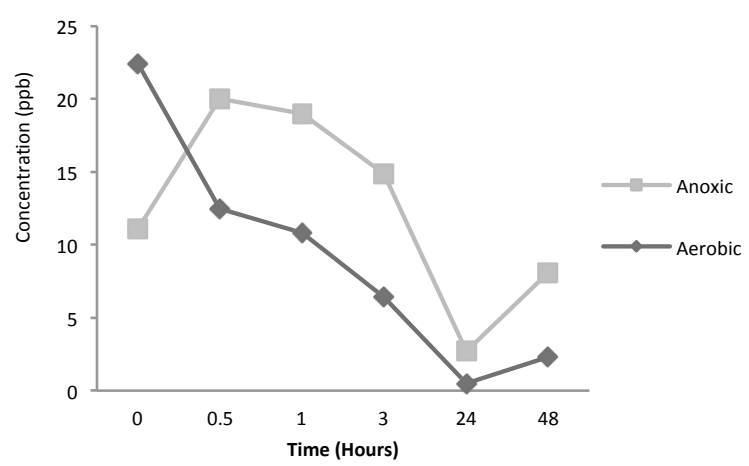

Figure 6-Pilot experiment 1: water phase concentrations of As over 48-hour sampling period for (a) Ladybug Sand and (b) Greensand 
As seen in Figure 7, Figure 8 and Figure 9, copper iron and zinc were not effective adsorbed by the sands. In each case they exhibited high levels of desorption or were not significantly reduced during the 48-hour sampling period.

(a) Ladybug Sand

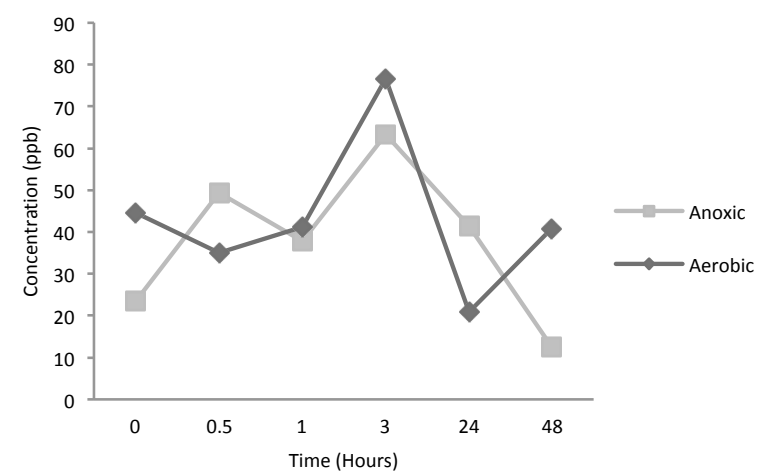

(b) Greensand

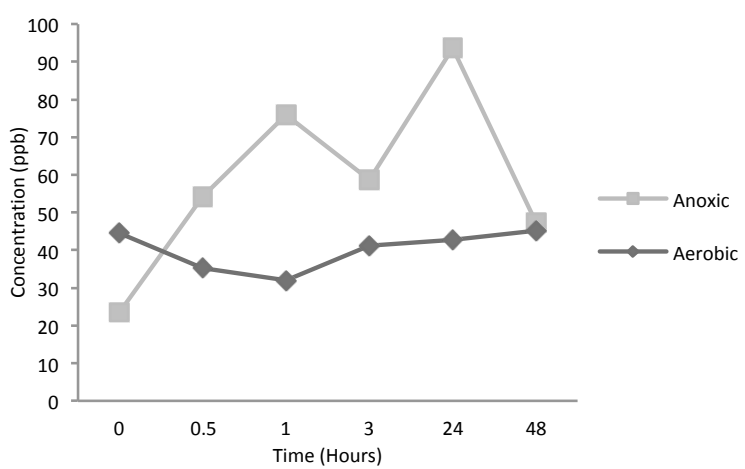

Figure 7 - Pilot experiment 1: water phase concentrations of Cu over 48-hour sampling period for (a) Ladybug Sand and (b) Greensand

(a) Ladybug Sand

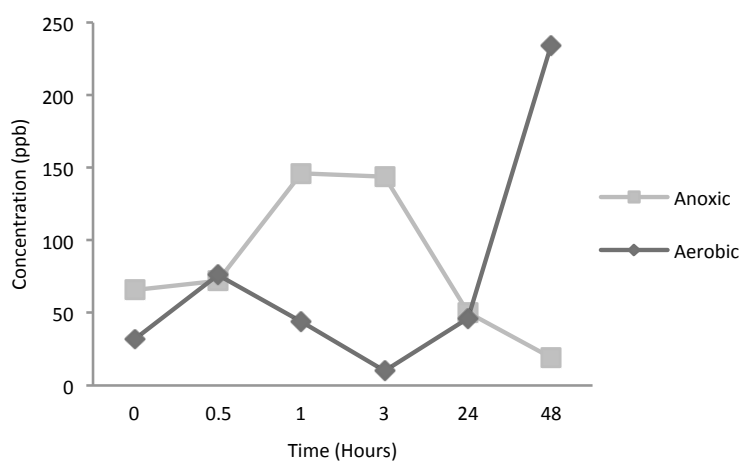

(b) Greensand

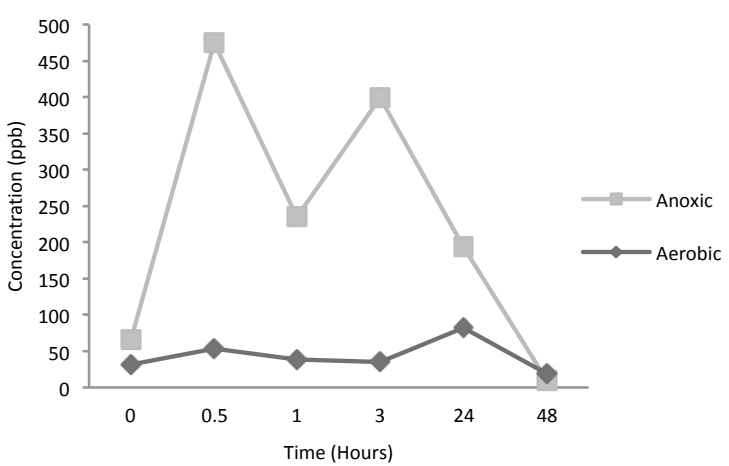

Figure 8-Pilot experiment 1: water phase concentrations of Fe over 48-sampling period for (a) Ladybug Sand and (b) Greensand 
(a) Ladybug Sand

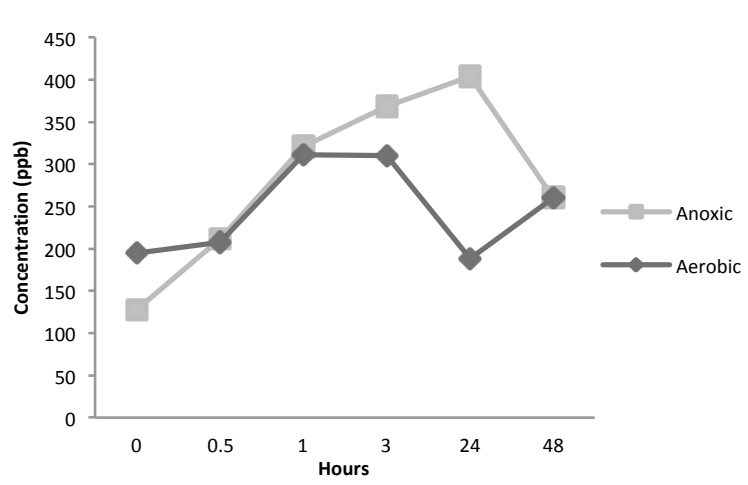

(b) Greensand

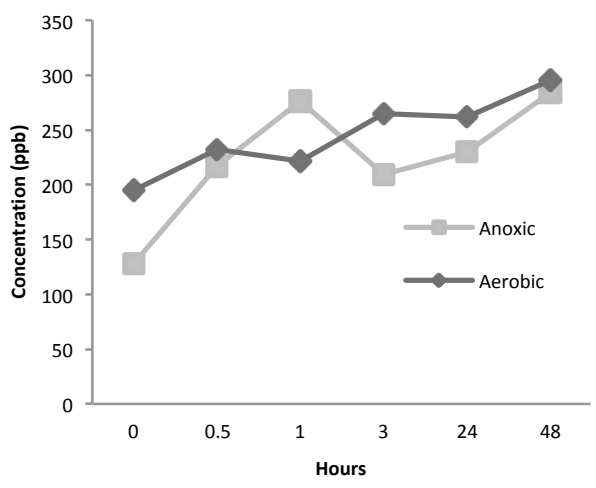

Figure 9-Pilot experiment 1: water phase concentrations of Zn over 48-hour sampling period for (a) Ladybug Sand and (b) Greensand

Analysis of the sand revealed that both the Ladybug Sand and Greensand contained high quantities of copper, iron and zinc relative to the concentrations used in the synthetic stormwaters (Table 11). The concentration of arsenic in both sands was below the minimum detection limit (MDL) of 5 ppm.

Table 11 - Concentration of $\mathrm{Cu}, \mathrm{Fe}, \mathrm{Zn}$ and As in Ladybug and Green sands as well as anoxic and oxic synthetic stormwaters from pilot experiment 1

\begin{tabular}{lcccc}
\hline Metal & Ladybug Sand & Greensand & Anoxic S.W. & Oxic S.W. \\
\hline Copper & $7 \mathrm{ppm}$ & $4 \mathrm{ppm}$ & $23.4 \mathrm{ppb}$ & $44.6 \mathrm{ppb}$ \\
Iron & $320000 \mathrm{ppm}$ & $190000 \mathrm{ppm}$ & $66 \mathrm{ppb}$ & $32 \mathrm{ppb}$ \\
Zinc & $7 \mathrm{ppm}$ & $17 \mathrm{ppm}$ & $127.8 \mathrm{ppb}$ & $194.9 \mathrm{ppb}$ \\
Arsenic & $<5 \mathrm{ppm} *$ & $<5 \mathrm{ppm} *$ & $11.1 \mathrm{ppb}$ & $22.4 \mathrm{ppb}$ \\
Cadmium & $1.9 \mathrm{ppm}$ & $<0.4 \mathrm{ppm} *$ & $\mathrm{NA}$ & $\mathrm{NA}$ \\
Lead & $86 \mathrm{ppm}$ & $<5 \mathrm{ppm} *$ & $\mathrm{NA}$ & $\mathrm{NA}$ \\
\hline *Below minimum detection limit $(M D L)$ & \\
\hline
\end{tabular}


Based on the results of the first pilot experiment, iron, copper and zinc were dropped from the subsequent experiments, while cadmium and lead, other SWAMP priority pollutants, were added to the investigation. The concentrations of cadmium and lead in the Ladybug Sand were $1.9 \mathrm{ppm}$ and $86 \mathrm{ppm}$ respectively and in the Greensand were below the MDL of $<0.4 \mathrm{ppm}$ and $<5$ ppm respectively. Therefore, it seemed plausible that the sands could be effective at removing these metals.

\subsection{PILOT EXPERIMENT 2}

The second pilot experiment determined if the sands were capable of removing the new set of metals. Arsenic, cadmium and lead were reduced by both the Ladybug and Greensand (Figure $10)$.

(a) Ladybug Sand

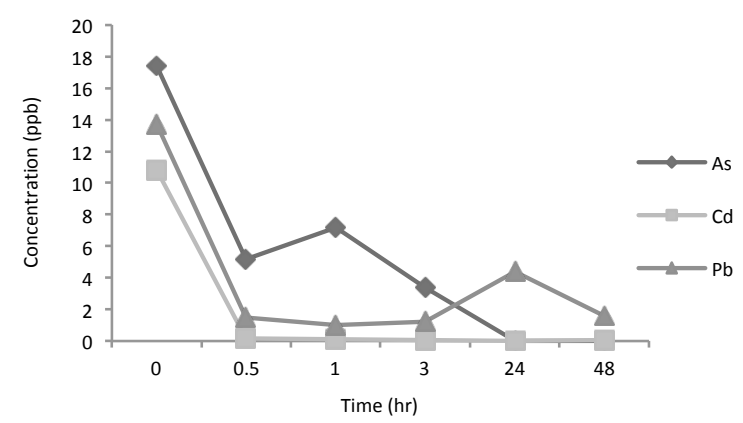

(b) Greensand

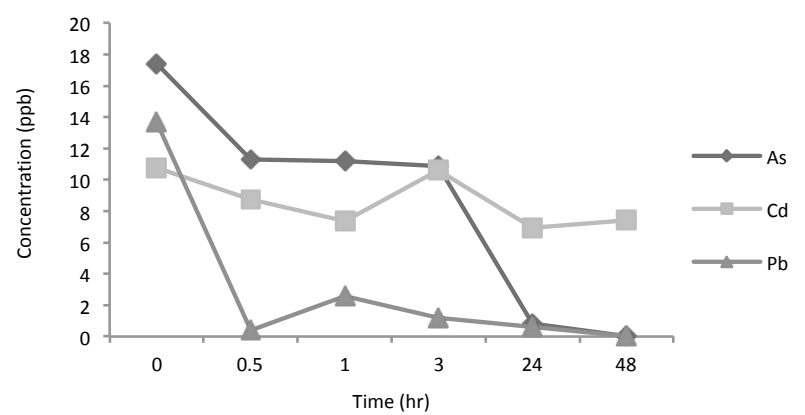

Figure 10 - Water phase concentration of $\mathrm{As}, \mathrm{Cd}$ and $\mathrm{Pb}$ in (a) Ladybug Sand samples and (b) Greensand samples

Since both sands were capable of removing arsenic, cadmium and lead, the adsorption isotherms and kinetics of these metals were investigated in the subsequent experiments. 


\subsection{ISOTHERM EXPERIMENTS}

The Langmuir, Freundlich and Henry isotherms were fit to the batch isotherm data using nonlinear and linear regressions. The linear regression plots are available in Appendix B. The coefficient of determination $\left(\mathrm{R}^{2}\right)$ and AIC were used to evaluate the fit of the different isotherm equations.

The adsorption isotherms determined likely represents the sands' maximum adsorption capacities of the metals considered, as in reality stormwater contains many additional contaminants that may compete for adsorption binding sites.

The blank samples tested to account for any potential adsorption to the containers showed that the metals did not adsorb to the container and therefore did not impact the isotherm or kinetic results.

\subsubsection{LADYBUG SAND}

The results of the nonlinear regression of the Langmuir, Freundlich and Henry isotherms fit to the Ladybug Sand batch data are provided in Table 12.

In order of preference, the arsenic data fit the Langmuir $\left(\mathrm{R}^{2}=0.943, \mathrm{AIC}=106\right)$ then Freundlich $\left(\mathrm{R}^{2}=0.823, \mathrm{AIC}=122\right)$ isotherms. The linear arsenic concentration range, 447 to 3 $384 \mathrm{ppb}$ (SW1 to SW4), fit the Henry isotherm well, with an $\mathrm{R}^{2}$ of 0.912 and AIC of 49.261.

The entirety of cadmium data also fit the Langmuir $\left(\mathrm{R}^{2}=0.940, \mathrm{AIC}=43\right)$, then Freundlich $\left(\mathrm{R}^{2}=0.823, \mathrm{AIC}=59\right)$ isotherms. The linear concentration range for cadmium, 12 to $344 \mathrm{ppb}$ (SW1 to SW6), fit the Henry isotherm very well with a $\mathrm{R}^{2}$ of 0.969 and AIC of 13. 
From the Langmuir parameters it can be seen that Ladybug Sand preferentially adsorbs arsenic over cadmium. The arsenic isotherm had a preferential b value of $9.388 \times 10^{-4}$ compared to cadmium's 0.188. A smaller b value indicates that the equilibrium adsorbent loading is reached at a lower concentration.

An isotherm could not be determined for lead because it was reduced to almost zero in every sample. Therefore, to establish an isotherm for lead, higher concentrations should be tested.

Table 12 - Isotherm parameters derived from nonlinear regression of Ladybug Sand batch data.

\begin{tabular}{llccc}
\hline Isotherm & Parameters & $\mathrm{As}$ & $\mathrm{Cd}$ & $\mathrm{Pb}^{\mathrm{a}}$ \\
\hline \hline Langmuir & $\mathrm{R}^{2}$ & 0.943 & 0.940 & - \\
(nonlinear) & $\mathrm{AIC}$ & 106.552 & 43.033 & - \\
& $\mathrm{b}$ & $9.388 \times 10^{-4}$ & 0.188 & - \\
& $\mathrm{q}_{\mathrm{m}}(\mu \mathrm{g} / \mathrm{g})$ & 269.644 & 42.626 & - \\
\hline Freundlich & $\mathrm{R}^{2}$ & 0.823 & 0.823 & - \\
(nonlinear) & $\mathrm{AIC}$ & 122.225 & 59.392 & - \\
& $\mathrm{K}(\mathrm{L} / \mathrm{g})$ & 19.842 & 8.582 & - \\
& $1 / \mathrm{n}$ & 0.256 & 0.355 & - \\
\hline Henry & $\mathrm{R}^{2}$ & 0.912 & 0.721 & 13.615 \\
(nonlinear) & $\mathrm{AIC}$ & 49.261 & 1.893 & - \\
\hline a the initial lead concentration in the water was not high enough to establish an isotherm
\end{tabular}

For comparison, the Langmuir parameters derived from the nonlinear and linear regressions are provided in Table 13. Based on the coefficients of determination, the nonlinear 
regression outperformed all linear regressions. Of the linearized equations, the first linear equation (LE 1) produced a good estimate of the fitting isotherm parameters, with a $\mathrm{R}^{2}$ of 0.941 .

Table 13 - Comparison of Langmuir isotherm parameters determined by nonlinear and linear regressions for Ladybug Sand batch data

\begin{tabular}{|c|c|c|c|c|}
\hline Isotherm & Parameters & As & $\mathrm{Cd}$ & $\mathrm{Pb}^{\mathrm{a}}$ \\
\hline \multirow[t]{3}{*}{ Langmuir (nonlinear) } & $\mathrm{R}^{2}$ & 0.943 & 0.940 & - \\
\hline & $\mathrm{b}$ & 0.001 & 0.188 & - \\
\hline & $\mathrm{q}_{\mathrm{m}}(\mu \mathrm{g} / \mathrm{g})$ & 269.644 & 42.626 & - \\
\hline \multirow[t]{3}{*}{ LE 1 (linear) } & $\mathrm{R}^{2}$ & 0.941 & 0.918 & - \\
\hline & $\mathrm{b}$ & 0.001 & 0.134 & - \\
\hline & $\mathrm{q}_{\mathrm{m}}(\mu \mathrm{g} / \mathrm{g})$ & 265.640 & 42.905 & - \\
\hline \multirow[t]{3}{*}{ LE 2 (linear) } & $\mathrm{R}^{2}$ & 0.383 & 0.456 & - \\
\hline & $\mathrm{b}$ & 0.005 & -0.035 & - \\
\hline & $\mathrm{q}_{\mathrm{m}}(\mu \mathrm{g} / \mathrm{g})$ & 135.983 & -129.751 & - \\
\hline \multirow[t]{3}{*}{ LE 3 (linear) } & $\mathrm{R}^{2}$ & 0.771 & 0.752 & - \\
\hline & $\mathrm{b}$ & 0.002 & 0.235 & - \\
\hline & $\mathrm{q}_{\mathrm{m}}(\mu \mathrm{g} / \mathrm{g})$ & 214.854 & 30.641 & - \\
\hline \multirow[t]{3}{*}{ LE 4 (linear) } & $\mathrm{R}^{2}$ & 0.908 & 0.872 & - \\
\hline & $\mathrm{b}$ & 0.002 & 0.081 & - \\
\hline & $\mathrm{q}_{\mathrm{m}}(\mu \mathrm{g} / \mathrm{g})$ & 253.272 & 64.888 & - \\
\hline
\end{tabular}

${ }^{a}$ the initial lead concentration in the water was not high enough to establish an isotherm

The Freundlich isotherm parameters derived from the nonlinear and linear regressions are provided in Table 14. Interestingly, the nonlinear and linear regressions produced the same $\mathrm{R}^{2}$ value but different isotherm parameters. Even when the Solver optimization program was run 
with the linear isotherm parameters as initial conditions, the nonlinear regression produced $\mathrm{K}$ and $1 / \mathrm{n}$ values of 19.842 and 0.256 respectively. Although the coefficients of determination were the same, the nonlinear SSE was 24 439, much smaller than the linear SSE of 48 404. A lower SSE indicates that the variances between model and experimental values were smaller.

Table 14 - Comparison of Freundlich isotherm parameters determined by nonlinear and linear regressions of Ladybug Sand batch data

\begin{tabular}{llccc}
\hline Isotherm & Parameters & $\mathrm{As}$ & $\mathrm{Cd}$ & $\mathrm{Pb}^{\mathrm{a}}$ \\
\hline \hline \multirow{2}{*}{ Freundlich (nonlinear) } & $\mathrm{R}^{2}$ & 0.823 & 0.823 & - \\
& $\mathrm{K}(\mathrm{L} / \mathrm{g})$ & 19.842 & 8.582 & - \\
& $1 / \mathrm{n}$ & 0.256 & 0.355 & - \\
\hline \multirow{2}{*}{ Freundlich (linear) } & $\mathrm{R}^{2}$ & 0.823 & 0.711 & - \\
& $\mathrm{K}(\mathrm{L} / \mathrm{g})$ & 6.320 & 3.961 & - \\
& $1 / \mathrm{n}$ & 0.385 & 0.681 & - \\
\hline
\end{tabular}

${ }^{a}$ the initial lead concentration in the water was not high enough to establish an isotherm

Plots of the Ladybug Sand batch equilibrium data and best-fit Langmuir, Freundlich and Henry isotherms are provided in Figure 11. 
(a) Arsenic

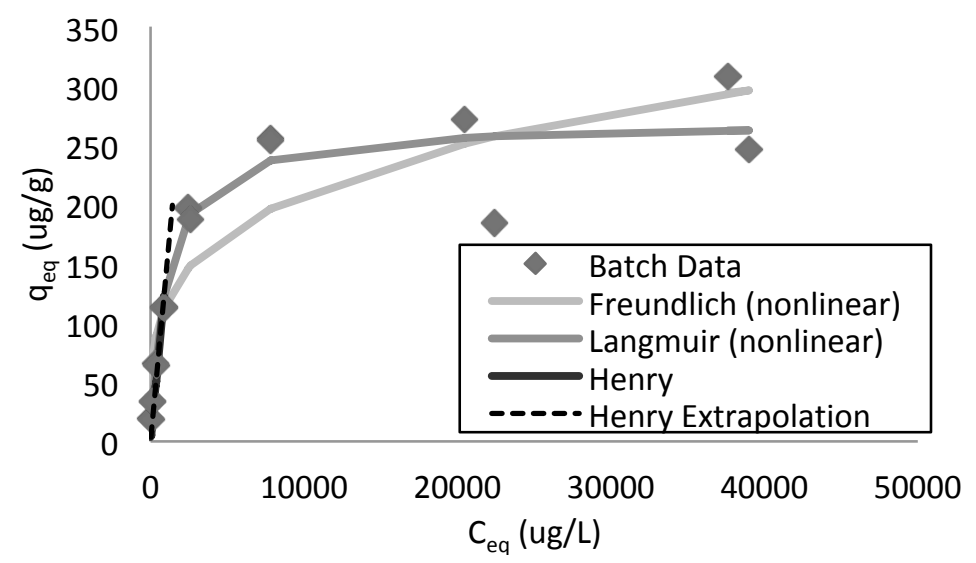

(b) Cadmium

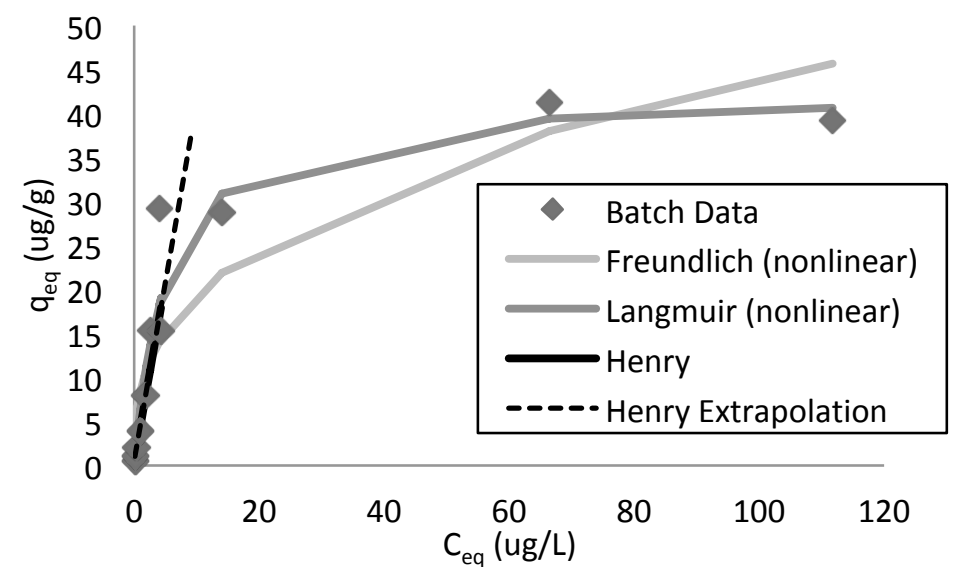

(c) Lead

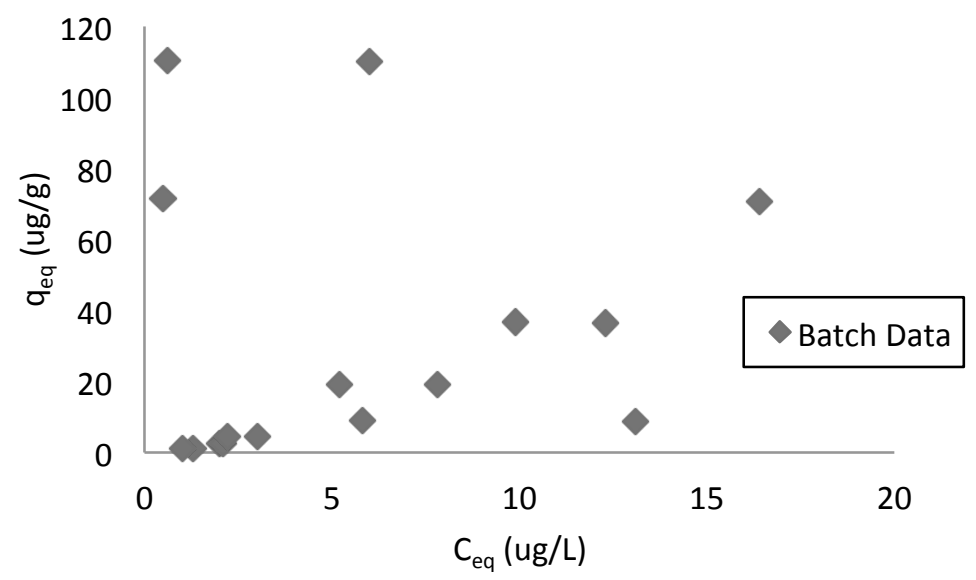

Figure 11 - Ladybug Sand batch equilibrium data and best-fit isotherms 


\subsubsection{GREENSAND}

The coefficients of determination and isotherm parameters of the Langmuir, Freundlich and Henry isotherms fit to the Greensand batch data using nonlinear regression are provided in Table 15.

In order of preference, the arsenic data fit the Freundlich $\left(\mathrm{R}^{2}=0.850, \mathrm{AIC}=127\right)$ then Langmuir $\left(\mathrm{R}^{2}=0.791, \mathrm{AIC}=138\right)$ isotherms. The arsenic Freundlich isotherm parameters, $\mathrm{K}$ and $1 / \mathrm{n}$, were 18.075 and 0.272 respectively. Over the linear concentration range the arsenic data fit the Henry isotherm with an $\mathrm{R}^{2}$ of 0.832 and AIC of 52. The linear concentration range for arsenic was 447 to $1780 \mathrm{ppb}$ (SW1 - SW3).

The lead data also fit the Freundlich $\left(\mathrm{R}^{2}=0.896\right.$ and AIC $\left.=79\right)$ then Langmuir $\left(\mathrm{R}^{2}=\right.$ 0.874, $\mathrm{AIC}=86)$ isotherms. The lead Freundlich isotherm parameters, $\mathrm{K}$ and $1 / \mathrm{n}$, were 13.278 and 0.327 respectively. The linear lead concentration range, 24 to $825 \mathrm{ppb}$ (SW1 - SW6), fit the Henry isotherm with a $\mathrm{R}^{2}$ of 0.744 and AIC of 64.

From the Freundlich adsorption isotherm parameters it can be seen that Greensand preferentially adsorbs arsenic over lead. The arsenic $\mathrm{K}$ and $1 / \mathrm{n}$ values were favorably larger and smaller respectively than the lead values.

The Greensand did not effectively remove cadmium. Therefore, the isotherms could not be fit to the cadmium data. 
Table 15 - Langmuir, Freundlich and Henry isotherm parameters and coefficient of determination of nonlinear regressions using Green sand batch data.

\begin{tabular}{llccc}
\hline Isotherm & Parameters & $\mathrm{As}$ & $\mathrm{Cd}^{\mathrm{a}}$ & $\mathrm{Pb}$ \\
\hline Langmuir & $\mathrm{R}^{2}$ & 0.791 & - & 0.874 \\
& $\mathrm{AIC}$ & 138.448 & - & 86.279 \\
& $\mathrm{~b}$ & $2.022 \times 10^{-4}$ & - & 0.026 \\
& $\mathrm{q}_{\mathrm{m}}(\mu \mathrm{g} / \mathrm{g})$ & 347.186 & - & 98.103 \\
\hline Freundlich & $\mathrm{R}^{2}$ & 0.850 & - & 0.896 \\
& $\mathrm{AIC}$ & 127.103 & - & 79.668 \\
& $\mathrm{~K}(\mathrm{~L} / \mathrm{g})$ & 18.075 & - & 13.278 \\
& $1 / \mathrm{n}$ & 0.272 & - & 0.327 \\
\hline Henry & $\mathrm{R}^{2}$ & 0.721 & - & 0.744 \\
& $\mathrm{AIC}$ & 1.893 & - & 64.610 \\
& $\mathrm{~K}_{\mathrm{H}}(\mathrm{L} / \mathrm{g})$ & 52.424 & - & 1.150 \\
\hline
\end{tabular}

${ }^{a}$ Cadmium was not effectively removed

For comparison, the Langmuir parameters derived from the nonlinear and linear regressions are provided in Table 16. As seen in Table 16, the nonlinear regression outperformed all of the linear regressions. Of the linearized equations, the first equation (LE 1) produced the best fitting Langmuir parameters with a $\mathrm{R}^{2}$ of 0.786 . 
Table 16 - Langmuir isotherm parameters determined by nonlinear and linear regressions for Greensand batch data

\begin{tabular}{llccc}
\hline Isotherm (regression) & Parameters & $\mathrm{As}$ & $\mathrm{Cd}^{\mathrm{a}}$ & $\mathrm{Pb}$ \\
\hline \hline Langmuir (nonlinear) & $\mathrm{R}^{2}$ & 0.791 & - & 0.874 \\
& $\mathrm{~b}$ & $2.022 \times 10^{-4}$ & - & 0.026 \\
& $\mathrm{q}_{\mathrm{m}}(\mu \mathrm{g} / \mathrm{g})$ & 347.186 & - & 98.103 \\
\hline LE 1 (linear) & $\mathrm{R}^{2}$ & 0.786 & - & 0.876 \\
& $\mathrm{~b}$ & $4.032 \times 10^{-4}$ & - & 0.031 \\
& $\mathrm{q}_{\mathrm{m}}(\mu \mathrm{g} / \mathrm{g})$ & 326.375 & - & 97.788 \\
\hline LE 2 (linear) & $\mathrm{R}^{2}$ & 0.287 & - & 0.309 \\
& $\mathrm{~b}$ & 0.193 & - & 7.159 \\
& $\mathrm{q}_{\mathrm{m}}(\mu \mathrm{g} / \mathrm{g})$ & 136.454 & - & 0.917 \\
\hline LE 3 (linear) & $\mathrm{R}^{2}$ & 0.353 & - & 0.044 \\
& $\mathrm{~b}$ & 0.178 & - & 1.251 \\
& $\mathrm{q}_{\mathrm{m}}(\mu \mathrm{g} / \mathrm{g})$ & 183.552 & - & 33.408 \\
& $\mathrm{R}^{2}$ & 0.588 & - & 0.686 \\
& $\mathrm{~b}$ & 0.054 & - & 0.054 \\
& $\mathrm{q}_{\mathrm{m}}(\mu \mathrm{g} / \mathrm{g})$ & 260.166 & - & 129.157 \\
& & &
\end{tabular}

${ }^{a}$ Cadmium was not effectively removed

The Freundlich isotherm parameters derived from the nonlinear and linear regressions are provided in Table 17. As with the Langmuir isotherm, the nonlinear regression provided better fitting Freundlich isotherm parameters than the linear regression. 
Table 17 - Freundlich isotherm parameters determined by nonlinear and linear regressions of Greensand batch equilibrium data

\begin{tabular}{llccc}
\hline Isotherm & Parameters & $\mathrm{As}$ & $\mathrm{Cd}^{\mathrm{a}}$ & $\mathrm{Pb}$ \\
\hline \hline & $\mathrm{R}^{2}$ & 0.850 & - & 0.896 \\
Freundlich (nonlinear) & $\mathrm{K}(\mathrm{L} / \mathrm{g})$ & 18.075 & - & 13.278 \\
& $1 / \mathrm{n}$ & 0.272 & - & 0.327 \\
\hline & $\mathrm{R}^{2}$ & 0.800 & - & 0.872 \\
Freundlich (linear) & $\mathrm{K}(\mathrm{L} / \mathrm{g})$ & 27.955 & - & 5.416 \\
& $1 / \mathrm{n}$ & 0.222 & & 0.511 \\
\hline${ }^{a}$ Cadmium was not effectively removed & & \\
\hline
\end{tabular}

There was no difference between the nonlinear and linear regressions of the Henry isotherm. This was expected, as the Henry isotherm is inherently linear.

The Greensand batch equilibrium data and best-fit Langmuir, Freundlich and Henry isotherms are provided in Figure 12. 
(a) Arsenic

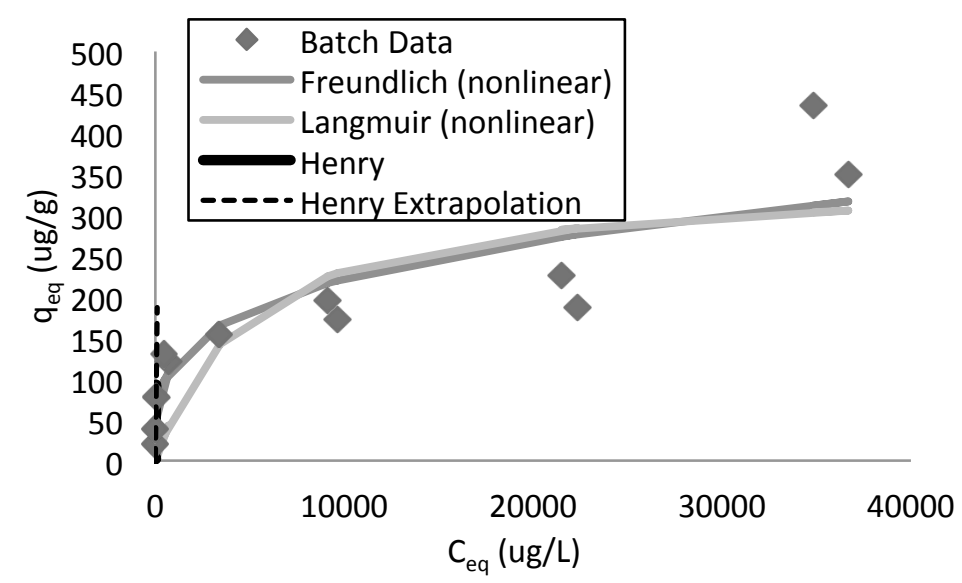

(b) Cadmium

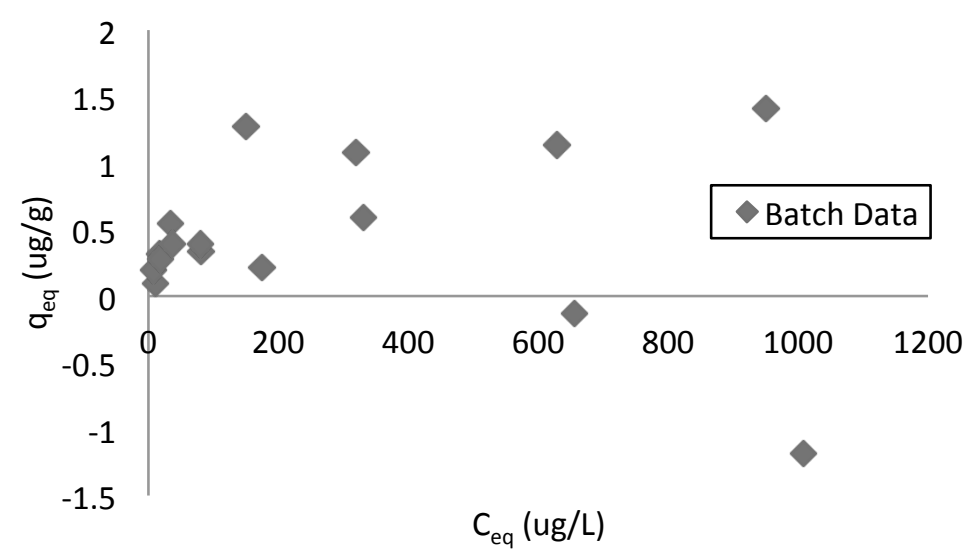

(c) Lead

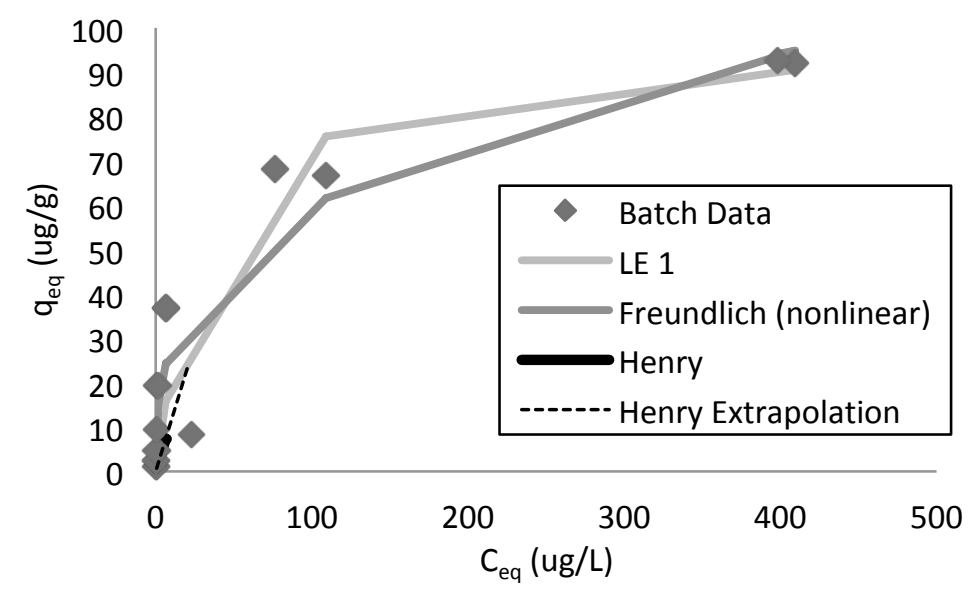

Figure 12 - Greensand batch equilibrium data and best-fit isotherms 


\subsection{KINETIC EXPERIMENTS}

The batch kinetic experiments were conducted to determine the sands' kinetic coefficients for the adsorption of arsenic, cadmium and lead. To determine these coefficients, the pseudo-first-order, pseudo-second-order and HSDM kinetic models were fit to the experimental data using nonlinear and linear regressions. The linear regression plots are available in Appendix C. The coefficient of determination $\left(\mathrm{R}^{2}\right)$ and AIC were used to identify the best-fit model. The model parameters that were obtained include the pseudo-first-order rate constant $\left(\mathrm{k}_{1}\right)$, the pseudo-second-order rate constant $\left(\mathrm{k}_{2}\right)$ and corresponding calculated equilibrium adsorbent loading $\left(\mathrm{q}_{\mathrm{e}, \text { calc }}\right)$, and the surface diffusion coefficient $\left(D_{s}\right)$. Adsorption kinetics were determined at two different stormwater concentrations: SW5 and SW8.

\subsubsection{LADYBUG SAND}

Table 19 has the results from the nonlinear regression of the Ladybug Sand kinetic data. The pseudo-first-order and pseudo-second-order reaction kinetic models described the experimental data well, with $\mathrm{R}^{2}$ values $>0.9$, except for the SW8 arsenic data. The model fitting for the SW8 arsenic data was affected by the concentration of the samples taken at 24 hours (Figure 13). At 24 hours the concentration was higher, and therefore the adsorbent loading was lower, than what would be expected by the models. This indicates that there may have been some desorption of arsenic around this time. The reaction kinetic coefficients were dependent on initial metal concentrations. Typically, the pseudo-first-order $\left(\mathrm{k}_{1}\right)$ and pseudo-second-order $\left(\mathrm{k}_{2}\right)$ reaction coefficients decrease with increasing initial concentration (Plazinski et al. 2009). A decrease in $\mathrm{k}_{1}$ or $\mathrm{k}_{2}$ corresponds to an increase in time required to reach equilibrium. Both cadmium and lead exhibited this inverse relationship, but arsenic did not. 
Table 18 - Reaction kinetic model parameters for Ladybug Sand

\begin{tabular}{|c|c|c|c|c|c|c|c|}
\hline \multirow{2}{*}{$\begin{array}{l}\text { Kinetic Model } \\
\text { (Regression) }\end{array}$} & \multirow{2}{*}{ Parameter } & \multicolumn{3}{|c|}{ SW5 } & \multicolumn{3}{|c|}{ SW8 } \\
\hline & & As & $\mathrm{Cd}$ & $\mathrm{Pb}$ & As & $\mathrm{Cd}$ & $\mathrm{Pb}$ \\
\hline \multirow{4}{*}{$\begin{array}{l}\text { Pseudo-1 } 1^{\text {st }} \text {-Order } \\
\text { (nonlinear) }\end{array}$} & $\overline{\mathrm{R}^{2}}$ & 0.980 & 0.984 & 0.988 & 0.712 & 0.995 & 0.926 \\
\hline & AIC & 69.302 & -22.165 & -3.475 & 115.111 & 6.142 & 73.894 \\
\hline & $\mathrm{k}_{1}\left(\mathrm{hr}^{-1}\right)$ & 0.070 & 0.351 & 0.497 & 0.555 & 0.041 & 0.120 \\
\hline & $\mathrm{q}_{\mathrm{e}, \text { calc }}(\mu \mathrm{g} / \mathrm{g})$ & 194.196 & 7.987 & 19.017 & 227.339 & 48.294 & 108.606 \\
\hline \multirow{4}{*}{$\begin{array}{l}\text { Pseudo-2 }{ }^{\text {nd }}-\text { Order } \\
\text { (nonlinear) }\end{array}$} & $\mathrm{R}^{2}$ & 0.983 & 0.971 & 0.960 & 0.702 & 0.994 & 0.910 \\
\hline & AIC & 66.965 & -15.329 & 12.368 & 113.176 & 9.448 & 76.818 \\
\hline & $\mathrm{k}_{2}(\mathrm{~g} / \mu \mathrm{g} \mathrm{hr})$ & $2.447 \times 10^{-4}$ & 0.054 & 0.032 & $3.425 \times 10^{-3}$ & $4.146 \times 10^{-4}$ & $8.104 \times 10^{-4}$ \\
\hline & $\mathrm{q}_{\mathrm{e}, \text { calc }}(\mu \mathrm{g} / \mathrm{g})$ & 254.631 & 8.681 & 20.619 & 243.594 & 71.264 & 134.502 \\
\hline \multirow{6}{*}{$\begin{array}{l}\text { HSDM } \\
\text { (nonlinear) }\end{array}$} & $\mathrm{R}^{2}$ & 0.751 & 0.593 & - & 0.755 & 0.580 & - \\
\hline & AIC & 106.553 & 18.247 & - & 113.007 & 77.169 & - \\
\hline & $\operatorname{Ds}\left(\mu \mathrm{m}^{2} / \mathrm{min}\right)$ & 11.076 & 2.392 & - & 23.009 & 5.602 & - \\
\hline & $\mathrm{r}_{\mathrm{p}}(\mu \mathrm{m})$ & 315.250 & 315.250 & - & 315.250 & 315.250 & - \\
\hline & $\mathrm{Ce} / \mathrm{Co}$ & 0.400 & 0.010 & - & 0.900 & 0.100 & - \\
\hline & $1 / \mathrm{n}$ & 0.300 & 0.400 & - & 0.300 & 0.400 & - \\
\hline
\end{tabular}

$q_{e}=$ equilibrium adsorbent loading

${ }^{a}$ the HSDM model could not be fit to the cadmium data for Ladybug Sand because a isotherm was not established

It is difficult to draw conclusions about the nature of the adsorption process based on the results of the pseudo-first-order and pseudo-second-order model fitting, because these models have successfully simulated the kinetics of adsorption systems with different controlling mass transfer mechanisms (Plazinski et al. 2009). Furthermore, for the purposes of predicting 
breakthrough behavior of adsorption columns, it has been found that the reaction coefficients determined from batch experiments are often not applicable in conditions dissimilar from the experiment (Worch 2012). However, these models are widely used in adsorption studies and may be useful for comparison with other adsorbents.

Diffusion models, such as the HSDM, tend to more accurately represent actual adsorption processes in column reactors and are therefore more useful for design purposes (Qiu et al. 2009). Unfortunately, the HSDM did not fit the kinetic data as well as the reaction models and therefore the surface diffusion coefficient $\left(D_{s}\right)$ derived from this experiment might not accurately predict breakthrough behavior. The coefficients of determination for the HSDM fit to the arsenic data was around 0.75 and fit to the cadmium data was around 0.6. Interestingly the AIC for cadmium was lower (i.e. better) than for arsenic. This was because the SSE for cadmium was smaller than that for arsenic. The poor fit of the HSDM may indicate that surface diffusion is not the rate controlling mass transfer mechanisms and that pore diffusion or adsorption reaction kinetics may be more significant. Due to the high shaker speeds used, it is unlikely that film diffusion significantly impacted the adsorption kinetics. However, to confirm if film diffusion resistance had been removed, the kinetic experiment could be repeated at higher agitation speeds. The calculation of the user-oriented HSDM solution may also be a source of error. Due to the useroriented HSDM solution's dependence on Freundlich isotherm parameters, the poor fit of the surface diffusion model could partially be a function of the less than optimal fit of the Freundlich isotherm. The user-oriented solution also relies on the selection of empirical constants to calculate a dimensionless concentration (Eq. 21). The constants provided by Zhang et al., (2009) do not match the experimental conditions exactly. Therefore, to obtain a better estimation of $\mathrm{D}_{\mathrm{s}}$ 
numerical methods could be applied. Furthermore, the HSDM assumes that the adsorbent is a homogenous sphere, which is likely not the case for Ladybug Sand.

The experimentally determined $\mathrm{D}_{\mathrm{s}}$ values for the adsorption of arsenic and cadmium by Ladybug Sand were within the typical range of $D_{\mathrm{s}}$ values for activated carbon $-10^{-11} \mathrm{~m}^{2} \mathrm{~s}^{-1}$ to $10^{-}$ ${ }^{15} \mathrm{~m}^{2} \mathrm{~s}^{-1}$ (Worch 2012). The surface diffusion coefficient $\left(D_{\mathrm{s}}\right)$ was dependent on the initial concentration. The surface diffusion coefficient $\left(D_{s}\right)$ increased, approximately doubling, as the initial concentration increased. The concentration dependence of the surface diffusion coefficient is a consequence of changing adsorbent surface loading and subsequently, changes in adsorption energy (Worch 2012). The HSDM could not be fit to the lead data because adsorption isotherms were not established for lead.

The experimental kinetic data and fitted kinetic models are provided in Figure 13. 
SW5

(a)

Arsenic

(b)

(c) Lead
Cadmium
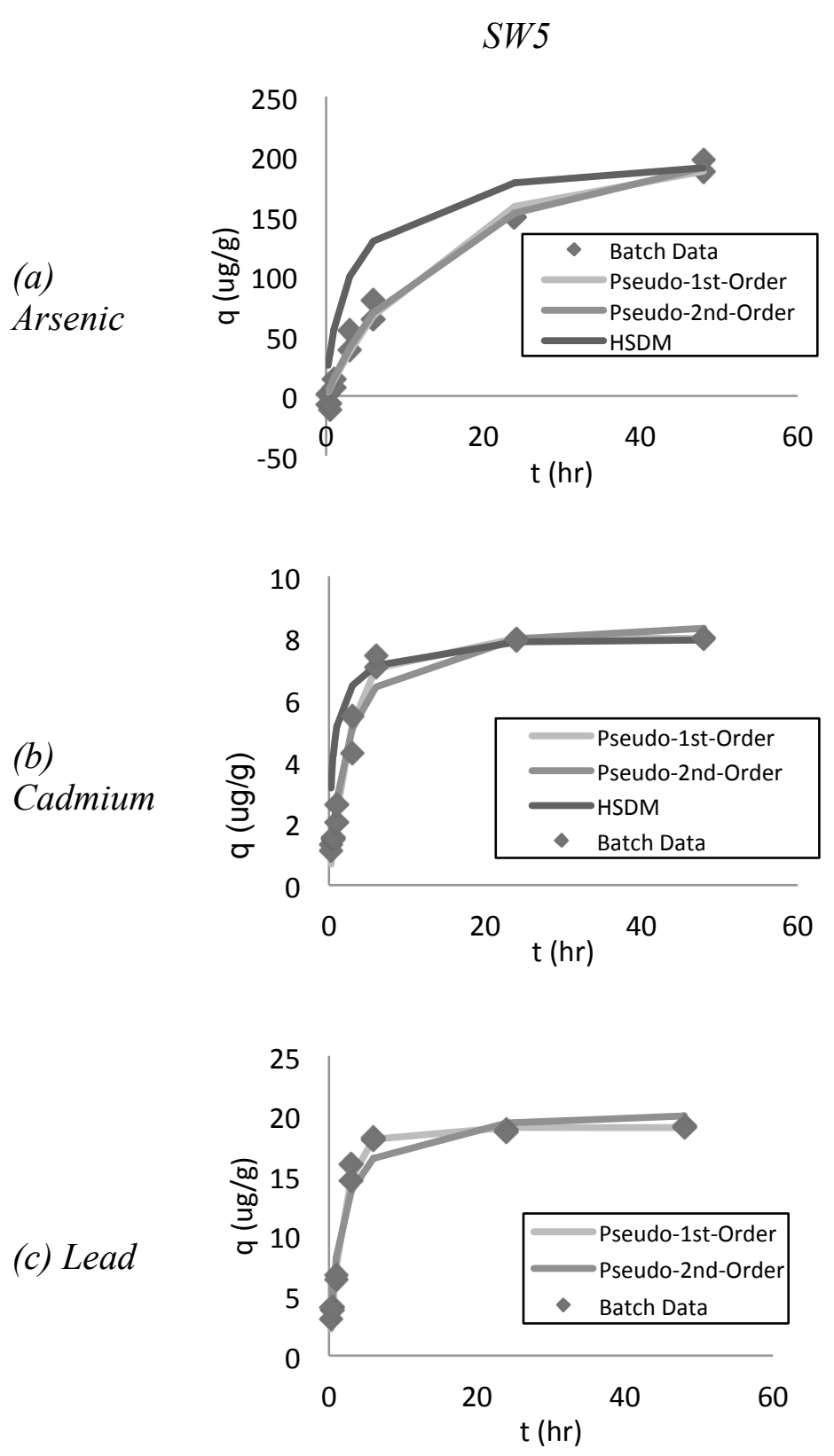

SW8
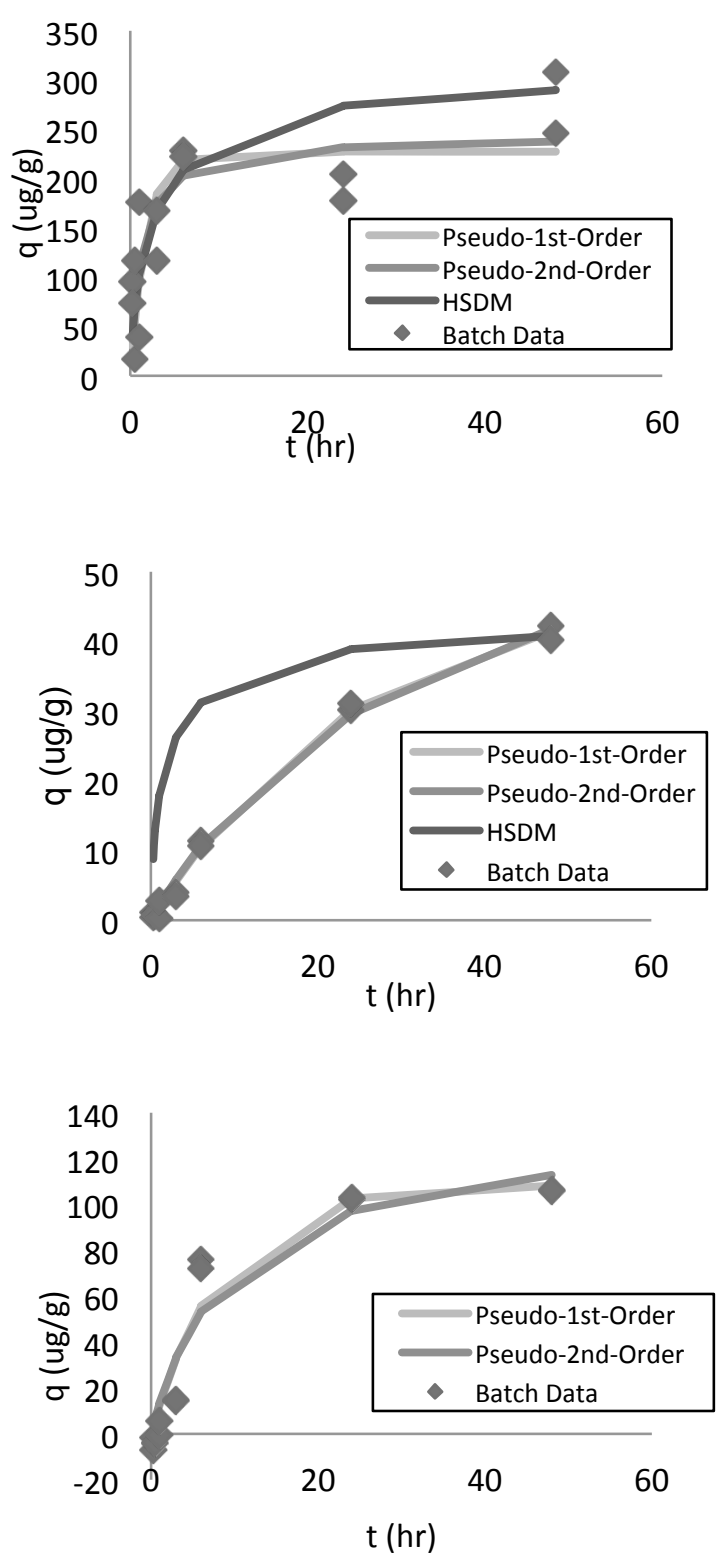

Figure 13 - Ladybug Sand kinetic data and kinetic models derived from nonlinear regression

For comparison, the reaction kinetic model parameters derived from the nonlinear and linear regressions are provided in Table 19. In general, the nonlinear regression outperformed the linear regression fitting procedure. The only exception was the linear pseudo-second-order model 
fit to the SW8 arsenic data, which had an $\mathrm{R}^{2}$ of 0.735 compared to the nonlinear 0.702 . The reason for this is unclear.

Table 19 - Comparison of reaction kinetic model parameters determined by nonlinear and linear regressions for Ladybug Sand

\begin{tabular}{|c|c|c|c|c|c|c|c|}
\hline \multirow{2}{*}{$\begin{array}{l}\text { Kinetic Model } \\
\text { (Regression) }\end{array}$} & \multirow{2}{*}{ Parameter } & \multicolumn{3}{|c|}{ SW5 } & \multicolumn{3}{|c|}{ SW8 } \\
\hline & & As & $\mathrm{Cd}$ & $\mathrm{Pb}$ & As & $\mathrm{Cd}$ & $\mathrm{Pb}$ \\
\hline \multirow{2}{*}{ Pseudo- $1^{\text {st }}$-Order } & 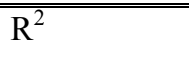 & 0.980 & 0.984 & 0.988 & 0.712 & 0.995 & 0.926 \\
\hline & $\mathrm{k}_{1}\left(\mathrm{hr}^{-1}\right)$ & 0.070 & 0.351 & 0.497 & 0.555 & 0.041 & 0.120 \\
\hline (nonlinear) & $\mathrm{q}_{\mathrm{e}, \text { calc }}(\mu \mathrm{g} / \mathrm{g})$ & 194.196 & 7.987 & 0.960 & 227.339 & 48.294 & 108.606 \\
\hline Pseudo- $1^{\text {st }}$-Order & $\mathrm{R}^{2}$ & 0.964 & 0.792 & 0.812 & 0.611 & 0.909 & 0.918 \\
\hline (linear) & $\mathrm{k}_{1}\left(\mathrm{hr}^{-1}\right)$ & 0.064 & 0.246 & 0.189 & 0.067 & 0.056 & 0.146 \\
\hline \multirow{3}{*}{ Pseudo-2 ${ }^{\text {nd }}-$ Order } & $\mathrm{R}^{2}$ & 0.983 & 0.971 & 0.960 & 0.702 & 0.994 & 0.910 \\
\hline & $\mathrm{k}_{2}(\mathrm{~g} / \mu \mathrm{g} \mathrm{hr})$ & $2.447 \times 10^{-4}$ & 0.054 & 0.032 & $3.425 \times 10^{-3}$ & $4.146 \times 10^{-4}$ & $8.104 \times 10^{-4}$ \\
\hline & $\mathrm{q}_{\mathrm{e}, \text { calc }}(\mu \mathrm{g} / \mathrm{g})$ & 254.631 & 8.681 & 20.619 & 243.594 & 71.264 & 134.502 \\
\hline \multirow{3}{*}{ Pseudo-2 ${ }^{\text {nd }}-$ Order } & $\mathrm{R}$ & 0.970 & 0.965 & 0.950 & 0.735 & 0.966 & 0.518 \\
\hline & $\mathrm{k}_{2}(\mathrm{~g} / \mu \mathrm{g} \mathrm{hr})$ & $4.359 \times 10^{-4}$ & 0.064 & 0.038 & $1.146 \times 10^{-3}$ & $2.832 \times 10^{-5}$ & $1.292 \times 10^{-4}$ \\
\hline & $\mathrm{q}_{\mathrm{e}, \text { calc }}(\mu \mathrm{g} / \mathrm{g})$ & 226.107 & 8.359 & 19.704 & 272.889 & 206.608 & 188.038 \\
\hline
\end{tabular}

\subsubsection{GREENSAND}

Table 20 has a summary of the kinetic model parameters derived from the nonlinear regression of the Greensand kinetic data. The pseudo-first-order and pseudo-second-order reaction kinetic models fit the lead kinetic data well, with $\mathrm{R}^{2}$ values around 0.9 and above. The reaction models described the arsenic kinetic data slightly worse, with $\mathrm{R}^{2}$ values of around 0.8 . Greensand did not 
effectively remove cadmium so a kinetic curve could not be established. The reaction kinetic coefficients $\left(\mathrm{k}_{1}\right.$ and $\left.\mathrm{k}_{2}\right)$ were concentration dependent, decreasing with increasing concentration.

Table 20 - Kinetic model parameters for Greensand

\begin{tabular}{|c|c|c|c|c|c|c|c|}
\hline \multirow{2}{*}{$\begin{array}{l}\text { Kinetic Model } \\
\text { (Regression) }\end{array}$} & \multirow{2}{*}{ Parameter } & \multicolumn{3}{|c|}{ SW5 } & \multicolumn{3}{|c|}{ SW8 } \\
\hline & & As & $\mathrm{Cd}^{\mathrm{a}}$ & $\mathrm{Pb}$ & As & $\mathrm{Cd}^{\mathrm{a}}$ & $\mathrm{Pb}$ \\
\hline \multirow{4}{*}{$\begin{array}{l}\text { Pseudo-1 } 1^{\text {st }} \text {-Order } \\
\text { (nonlinear) }\end{array}$} & $\overline{\mathrm{R}^{2}}$ & 0.793 & - & 0.869 & 0.798 & - & 0.962 \\
\hline & AIC & 96.645 & - & 19.502 & 122.982 & - & 53.649 \\
\hline & $\mathrm{k}_{1}\left(\mathrm{hr}^{-1}\right)$ & 0.220 & - & 1.441 & 0.034 & - & 0.079 \\
\hline & $\mathrm{q}_{\mathrm{e}, \text { calc }}(\mu \mathrm{g} / \mathrm{g})$ & 133.582 & - & 18.002 & 454.532 & - & 84.903 \\
\hline \multirow{4}{*}{$\begin{array}{l}\text { Pseudo-2 } 2^{\text {nd }}- \\
\text { Order } \\
\text { (nonlinear) }\end{array}$} & $\mathrm{R}^{2}$ & 0.800 & - & 0.944 & 0.777 & - & 0.973 \\
\hline & AIC & 93.153 & - & 4.774 & 121.706 & - & 47.649 \\
\hline & $\mathrm{k}_{2}(\mathrm{~g} / \mu \mathrm{g} \mathrm{hr})$ & $2.611 \times 10^{-3}$ & - & $1.089 \times 10^{-1}$ & $1.907 \times 10^{-4}$ & - & $7.762 \times 10^{-4}$ \\
\hline & $\mathrm{q}_{\mathrm{e}, \text { calc }}(\mu \mathrm{g} / \mathrm{g})$ & 141.569 & - & 19.160 & 415.014 & - & 105.285 \\
\hline \multirow{6}{*}{$\begin{array}{l}\text { HSDM }^{\mathrm{a}} \\
\text { (nonlinear) }\end{array}$} & $\mathrm{R}^{2}$ & 0.712 & - & 0.940 & 0.729 & - & 0.700 \\
\hline & AIC & 99.441 & - & 8.648 & 125.409 & - & 88.438 \\
\hline & $\mathrm{D}_{\mathrm{s}}\left(\mu \mathrm{m}^{2} / \mathrm{min}\right)$ & 25.921 & - & 0.898 & 9.298 & - & 11.617 \\
\hline & $\mathrm{r}_{\mathrm{p}}(\mu \mathrm{m})$ & 315.250 & - & 315.250 & 315.250 & - & 315.250 \\
\hline & $\mathrm{Ce} / \mathrm{Co}$ & 0.500 & - & 0.002 & 0.800 & - & 0.200 \\
\hline & $1 / \mathrm{n}$ & 0.3 & - & 0.3 & 0.3 & - & 0.300 \\
\hline $\begin{array}{l}q_{e}=\text { equilibri } \\
{ }^{a} \text { Cadmium wo }\end{array}$ & adsorben & ved & & & & & \\
\hline
\end{tabular}

It seems like the HSDM may be an appropriate model to describe the adsorption kinetics of arsenic and cadmium by Greensand. The HSDM coefficients of determination, fit to the experimental data, were around 0.7, except for SW5 lead, which had an $\mathrm{R}^{2}$ of 0.94 . As with the Ladybug Sand data, the fit of the HSDM to the Greensand data is influenced by the Freundlich 
parameters and the empirical constants used to calculate the dimensionless concentration in the user-oriented solution from Zhang et al. (2009). This user-oriented solution was used for its convenience, but does not provide an entirely accurate picture of the model's true fit. To get a better sense of the surface diffusion model's true fit, it would be best to employ a numerical solution to get a more exact solution.

The $\mathrm{D}_{\mathrm{s}}$ values were dependent on metal concentration. The $\mathrm{D}_{\mathrm{s}}$ for arsenic decreased when the initial concentration increased, whereas the $\mathrm{D}_{\mathrm{s}}$ for lead increased. Additional experiments should be conducted to determine $\mathrm{D}_{\mathrm{s}}$ values at lower metal concentrations that are more representative of stormwater concentrations. The $\mathrm{D}_{\mathrm{s}}$ values obtained seem reasonable as they are within the typical range for activated carbon.

As seen in Table 21, the nonlinear regression produced better fitting parameters for the pseudofirst-order models. Interestingly, the linear regression of the pseudo-second-order model marginally outperformed the nonlinear regression in most instances. 
Table 21 - Comparison of reaction kinetic model parameters determined by nonlinear and linear regressions for Greensand

\begin{tabular}{|c|c|c|c|c|c|c|c|}
\hline \multirow{2}{*}{$\begin{array}{l}\text { Kinetic Model } \\
\text { (Regression) }\end{array}$} & \multirow{2}{*}{ Parameter } & \multicolumn{3}{|c|}{ SW5 } & \multicolumn{3}{|c|}{ SW8 } \\
\hline & & As & $\mathrm{Cd}^{\mathrm{a}}$ & $\mathrm{Pb}$ & As & $\mathrm{Cd}^{\mathrm{a}}$ & $\mathrm{Pb}$ \\
\hline \multirow{2}{*}{ Pseudo- $1^{\text {st }}$-Order } & $\overline{\mathrm{R}^{2}}$ & 0.793 & - & 0.869 & 0.798 & 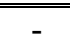 & 0.962 \\
\hline & $\mathrm{k}_{1}\left(\mathrm{hr}^{-1}\right)$ & 0.220 & - & 1.441 & 0.034 & - & 0.079 \\
\hline (nonlinear) & $\mathrm{q}_{\mathrm{e}, \text { calc }}(\mu \mathrm{g} / \mathrm{g})$ & 133.582 & - & 18.002 & 454.532 & - & 84.903 \\
\hline \multirow{2}{*}{$\begin{array}{l}\text { Pseudo- } 1^{\text {st }} \text {-Order } \\
\text { (linear) }\end{array}$} & $\mathrm{R}^{2}$ & 0.773 & - & 0.726 & 0.707 & - & 0.947 \\
\hline & $\mathrm{k}_{1}\left(\mathrm{hr}^{-1}\right)$ & 0.068 & - & 0.270 & 0.029 & - & 0.057 \\
\hline \multirow{3}{*}{ Pseudo-2 ${ }^{\text {nd }}-$ Order } & $\overline{\mathrm{R}^{2}}$ & 0.800 & - & 0.944 & 0.777 & - & 0.973 \\
\hline & $\mathrm{k}_{2}(\mathrm{~g} / \mu \mathrm{g} \mathrm{hr})$ & $2.611 \times 10^{-3}$ & - & 0.109 & $1.907 \times 10^{-4}$ & - & 0.001 \\
\hline & $\mathrm{q}_{\mathrm{e}, \text { calc }}(\mu \mathrm{g} / \mathrm{g})$ & 141.569 & - & 19.160 & 415.014 & - & 105.320 \\
\hline \multirow{3}{*}{ Pseudo-2 ${ }^{\text {nd }}-$ Order } & $\mathrm{R}^{2}$ & 0.826 & - & 0.947 & 0.758 & - & 0.973 \\
\hline & $\mathrm{k}_{2}(\mathrm{~g} / \mu \mathrm{g} \mathrm{hr})$ & 0.002 & - & 0.093 & $3.359 \mathrm{E}-04$ & - & 0.001 \\
\hline & $\mathrm{q}_{\mathrm{e}, \text { calc }}(\mu \mathrm{g} / \mathrm{g})$ & 158.730 & - & 19.608 & 370.370 & - & 113.636 \\
\hline
\end{tabular}


The Greensand kinetic data and fitted kinetic models are provided in Figure 14.

(a)

Arsenic

(b)

Cadmium

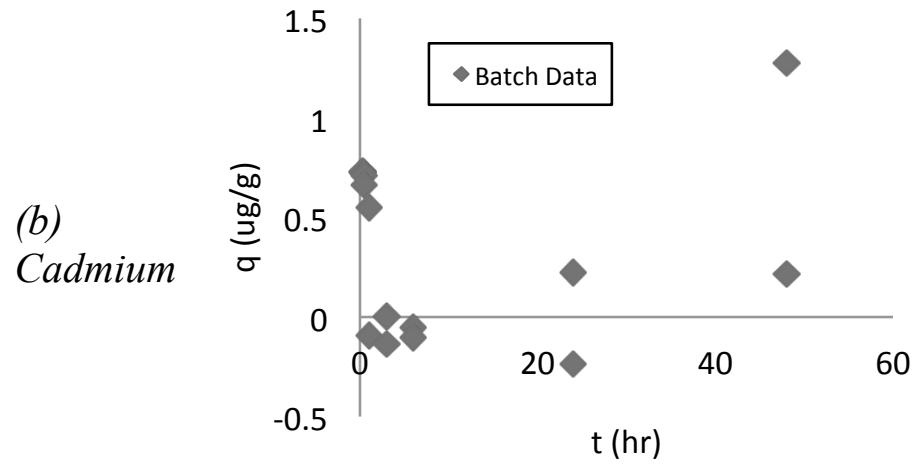

(c) Lead
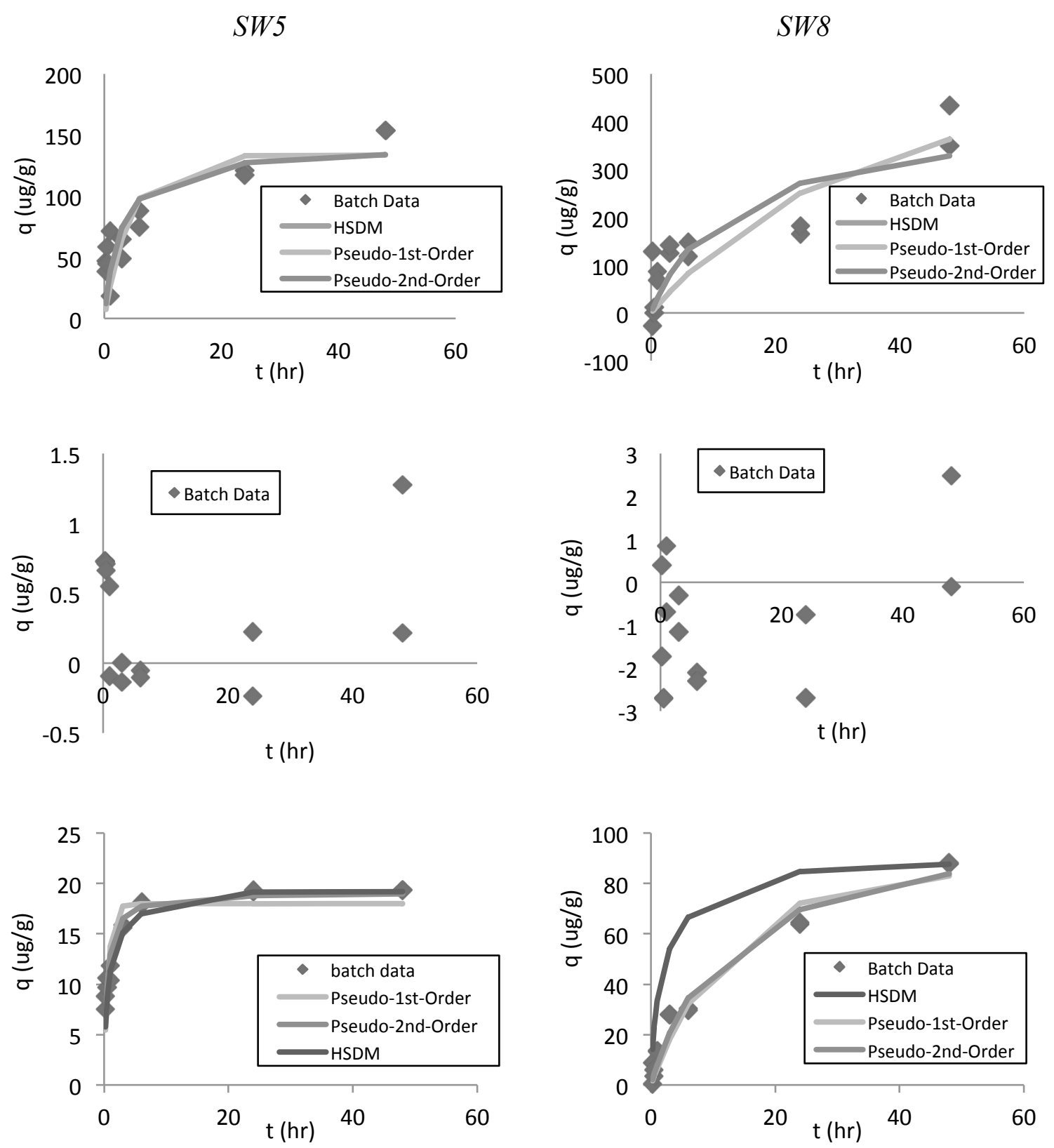

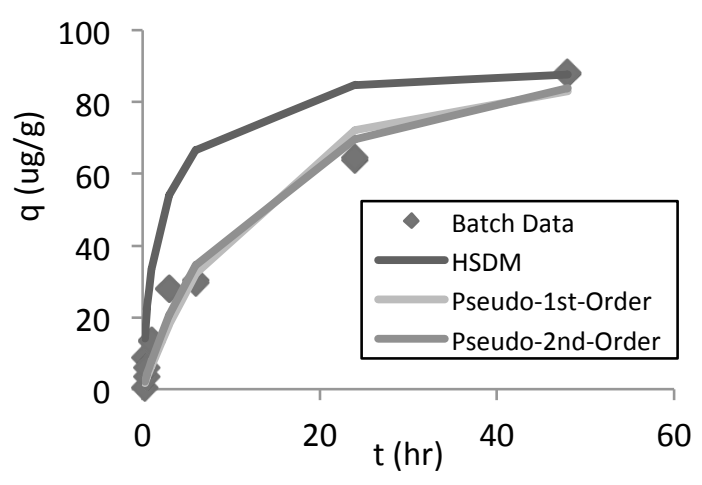

Figure 14 - Greensand kinetic data and kinetic models derived from nonlinear regression 


\subsection{PROBABLE METAL SPECIES}

Unfortunately the $\mathrm{pH}$ was not controlled during the experiment. However, $\mathrm{pH}$ values were obtained retroactively. The initial $\mathrm{pH}$ of the 8 stormwaters ranged from approximately $2-3$, with $\mathrm{pH}$ decreasing with increasing stormwater concentration. After adding $1 \mathrm{~g}$ of sand and 24 hours of shaking, the $\mathrm{pH}$ of the stormwaters increased. The $\mathrm{pH}$ of the stormwaters with Ladybug Sand increased to $7-11$. The increase in $\mathrm{pH}$ is likely due to the buffering capacity of the $\mathrm{CaCO}_{3}$ in the Ladybug Sand. Greensand on the other hand did not have much buffering capacity with the final $\mathrm{pH}$ of the stormwaters ranging between $2-4$. Given the stormwater was oxic, the probable metal species are presented in Table 22. These metal species were obtained from the Eh-pH diagrams presented in Appendix E.

Table 22 - Probable metal species in stormwater samples after 24 hours

\begin{tabular}{lcc}
\hline Metal & Ladybug Sand Samples & Greensand Samples \\
\hline \hline $\mathrm{As}$ & $\mathrm{HA}_{\mathrm{S}} \mathrm{O}_{4}^{[2-]}$ & $\mathrm{H}_{2} \mathrm{~A}_{\mathrm{S}} \mathrm{O}_{4}{ }^{[1-]} / \mathrm{HA}_{\mathrm{S}} \mathrm{O}_{2}(\mathrm{aq})$ \\
$\mathrm{Cd}$ & $\mathrm{Cd}^{[2+]} / \mathrm{CdOH}^{[1+]} / \mathrm{CdO}_{(\mathrm{aq})}$ & $\mathrm{Cd}^{[2+]}$ \\
$\mathrm{Pb}$ & $\mathrm{PbOH}^{[1+]} / \mathrm{PbO}_{(\mathrm{aq})}$ & $\mathrm{Pb}^{[2+]}$ \\
\hline
\end{tabular}

\subsection{FEASIBILITY OF ADSORBENT COLUMN: MAXIMUM SERVICE LIFE}

The feasibility of using Ladybug Sand and Greensand in an adsorption column to treat stormwater was investigated by calculating their potential maximum service life using the equilibrium column model (ECM). The ECM is the simplest "BTC" model, as it only considers the adsorption isotherm (Worch 2012). However, it can't be considered a complete BTC model, because it does not consider kinetics and therefore cannot be used to predict actual breakthrough 
behavior. To calculate the maximum service time the following equation was used (Worch 2012),

$$
t_{s t}=\frac{q_{o} m_{A}}{\dot{V} c_{o}} \quad E q .26
$$

where $\mathrm{t}_{\mathrm{st}}$ is the stoichiometric time (or maximum service time), $\mathrm{m}_{\mathrm{A}}$ is the mass of adsorbent, $\dot{V}$ is the volumetric flow rate, $\mathrm{c}_{\mathrm{o}}$ is the inlet concentration and $\mathrm{q}_{\mathrm{o}}$ is the equilibrium adsorbent loading related to the inlet concentration.

The mass of adsorbent was calculated using Eq. 27

$$
m_{A}=\rho_{A} V_{A}
$$

where $\rho_{A}$ is the adsorbent density and $V_{A}$ is the adsorbent volume. For a cylindrical column the adsorbent volume is described by

$$
V_{A}=\pi \cdot r_{c o l}^{2} \cdot h_{c o l}
$$

where $r_{\text {col }}$ is the column radius and $h_{\text {col }}$ is the column height. The volumetric flow rate was calculated using rational method formula Eq. 29,

$$
\dot{V}=W \cdot i \cdot A
$$

where $\mathrm{W}$ is the runoff coefficient (i.e. the percentage of precipitation that is converted into runoff), $\mathrm{i}$ is the rainfall intensity and $\mathrm{A}$ is the drainage area. 
The first step to calculate the maximum service life using the ECM is to determine the sands' adsorption capacity for each metal $\left(\mathrm{q}_{\mathrm{o}}\right)$ at the relevant inlet concentrations from the adsorption isotherms. For this exercise the inlet concentrations for arsenic, cadmium, and lead were taken as $100 \mu \mathrm{g} / \mathrm{L}, 2 \mu \mathrm{g} / \mathrm{L}$ and $40 \mu \mathrm{g} / \mathrm{L}$ respectively. These concentrations are representative of the event mean concentrations from the SWAMP study and typical stormwater concentrations.

For comparison, the equilibrium adsorbent loadings ( $\left.\mathrm{q}_{\mathrm{o}}\right)$ of Ladybug Sand, Greensand and selected adsorbents are provided in Table 23. All of the adsorbents listed were studied for stormwater treatment. The equilibrium adsorbent loadings $\left(\mathrm{q}_{\mathrm{o}}\right)$ were calculated from the best-fit isotherms presented in the journal articles referenced, and correspond to the previously mentioned equilibrium concentrations for arsenic, cadmium and lead. 


\section{Table 23 - Equilibrium adsorbent loadings for As, Cd and $\mathrm{Pb}$ at 100, 2 and $40 \mu \mathrm{g} / \mathrm{L}$}

\begin{tabular}{|c|c|c|c|c|c|}
\hline Metal & Adsorbent $^{\mathrm{a}}$ & $\mathrm{q}_{\mathrm{o}}{ }^{\mathrm{b}}(\mathrm{mg} / \mathrm{g})$ & Isotherm & $\mathrm{R}^{2}$ & Reference \\
\hline As & Ladybug Sand & 0.023 & Langmuir & 0.94 & \\
\hline As & Greensand & 0.066 & Freundlich & 0.85 & \\
\hline $\mathrm{Cd}$ & Ladybug Sand & 0.012 & Langmuir & 0.94 & \\
\hline $\mathrm{Pb}$ & Greensand & 0.044 & Langmuir & 0.90 & \\
\hline As & Alumina & $1.600 \times 10^{208}$ & Freundlich & 0.93 & Genç-Fuhrman et al., 2007 \\
\hline As & GFH & 155.191 & Freundlich & 0.87 & Genç-Fuhrman et al., 2007 \\
\hline As & Ironhydroxide & 0.102 & Freundlich & 0.93 & Wu \& Zhou, 2009 \\
\hline As & $\begin{array}{l}\text { 50/50 Ironhydroxide \& } \\
\text { Zeolite }\end{array}$ & 0.122 & Freundlich & 0.89 & Wu \& Zhou, 2009 \\
\hline $\mathrm{Cd}$ & Alumina & 14.217 & Freundlich & 0.91 & Genç-Fuhrman et al., 2007 \\
\hline $\mathrm{Cd}$ & NZ & 0.401 & Freundlich & 0.94 & Genç-Fuhrman et al., 2007 \\
\hline $\mathrm{Cd}$ & GFH & 10.133 & Freundlich & 0.89 & Genç-Fuhrman et al., 2007 \\
\hline $\mathrm{Cd}$ & IOCS & 0.122 & Freundlich & 0.89 & Genç-Fuhrman et al., 2007 \\
\hline $\mathrm{Cd}$ & Ironhydroxide & 0.008 & Freundlich & 0.93 & Wu \& Zhou, 2009 \\
\hline $\mathrm{Cd}$ & $\begin{array}{l}\text { 50/50 Ironhydroxide and } \\
\text { Zeolite }\end{array}$ & 0.007 & Freundlich & 0.94 & Wu \& Zhou, 2009 \\
\hline $\mathrm{Pb}$ & Olivine & 0.457 & Freundlich & 0.94 & Wium-Andersen et al., 2012 \\
\hline $\mathrm{Pb}$ & Limestone & 0.098 & Langmuir & 0.94 & Wium-Andersen et al., 2012 \\
\hline \multicolumn{6}{|c|}{$\begin{array}{l}{ }^{a} \text { The adsorption isotherms of selected adsorbents were studied at typical stormwater concentrations } \\
G F H=\text { granulated ferric hydroxide } \\
N Z=\text { natural zeolite } \\
\text { IOCS }=\text { iron oxide-coated sand } \\
{ }^{b} \text { The adsorbent loadings }\left(q_{e}\right) \text { correspond to the equilibrium concentrations }\left(c_{e}\right), A s=100 \mu \mathrm{g} / \mathrm{L}, \mathrm{Cd}=2 \mu \mathrm{g} / \mathrm{L} \text { and } \mathrm{Pb}=40 \\
\mu \mathrm{g} / \mathrm{L}\end{array}$} \\
\hline
\end{tabular}


As seen in Table 23 the adsorption capacities of Ladybug Sand and Greensand are lower than most of the other adsorbents listed. The only exceptions were ironhydroxide, 50/50 ironhydroxide and zeolite, and limestone.

If a filter were to be designed to remove the selected metals, the metal with the lowest removal efficiency would likely determine the maximum service life. The efficiency of an adsorbent can be characterized using the distribution coefficient $\mathrm{K}_{\mathrm{d}}(\mathrm{Wu}$ and Zhou 2009).

$$
K_{d}=\frac{q_{o}}{c_{o}}
$$

The distribution coefficient can be thought of as the volume of water treated per mass of adsorbent. A lower $\mathrm{K}_{\mathrm{d}}$ value indicates a less efficient adsorbent. As seen in Table 24 the metal with the lowest $\mathrm{K}_{\mathrm{d}}$ for both Ladybug Sand and Greensand was arsenic. Therefore, the maximum service life was calculated based on the equilibrium adsorbent loading for arsenic.

Table 24 - Ladybug Sand and Greensand adsorption efficiencies

\begin{tabular}{lcccc}
\hline Adsorbent & Metal & $\mathrm{c}_{\mathrm{o}}(\mu \mathrm{g} / \mathrm{L})$ & $\mathrm{q}_{\mathrm{o}}(\mu \mathrm{g} / \mathrm{g})$ & $\mathrm{K}_{\mathrm{d}}(\mathrm{L} / \mathrm{g})$ \\
\hline \hline Ladybug Sand & $\mathrm{As}$ & 100 & 23 & 0.23 \\
Ladybug Sand & $\mathrm{Cd}$ & 2 & 12 & 6 \\
Greensand & $\mathrm{As}$ & 100 & 66 & 0.66 \\
Greensand & $\mathrm{Pb}$ & 40 & 44 & 1.1 \\
\hline
\end{tabular}

To calculate the estimated maximum service life the following assumptions were made: 
- An average annual rainfall intensity of $800 \mathrm{~mm}$ - the average annual rainfall in Toronto is $792 \mathrm{~mm}$ (Statistics Canada 2007)

- The land has been developed with single family residential units, with a runoff coefficient of sixty-five percent (i.e. $W=0.65)$ (City of Toronto 2009),

- The filter is a cylinder with a depth of 2 meters

The maximum service life as a function of drainage area and filter diameter is provided in Table 25 and Table 26. The longest calculated life expectancy, which assumes a drainage area of 10 acres and a filter diameter of $5 \mathrm{~m}$, for a Ladybug Sand filter was 6.7 months and for a Greensand filter was 20.7 months.

Table 25 - Ladybug Sand filter life expectancy in months as a function of drainage area and column diameter

\begin{tabular}{cccccc}
\hline & \multicolumn{5}{c}{ Filter Diameter $(\mathrm{m})$} \\
\cline { 2 - 6 } Drainage Area (Acres) & 1 & 2 & 3 & 4 & 5 \\
\hline \hline 10 & 0.3 & 1.1 & 2.4 & 4.3 & 6.7 \\
25 & 0.1 & 0.4 & 1.0 & 1.7 & 2.7 \\
50 & 0.1 & 0.2 & 0.5 & 0.9 & 1.3 \\
100 & 0.0 & 0.1 & 0.2 & 0.4 & 0.7 \\
\hline
\end{tabular}


Table 26-Greensand filter life expectancy in months as a function of drainage area and column diameter

\begin{tabular}{cccccc}
\hline & \multicolumn{5}{c}{ Filter Diameter $(\mathrm{m})$} \\
\cline { 2 - 6 } Drainage Area (Acres) & 1 & 2 & 3 & 4 & 5 \\
\hline \hline 10 & 0.8 & 3.3 & 7.5 & 13.3 & 20.7 \\
25 & 0.3 & 1.3 & 3.0 & 5.3 & 8.3 \\
50 & 0.2 & 0.7 & 1.5 & 2.7 & 4.1 \\
100 & 0.1 & 0.3 & 0.7 & 1.3 & 2.1 \\
\hline
\end{tabular}

The lifespan of the adsorption filter is dependent on the influent solute concentration. In the tables presented above, the inlet concentrations assumed were 100, 2 and $40 \mu \mathrm{g} / \mathrm{L}$ for arsenic, cadmium and lead respectively. In reality, the inlet concentrations received by the filter could be an order of magnitude smaller. According to the International Storwmater BMP database, the average concentrations of arsenic, cadmium in the effluent of stormwater BMP are 1.5, 0.3 and $5.3 \mu \mathrm{g} / \mathrm{L}$ respectively. The sensitivity of the filters' life expectancies to changes in influent solute concentration are presented in Table 27 and Table 28. The life expectancies were calculated assuming a drainage area of 10 acres, and a filter diameter and depth of 5 and $2 \mathrm{~m}$ respectively. The difference between the ladybug sand's and greensand's sensitivity to changes in influent arsenic concentration is due to the shape of the sands' adsorption isotherms within the concentration range considered. The ladybug sand's adsorption isotherm within this range is linear, and therefore the sand's life expectancy was not very sensitive to changes in influent arsenic concentration. On the other hand, the Greensand's life expectancy was very sensitive to changes in influent arsenic concentration due to nonlinearity of the adsorption isotherm within this range. 
Table 27 - Life expectancy of a Ladybug Sand filter at different influent arsenic concentrations

\begin{tabular}{ccc}
\hline$C_{\circ}(\mu \mathrm{g} / \mathrm{L})$ & $\mathrm{q}_{\mathrm{o}}(\mu \mathrm{g} / \mathrm{g})$ & $\begin{array}{c}\text { Life Expectancy } \\
\text { (months) }\end{array}$ \\
\hline \hline 0.1 & 10.16 & 7.4 \\
1 & 19.00 & 7.4 \\
5 & 29.44 & 7.4 \\
10 & 35.55 & 7.3 \\
50 & 55.07 & 7.1 \\
100 & 66.50 & 6.8 \\
\hline
\end{tabular}

Table 28 - Life expectancy of a Greensand filter at different influent arsenic concentrations

\begin{tabular}{ccc}
\hline$C_{o}(\mu \mathrm{g} / \mathrm{L})$ & $\mathrm{q}_{\mathrm{o}}(\mu \mathrm{g} / \mathrm{g})$ & $\begin{array}{c}\text { Life Expectancy } \\
\text { (months) }\end{array}$ \\
\hline \hline 0.1 & 10.16 & 3192.8 \\
1 & 19.00 & 597.3 \\
5 & 29.44 & 185.1 \\
10 & 35.55 & 111.7 \\
50 & 55.07 & 34.6 \\
100 & 66.50 & 20.9 \\
\hline
\end{tabular}

The results of the feasibility study suggests that Ladybug Sand is likely not suitable for use in stormwater treatment due to the relatively low filter life expectancy, however, greensand may be a viable adsorbent.

\subsection{ADSORBENT DISPOSAL}

If using Greensand in an adsorption filter, an important consideration is what to do with the sand after it has reached its adsorption capacity. "In Canada, environmental exceedance standards are set by [the] Soil, Groundwater and Sediment Standards for Use under Part XV.1 of the Environmental Protection Act (EPA) (2011)" (Koumoulas 2015). The generic environmental exceedance standards for arsenic, cadmium and lead in sediment are 6, 0.6 and $31 \mu \mathrm{g} / \mathrm{g}$ respectively (April 2011). If the Greensand's metals concentrations fall below the environmental 
exceedance standards the sand is suitable for direct reuse. Given Greensand's equilibrium adsorbent loadings for arsenic (see Table 28), it is likely the criteria for arsenic will be exceeded. In this case, the sand will need to be transferred to a landfill. The disposal of contaminated sediment falls under O. Reg. 347 of the EPA (Koumoulas 2015). To determine if the sand is suitable for disposal in a non-hazardous landfill a Toxicity Characteristic Leaching Procedure (TCLP) test must be conducted (Koumoulas 2015). The TCLP is a test to determines the sand's potential to leach the metals from a landfill (Koumoulas 2015). If the TCLP results exceed Ontario's leachate quality criteria under Schedule 4 of O. Reg. 347 the sand will need to be disposed of at a hazardous landfill (Koumoulas 2015).

\section{CONCLUSION}

Ladybug Sand and Greensand were not effective at adsorbing copper, iron and zinc but were effective at adsorbing arsenic and lead. Ladybug Sand was also effective at removing cadmium. The Langmuir, Freundlich and Henry isotherms fit the equilibrium data for both adsorbents well. Furthermore, the pseudo-first-order and pseudo-second order reaction kinetic models fit the kinetic data well and the $\mathrm{k}_{1}$ and $\mathrm{k}_{2}$ reaction coefficients were determined. The HSDM data not fit the kinetic data as well as the reaction models and therefore the surface diffusion coefficient $\left(\mathrm{D}_{\mathrm{s}}\right)$ derived might not accurately predict breakthrough behavior.

Ladybug Sand is not likely suitable for use in stormwater treatment due its low adsorption capacities. Greensand may be a viable alternative if used in conjunction with other adsorbents. If the adsorbent were to be used in stormwater treatment or other applications, the adsorption isotherms and kinetic parameters determined from this study could be use to design a pilot scale 
adsorption column to remove arsenic, cadmium or lead at low concentrations. However, the accuracy of the design would benefit from further work to refine the surface diffusion coefficient $\left(D_{s}\right)$ in the HSDM. This could be accomplished by more accurately solving the HSDM using software such as MatLAB.

\subsection{FUTURE RESEARCH}

Although the adsorbents are not suitable for use in stormwater treatment, future research could be performed to better understand the adsorption mechanisms and to refine the isotherm and kinetic parameters if desired.

\section{Adsorption Mechanism}

Additional information, such as surface morphology, surface chemistry and adsorptive thermodynamic data, is required to accurately determine the dominant adsorption mechanisms (Tran et al. 2017). To determine the surface morphology, analytical techniques such as a scanning electron microscope (SEM), nitrogen adsorption isotherms or X-ray diffraction (XRD) can be used (Prahas et al. 2008; Tran et al. 2017). Surface chemistry can be characterized using techniques such as Boehm titration and Fourier Transformation Infrared Spectroscopy (FTIR) (Prahas et al. 2008; Tran et al. 2017).

\section{Adsorption Parameters}

Additional studies can be performed to test the effects of $\mathrm{pH}$, temperature, grain size and adsorbent dose on the adsorption isotherms and kinetics. If the isotherm experiments were repeated, it would be worthwhile to extend the duration of the experiment to ensure equilibrium has been reached. To determine the effects of inter-solute interactions, the isotherms and kinetics 
can also be determined in isolation (i.e. from single solute experiment) and then compared to the multi-solute isotherms and the apparent kinetic rates from this study. To refine the surface diffusion coefficient $\left(D_{s}\right)$ additional kinetic experiments can be conducted at different shaker speeds to ensure the effects of film diffusion have been negated. Furthermore, software such as MATLAB can be used to determine a more exact numerical solution of the HSDM. 


\section{APPENDIX A: SWAMP DATA}

Table 29 - SWAMP Average Event Mean Concentrations and Performance Data (SWAMP, 2015)

\begin{tabular}{|c|c|c|c|c|c|c|c|c|c|c|c|c|c|c|c|c|c|c|c|c|c|c|c|c|c|}
\hline \multirow{4}{*}{ Parameter } & \multirow[b]{4}{*}{ units } & \multicolumn{23}{|c|}{ Outlet Average Event Mean Concentrations (AEMC) and Performance (96) } & \multirow{4}{*}{$\begin{array}{c}\text { Receiving } \\
\text { Water } \\
\text { Guidelines }\end{array}$} \\
\hline & & \multicolumn{4}{|c|}{ Rouge River Highway pond } & \multicolumn{4}{|c|}{ Harding Park Retrofit pond } & \multicolumn{4}{|c|}{ Heritage Estates pond } & \multicolumn{4}{|c|}{ Markham pond/wetland } & \multicolumn{4}{|c|}{ Aurora Wetland } & \multirow{2}{*}{\multicolumn{3}{|c|}{$\begin{array}{l}\text { Dunkers FBS } \\
\text { summer/fall }\end{array}$}} & \\
\hline & & \multirow{2}{*}{\multicolumn{2}{|c|}{ summer/fall }} & \multicolumn{2}{|c|}{ winter/spring } & \multirow{2}{*}{\multicolumn{2}{|c|}{ summer/fall }} & \multicolumn{2}{|c|}{ winter/spring } & \multicolumn{2}{|c|}{ summer/fall } & \multicolumn{2}{|c|}{ winter/spring } & \multicolumn{2}{|c|}{ summer/fall } & \multicolumn{2}{|c|}{ winter/spring } & \multicolumn{2}{|c|}{ summer/fall } & winter/s & ispring & & & & \\
\hline & & & & Effl. & 96 & & & Effl & 96 & Effil. & $9 \%$ & Effl. & 96 & Effl. & 96 & Effl. & 96 & Effl. & $9 \%$ & Effl. & 96 & cell 5 & cell 3 & $9 \%$ & \\
\hline General Chem. & & $\mathrm{n}=21$ & $\mathrm{n}=21$ & $\mathrm{n}=11 \mathrm{n}=$ & $\mathrm{n}=8-11$ & $n=12$ & $\mathrm{n}=10$ & $\mathrm{n}=4$ & $\mathrm{n}=4$ & $\mathrm{n}=19$ & $\mathrm{n}=9$ & $\mathrm{n}=14$ & $\mathrm{n}=11$ & $n=12-13$ & $\mathrm{n}=9$ & $\mathrm{n}=6$ & $\mathrm{n}=5$ & $n=18$ & $\mathrm{n}=18$ & $\mathrm{n}=11$ & $\mathrm{n}=11$ & $\mathrm{n}=38$ & $\mathrm{n}=52$ & $\mathrm{n}=11^{2}$ & \\
\hline Suspended Solids & $\mathrm{mg} / 1$ & 37.2 & 90 & 46.3 & 75 & 46.0 & 80 & 39.2 & 78 & 15.7 & 85 & 14.9 & 86 & 23.0 & 95 & 7.1 & 98 & 20.9 & 90 & 29.3 & 79 & 13.8 & 11.2 & 81 & $25-80$ \\
\hline Oil and & & 1.5 & 87 & 1.7 & 51 & 0.8 & 48 & 1.1 & 6 & - & & - & & 1.0 & 80 & 0.9 & 77 & 1.0 & 71 & 1.6 & 52 & 0.8 & 0.8 & 70 & \\
\hline Chlorid & & 579.5 & -86 & \begin{tabular}{|l|}
1613.0 \\
\end{tabular} & -17 & 71.0 & -548 & 274.0 & -3 & 81.4 & -487 & 251.4 & -73 & 107.9 & -60 & 325.5 & -76 & 15.7 & 45 & \begin{tabular}{|l|}
254.1 \\
\end{tabular} & -5 & 47.6 & 46.8 & 10 & 250.0 \\
\hline Carbon; DO & $\mathrm{mg} 1$ & 3.1 & 73 & 4.5 & 1 & 4.6 & -70 & 2.6 & -24 & 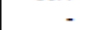 & & 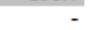 & & 4.3 & 46 & 3.0 & 54 & 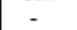 & - & - & - & 3.1 & 3.3 & 49 & \\
\hline Carbon; DI & $\mathrm{mg} / \mathrm{I}$ & 47.7 & -35 & 49.1 & -64 & 30.7 & -155 & 32.3 & -95 & - & & - & & 22.9 & 26 & 24.4 & 21 & - & - & - & - & 22.5 & 23.0 & -37 & \\
\hline Metals & & $\mathrm{n}=21$ & $\mathrm{n}=21$ & $\mathrm{n}=11 \mathrm{a}=$ & $=4-11$ & $n=9-12$ & $n=7-10$ & $n=3-4$ & $n=1-4$ & $n=19$ & $n=8-9$ & $\mathrm{n}=14$ & $n=5-11$ & $n=13$ & $n=8-9$ & $n=5-6$ & $n=5$ & $\mathrm{n}=18$ & $\mathrm{n}=18$ & $n=11$ & $n=11$ & $n=38$ & $n=52$ & $n=11$ & \\
\hline Aluminur & $\mu \mathrm{g} / 1$ & 263.0 & 73 & 212.0 & 65 & 290.0 & 74 & 226.0 & 48 & & & & & 187.1 & 86 & 115.4 & 80 & 291.3 & 53 & 419.1 & 20 & 95.0 & 80.9 & 78 & \\
\hline Barium & $\mu \mathrm{g} / 1$ & 120.6 & 10 & 116.1 & -21 & 36.5 & -11 & 39.0 & -14 & - & & & & 35.0 & 40 & 37.2 & 35 & 16.0 & 46 & 22.0 & 6 & 28.2 & 27.9 & 20 & \\
\hline & $\mu_{8}$ & 0.5 & 60 & 1.7 & 64 & 0.5 & 11 & 0.1 & 83 & 0.3 & 21 & 0.9 & 49 & 0.4 & T & 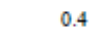 & $49]$ & 0.3 & e & 0. & . & - & & -25 & 0.5 \\
\hline Coba & & 0.8 & 68 & 2.7 & 57 & 0.8 & 82 & 0.4 & 60 & - & & & & 0.9 & 53 & 0.8 & 36 & 0.7 & 69 & Call & 39 & 0.6 & 0.6 & 43 & 0.9 \\
\hline Chromium & $\mu$ & 2.0 & 79 & 8.6 & -108 & 2.4 & 53 & 2.2 & -13 & 1.0 & 59 & 5.0 & 59 & 0.6 & 84 & 0.7 & 74 & 1.2 & 48 & 2.0 & 27 & 0.7 & 0.6 & 81 & 8.9 \\
\hline הernon & $\mu$ & 10.2 & 85 & 16.2 & 41 & 4.5 & 48 & 10.2 & 22 & 8.0 & 76 & 9.0 & 65 & 8.2 & 85 & 3.7 & 76 ] & 5.0 & 68 & 5.8 & 42 & 3.4 & 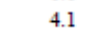 & 85 & 5.0 \\
\hline & & 470.7 & 72 & 401. & 59 & 386.0 & 66 & 431.0 & 48 & 320.0 & 74 & 350.0 & 79 & 199.5 & 81 & 107 & 80 & 363.4 & 49 & 515.5 & 29 & 233.6 & & 75 & 300.0 \\
\hline Lead & $\mu \underline{\xi}$ & 6.0 & 88 & 6.0 & 73 & 2.5 & 83 & 6.0 & 10 & 4.0 & 18 & 5.0 & 27 & $<\mathrm{dl}$ & $\mathrm{n} / \mathrm{a}$ & cdl & $\mathrm{n} / \mathrm{a}$ & <dl & $\mathrm{n} / \mathrm{a}$ & <dl & $\mathrm{n} / \mathrm{a}$ & 5.2 & 4.7 & $73 \mid$ & 5.0 \\
\hline Man & & 119.9 & 69 & 110.3 & 45 & 115.8 & 9 & 159.4 & -23 & & & 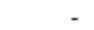 & & 42.8 & 86 & 14.1 & 88 & 51.6 & 66 & 57.7 & 41 & 33.8 & & 63 & \\
\hline & & 24 & 75 & 1.5 & 61 & 3.2 & 62 & 1.8 & 38 & 20.0 & $16]$ & 7.0 & 44 & 1.3 & 62 & 1 & 79 & 1.0 & 56 & 1.0 & $\begin{array}{l}7 \\
32\end{array}$ & 0.9 & (2) & 77 & 25.0 \\
\hline & $\mu$ & 488.8 & 13 & 507.2 & 2 & 270.5 & -63 & 264.0 & 43 & & - & - & & 275.2 & & 332.3 & -12 & 129.7 & 27 & 218.1 & 1 & 160.7 & 161.7 & -41 & \\
\hline Titani & & 4.4 & 49 & 12.3 & 59 & - & - & 2.7 & -19 & - & - & - & - & 3.8 & 34 & 2.1 & 68 & -4.0 & 2 & 6.1 & 44 & 4.0 & 2.8 & & \\
\hline Vanad & $\mu$ & 1.5 & 74 & 1.5 & 69 & 1.1 & 66 & 1.6 & -3 & - & - & 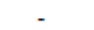 & - & 1.1 & 75 & 1.1 & 72 & 1.7 & 2. & 1.3 & 8 & 0.8 & 7 & 79 & 6.0 \\
\hline Zinc & $\mu \mathrm{g} / 1$ & 67.2 & 84 & 108.9 & 25 & 16.4 & 70 & 40.0 & 38 & 10.0 & 71 & 20.0 & 72 & 14.1 & 87 & 7.0 & 88 & 25.3 & 59 & 46.1 & -40 & 4.9 & 6.7 & 89 & 20.0 \\
\hline Bacter & & $\mathrm{n}=13$ & - & $\mathrm{n}=1$ & 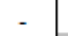 & $n=4$ & $n=5$ & $n=3$ & $\mathrm{n}=3$ & $n=15$ & $n=7$ & $n=12$ & $n=8$ & $n=7$ & $\mathrm{n}=4$ & & $\mathrm{n}=2$ & $\mathrm{n}=18$ & $\mathrm{n}=18$ & $\mathrm{n}=11$ & $\mathrm{n}=11$ & $n=7$ & $\mathrm{n}=11$ & $n=4$ & \\
\hline Escherichia Coli & c. $/ 100 \mathrm{ml}$ & 356.5 & & 10.0 & & 1429.0 & 53 & 185.0 & -44 & 1362.0 & 79 & 395.0 & 75 & 236.9 & 79 & 10.1 & 99 & 477.0 & 90 & 444.4 & 31 & 73.5 & 279 & 75 & 100.0 \\
\hline Nutrients & & $\mathrm{n}=21$ & $\mathrm{n}=21$ & $n=9-11 n=$ & $=8-11$ & $n=12$ & $\mathrm{n}=10$ & $n=4$ & $\mathrm{n}=4$ & $n=19$ & $n=7-9$ & $n=9-14 \quad n$ & $n=10-11$ & $n=12-13$ & $\mathrm{n}=8-9$ & $n=6$ & $n=4-5$ & $\mathrm{n}=18$ & $\mathrm{n}=18$ & $\mathrm{n}=11$ & $\mathrm{n}=11$ & $n=37$ & $n=52$ & $n=11$ & \\
\hline Ammo & $\mathrm{m}$ & 0.1 & 79 & 0.5 & 14 & 0.1 & 54 & 0.4 & 18 & 0.1 & -123 & 0.4 & -68 & 0.1 & 22 & 0.1 & 37 & 0.06 & 75 & 0.07 & 46 & 0.10 & 0.09 & -24 & \\
\hline & & 0.00 & - & 0. & - & 0.00 & & 0.00 & & 0.00 & & 0.00 & & & & 0.00 & & 0.00 & & 0.00 & & 0. & 0.00 & & 0.02 \\
\hline & & 0. & 44 & 0. & -18 & 0. & 28 & 0 & -12 & 0. & -15 & a & 45 & & 64 & & 46 & 0.0 & 28 & . & 0 & . & & 56 & 0.06 \\
\hline Netr: & & 0. & 66 & 1. & -18 & 0.70 & 42 & 1. & $\begin{array}{r}52 \\
52\end{array}$ & 0.65 & $\begin{array}{l}62 \\
\end{array}$ & 1.17 & -1 & 0.50 & 69 & 0.92 & 51 & 0.16 & 61 & 0. & 19 & 0.3 & 0.4 & 64 & 1.0 \\
\hline & $\mathrm{m}$ & 0. & 78 & 0.01 & 74 & 0.01 & 87 & 0. & 66 & 0.03 & 71 & 0.07 & 30 & 0 & 89 & 0. & 82 & 0.04 & 59 & 0.07 & 22 & 0.0 & 0. & 75 & \\
\hline $10 \mathrm{E}$ & $\mathrm{mg} / 1$ & 0.06 & 85 & 0.09 & 67 & 0.11 & 42 & 0.10 & 56 & 0.07 & 80 & 0.10 & 65 & 0.08 & 87 & 0.04 & 80 & 0.13 & 72 & 0.17 & 33 & 0.07 & 0.06 & 77 & 0.03 \\
\hline Nitrogen; T & $\mathrm{mg} 1$ & 0.8 & 70 & 1.1 & 31 & 1.0 & -24 & 1.1 & 31 & 0.9 & -19 & 1.3 & 34 & 0.8 & 55 & 0.7 & 45 & 0.9 & 59 & 0.9 & 37 & 0.7 & 0.68 & 59 & \\
\hline
\end{tabular}

Notes: 1. The terms 'winter/spring' and 'summer/fall' refer to the months from December to April and from May to November, respectively. Water quality samples in the winter/spring were collected as grabs at the Rouge, Harding Park, Heritage Estates, and Markham sites. 2. n=30 for TSS at the Dunkers FBS. 3. n=5 for lead during the winter/spring period 4. Guideline Sources are Provincial Water Quality Objectives (OMOE, 1999) except as follows: TSS (EIFAC, 1965; USEPA, 1973); Chloride (Enviroument Canada and Health Canada, 2001); Nitrate (CAST, 1992); The PWQO for aluminium is $75 \mathrm{ug} / \mathrm{L}$ but applies only to clay free samples. 
Table 30 - SWAMP Average Event Mean Concentrations and Performance Data (Continued) (SWAMP, 2015)

\begin{tabular}{|c|c|c|c|c|c|c|c|c|c|c|c|c|c|c|}
\hline \multirow{4}{*}{ Parameter } & \multirow[b]{4}{*}{ units } & \multicolumn{12}{|c|}{ Effluent Average Event Mean Concentrations (AEMCs) ${ }^{1}$ and Load Based Removal Efficiencies ( $(\%)$} & \multirow{4}{*}{$\begin{array}{l}\text { Receiving } \\
\text { Water } \\
\text { Guidelines }^{2}\end{array}$} \\
\hline & & \multicolumn{4}{|c|}{ Beaches Detention Tank } & \multicolumn{4}{|c|}{ 3-Chamber OGS } & \multicolumn{4}{|c|}{ Stormceptor\& OGS } & \\
\hline & & \multicolumn{2}{|c|}{ summer/fall } & \multicolumn{2}{|c|}{ winter/spring } & \multicolumn{2}{|c|}{ summer/fall } & \multicolumn{2}{|c|}{ winter/spring } & \multicolumn{2}{|c|}{ summer/fall } & \multicolumn{2}{|c|}{ winter/spring } & \\
\hline & & Effl. & $\%$ & Effl. & $\%$ & Effl. & $\%$ & Effl. & $\%$ & Effl. & $\%$ & Effl. & $\%$ & \\
\hline General Chemistry & & $\mathrm{n}=9-10$ & $\mathrm{n}=6-7$ & $n=7-9$ & $n=4-5$ & $n=40$ & $\mathrm{n}=14$ & $\mathrm{n}=14$ & $\mathrm{n}=\mathbf{5}$ & $\mathrm{n}=23-24$ & $\mathrm{n}=7-10$ & $\mathrm{n}=13$ & $\mathrm{n}=6$ & \\
\hline Suspended Solids & $\mathrm{mg} / \mathrm{l}$ & 55.8 & 59 & 56.0 & 24 & 30.4 & 58 & 59.0 & 53 & 42.1 & 65 & 72.5 & 47 & $25-80$ \\
\hline Oil and Grease & $\mathrm{mg} / \mathrm{l}$ & 3.4 & 29 & 5.0 & 24 & 5.3 & 60 & 11.8 & 39 & 5.9 & 51 & 10.3 & 34 & \\
\hline Chloride & $\mathrm{mg} / \mathrm{l}$ & 138.5 & -27 & 1052.5 & 8 & - & - & - & & - & - & - & & 250.0 \\
\hline Carbon; DO & $\mathrm{mg} / 1$ & 4.9 & 12 & 5.8 & 11 & - & - & - & & - & & - & & - \\
\hline Carbon; DI & $\mathrm{mg} / \mathrm{l}$ & 25.9 & -15 & 36.8 & -43 & - & & - & & - & & - & & \\
\hline Metals & & $\mathrm{n}=10$ & $n=5-7$ & $\mathrm{n}=9-11$ & $n=3-5$ & $\mathrm{n}=40$ & $n=12$ & $\mathrm{n}=14$ & $\mathrm{n}=5$ & $n=23$ & $n=8$ & $\mathrm{n}=13$ & $\mathrm{n}=6$ & \\
\hline Aluminum & $\mu g / 1$ & 342.8 & 52 & 450.0 & 5 & 186.4 & 60 & 396.4 & 47 & 238.5 & 55 & 448.9 & 41 & \\
\hline Banium & $\mu g / 1$ & 32.6 & 22 & 39.0 & 8 & 24.5 & 41 & 30.3 & 44 & 34.7 & 4 & 42.5 & 1 & - \\
\hline Cadmium & $\mu g / 1$ & 0.6 & 56 & 0.5 & 68 & 0.3 & 58 & 0.6 & 42 & 0.1 & 46 & 1.1 & 41 & 0.5 \\
\hline Cobalt & $\mu g / 1$ & 0.9 & 59 & $\mathrm{n} / \mathrm{a}$ & 76 & 0.5 & 42 & 0.9 & 10 & 0.6 & 43 & 0.4 & 64 & 0.9 \\
\hline Chromium & $\mu g / 1$ & 2.9 & 92 & 5.0 & 96 & 3.4 & 53 & 9.1 & 40 & 4.6 & 52 & 8.7 & 45 & 8.9 \\
\hline Copper & $\mu g / 1$ & 19.0 & 45 & 26.0 & 43 & 15.4 & 63 & 31.1 & 47 & 17.7 & 51 & 36.5 & 37 & 5.0 \\
\hline Iron & $\mu g / 1$ & 849.2 & 47 & 900.0 & 8 & 345.7 & 40 & 596.7 & 41 & 404.0 & 52 & 759.9 & 37 & 300.0 \\
\hline Lead & $\mu g / 1$ & 25.2 & 47 & 26.0 & 62 & 8.2 & 57 & 28.6 & 48 & 9.7 & 59 & 41.9 & 28 & 5.0 \\
\hline Manganese & $\mu g / 1$ & 101.5 & 36 & 105.0 & 6 & 59.9 & 35 & 103.7 & 53 & 109.8 & 51 & 134.6 & 36 & - \\
\hline Nickel & $\mu g / 1$ & 4.1 & 39 & 4.0 & 53 & 2.4 & 60 & 3.8 & 52 & 2.9 & 45 & 4.9 & 45 & 25.0 \\
\hline Strontium & $\mu g / 1$ & 121.7 & -4 & 280.0 & 15 & 133.7 & 10 & 216.1 & 41 & 177.0 & -75 & 245.6 & -76 & - \\
\hline Titanium & $\mu g / 1$ & 8.6 & 15 & 11.0 & 24 & 3.4 & 58 & 7.3 & -29 & 1.3 & 33 & 5.4 & 32 & - \\
\hline Vanadium & $\mu g / 1$ & 2.3 & & 4.0 & -1 & 3.2 & 57 & 3.7 & 37 & 3.0 & 46 & 3.7 & 24 & 6.0 \\
\hline Zine & $\mu g /$ & 87.7 & 52 & 135.5 & 29 & 62.2 & 62 & 116.8 & 62 & 110.4 & 47 & 169.4 & 36 & 20.0 \\
\hline Bacteria & & $n=6$ & $n=3$ & - & - & - & & - & & - & & - & & \\
\hline Escherichia Coli & c. $/ 100 \mathrm{ml}$ & 44179.0 & -22 & - & & - & 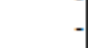 & - & & - & & - & & 100.0 \\
\hline Nutrients & & $n=10$ & $n=6-7$ & $n=6-9$ & $n=3-5$ & - & & - & & - & - & - & & \\
\hline Ammonia & $\mathrm{mg} / 1$ & 0.35 & -25 & 0.29 & 33 & - & & - & & . & -1 & - & & \\
\hline Un-ionized amm. & $\mathrm{mg} / \mathrm{l}$ & 0.01 & - & 0.00 & & - & d & - & & - & - & - & & 0.02 \\
\hline Nitrite & $\mathrm{mg} / \mathrm{l}$ & 0.10 & -37 & 0.21 & 35 & - & - & - & & - & - & - & & 0.06 \\
\hline Nitrates & $\mathrm{mg} / \mathrm{l}$ & 2.07 & -33 & 2.85 & -41 & - & & - & & - & - & - & & 1.0 \\
\hline Phosphate & $\mathrm{mg} / \mathrm{l}$ & 0.17 & -39 & 0.15 & 24 & - & - & - & & - & - & - & & . \\
\hline Phosphorus; total & $\mathrm{mg} / 1$ & 0.31 & 29 & 0.34 & 22 & - & - & - & & - & - & - & & 0.03 \\
\hline Nitrogen; TK & $\mathrm{mg} / 1$ & 1.4 & 22 & 1.2 & 78 & - & & - & & - & & - & & \\
\hline
\end{tabular}

Notes: 1. The terms 'winter/spring' and 'summer/fall' refer to the months from December to April and from May to November, respectively. 2. Grideline Sources are Provincial Water

Notes: 1. The terns 'winter/spring' and 'summer/fall' refer to the months from December to Aprl and from May to November, respectively. 2. Guideline Sources are Provincial Water
Quality Objectives (OMOE, 1999) except as follows: TSS (EIFAC, 1965; USEPA, 1973); Chloride (Enviroument Canada and Health Canada, 2001); Nitrate (CAST, 1992); The PWQO for aluminimu is 75 ugL but applies only to clay free sanples. 
APPENDIX B: ISOTHERM LINEAR REGRESSION

\section{$\underline{\text { ARSENIC }}$}

LADYBUG SAND

Henry Isotherm

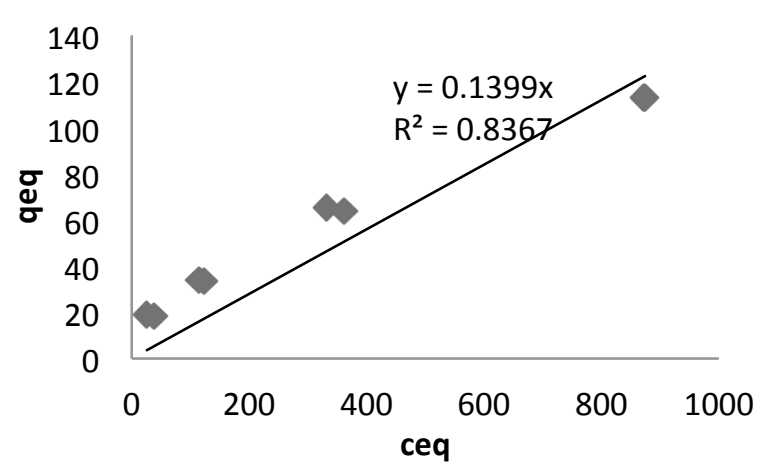

LE 1

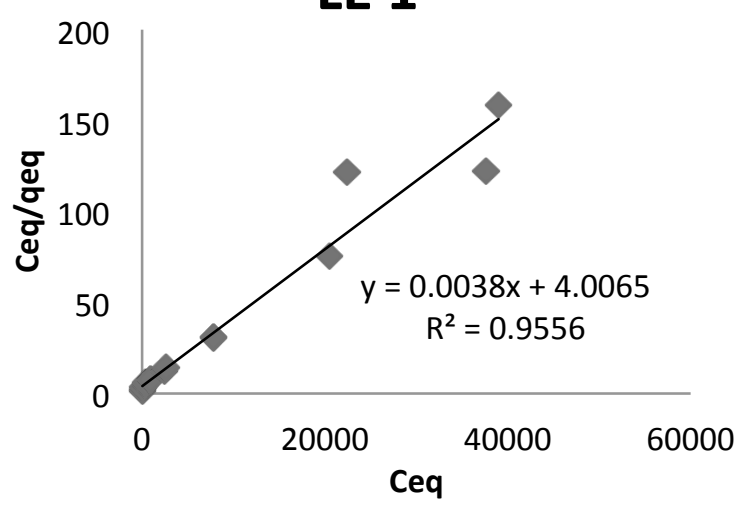

GREENSAND

Henry Isotherm

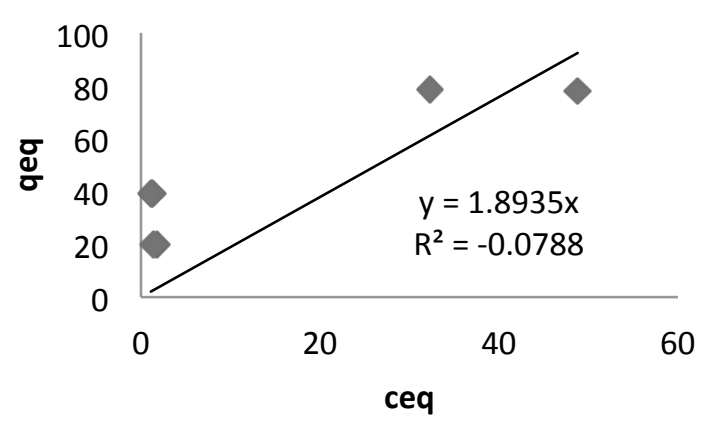

LE 1

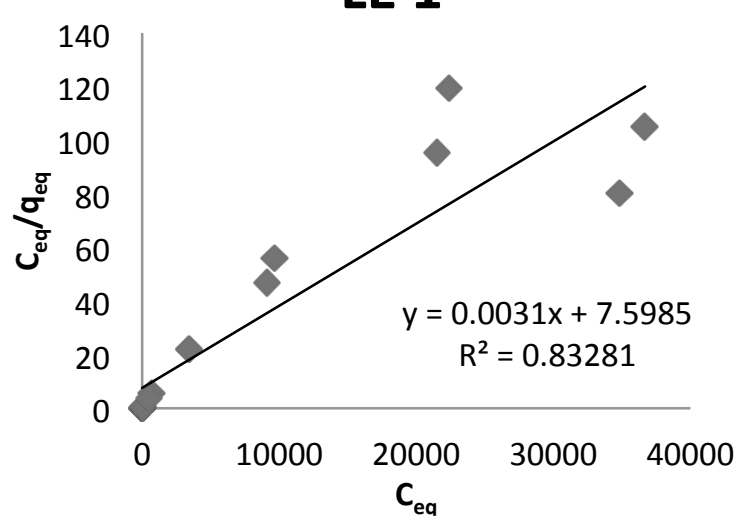



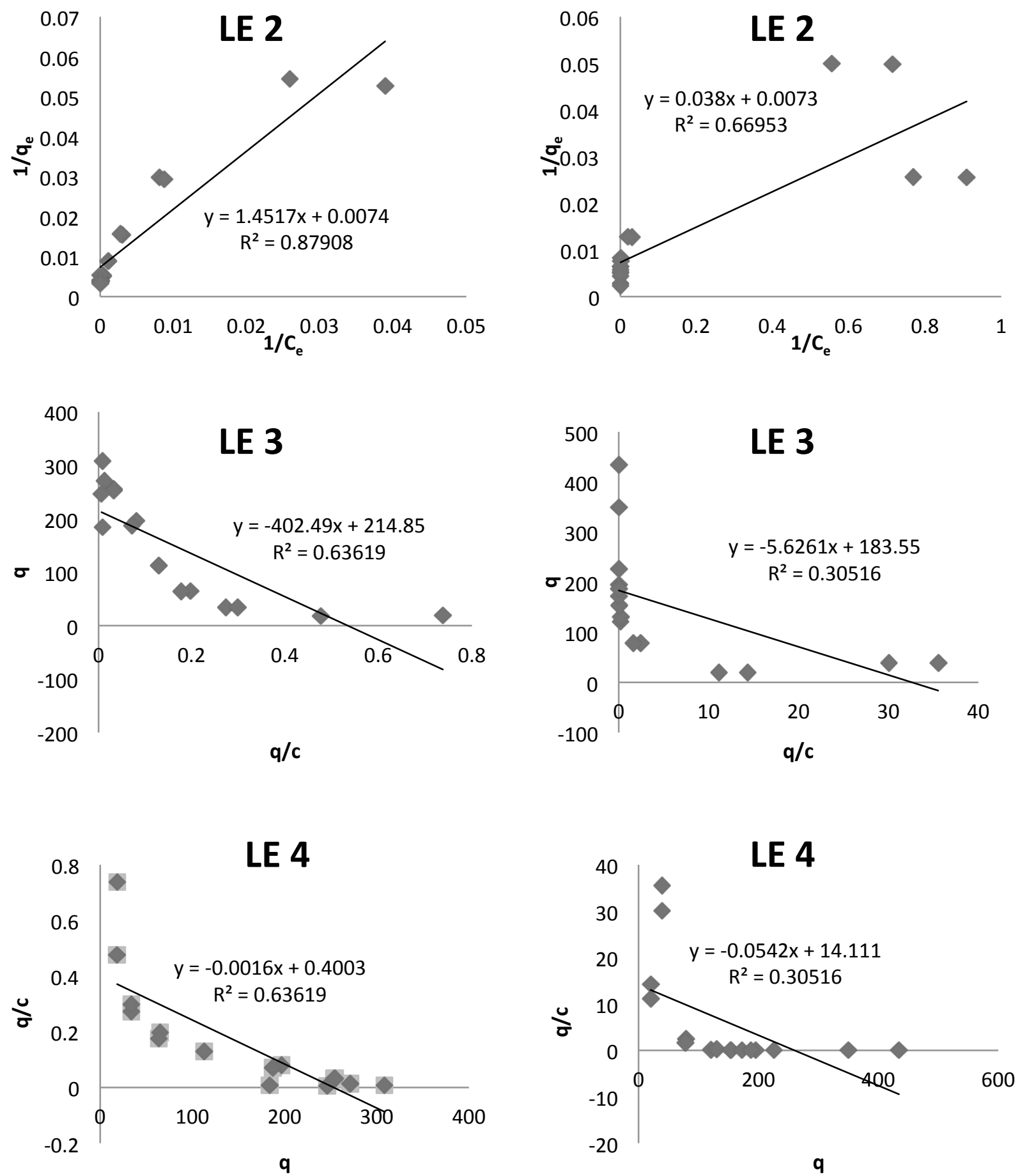

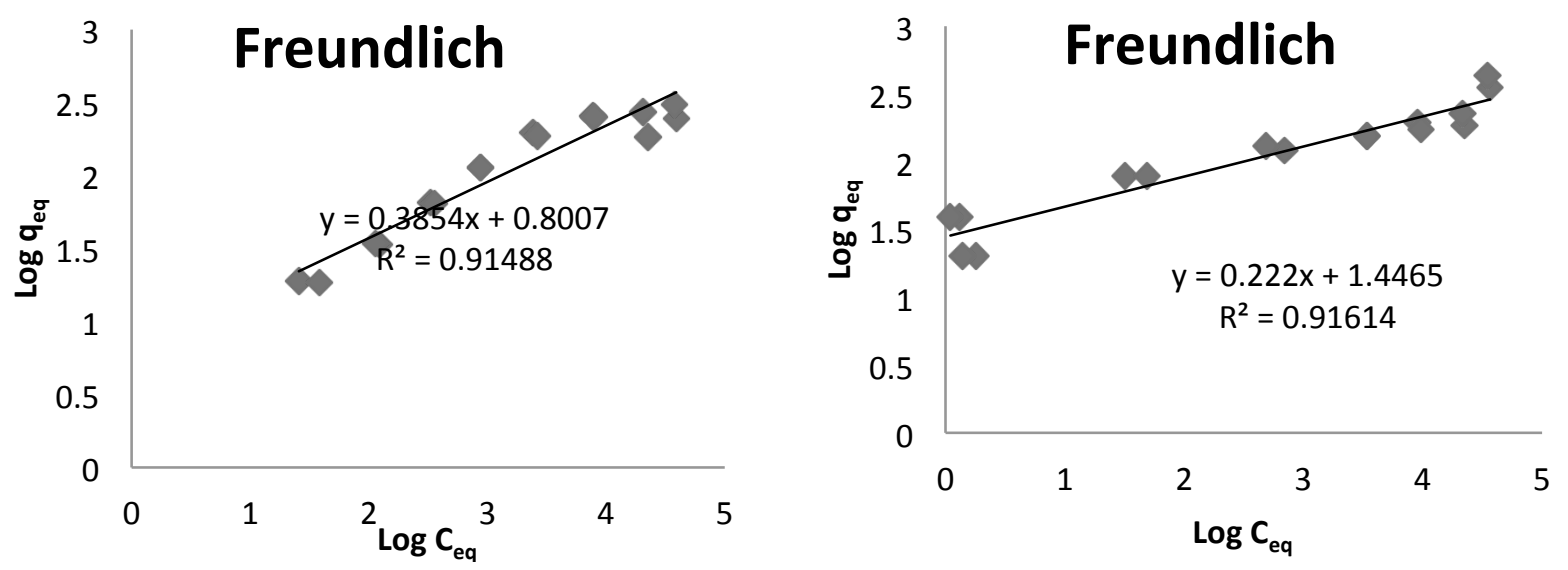

Figure 15 - Linear regression plots for arsenic equilibrium data 


\section{CADMIUM}

\section{LADYBUG SAND}
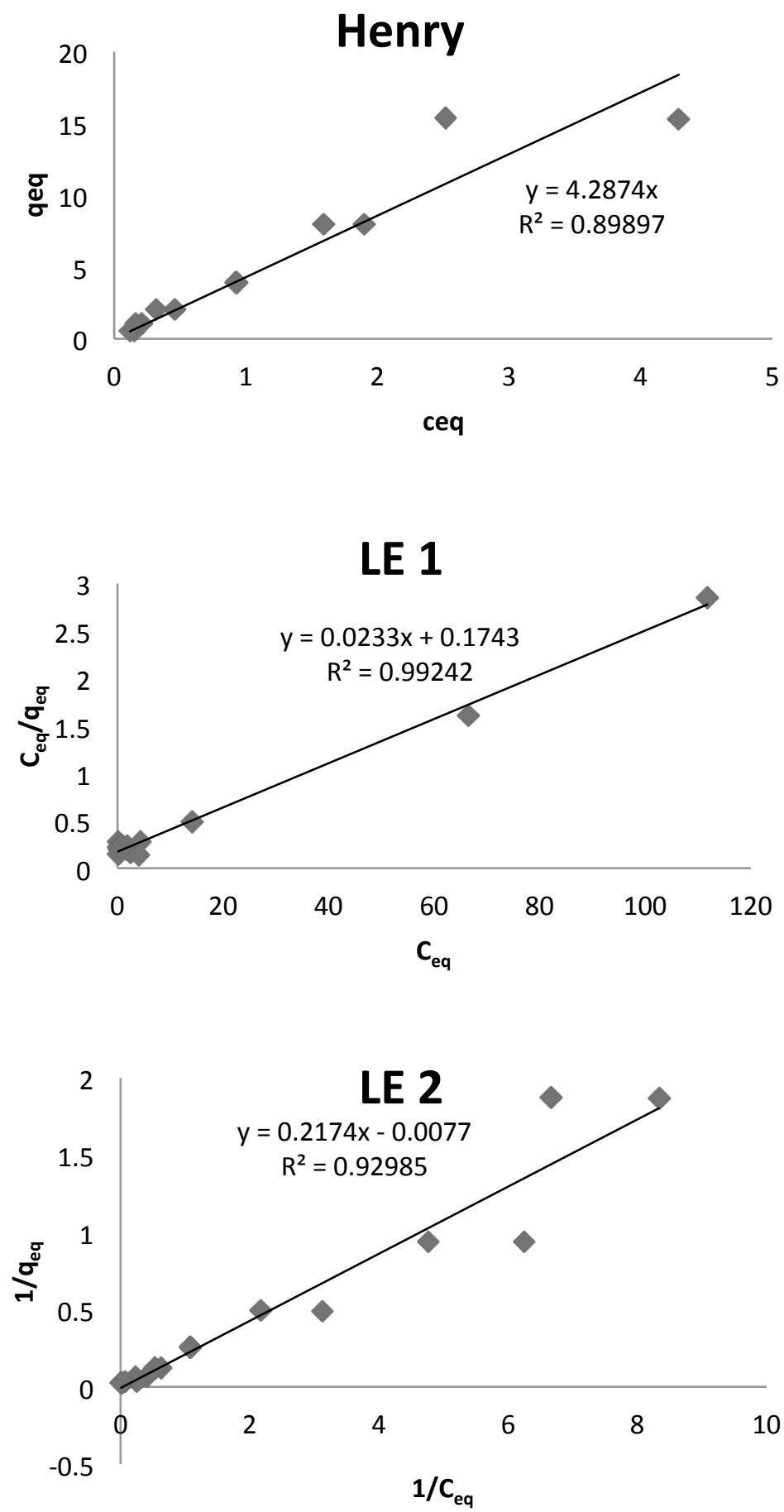

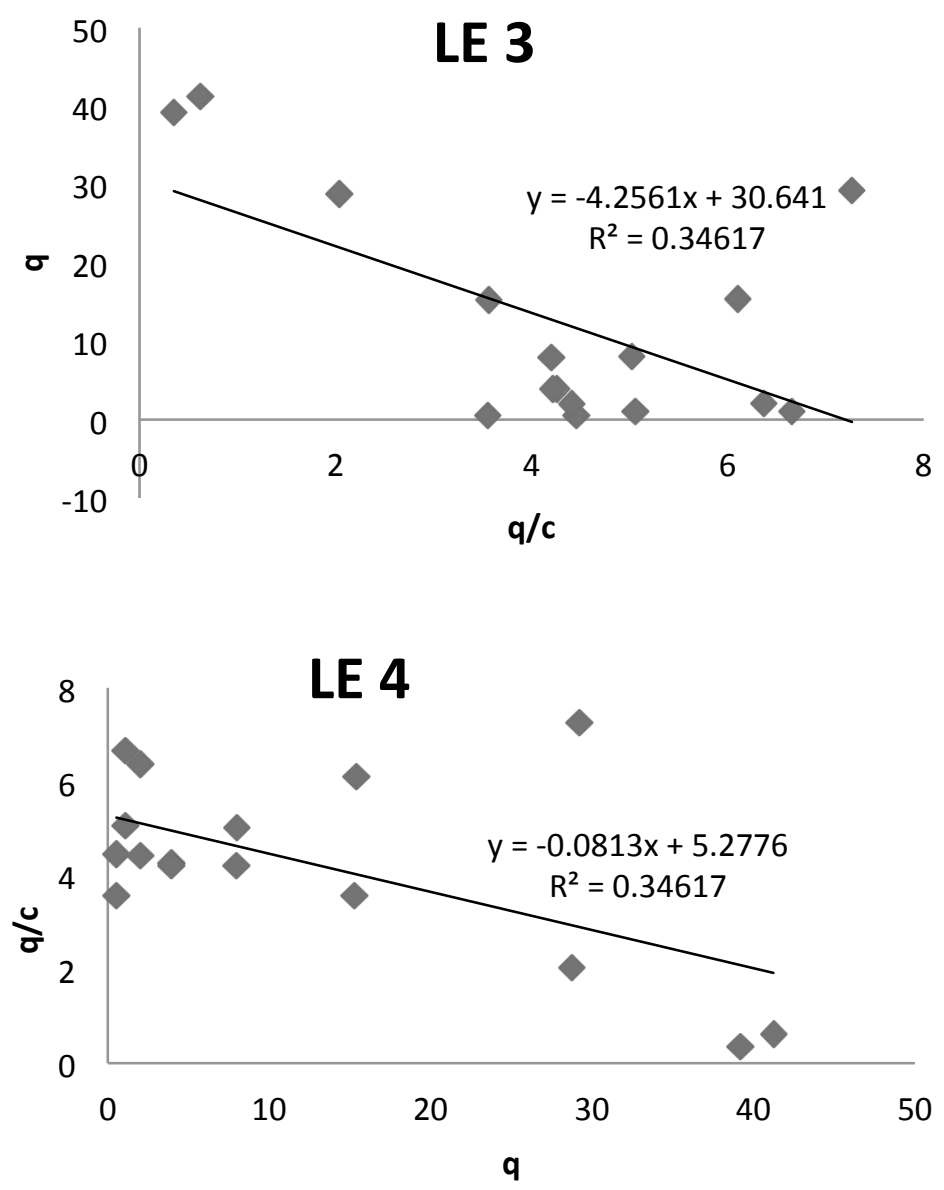

\section{Freundlich}

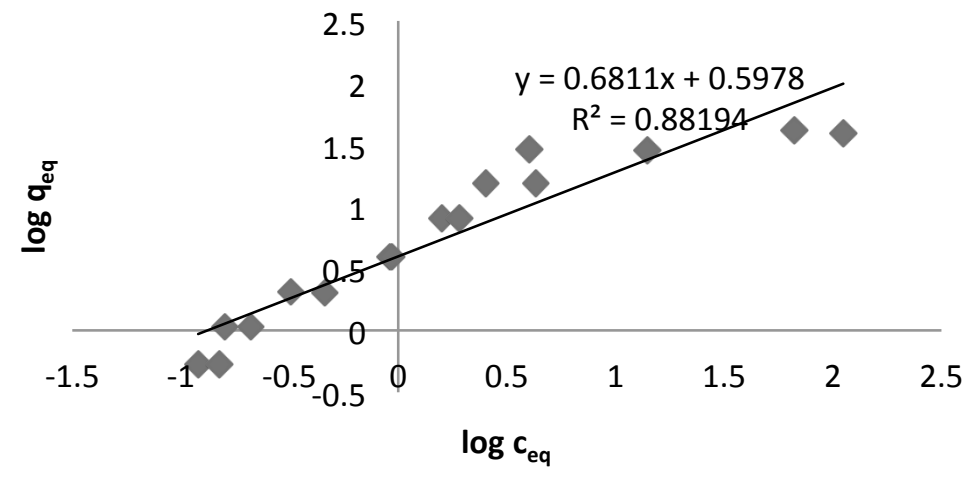

Figure 16 - Linear regression plots for cadmium data 
$\underline{\text { LEAD }}$

GREENSAND
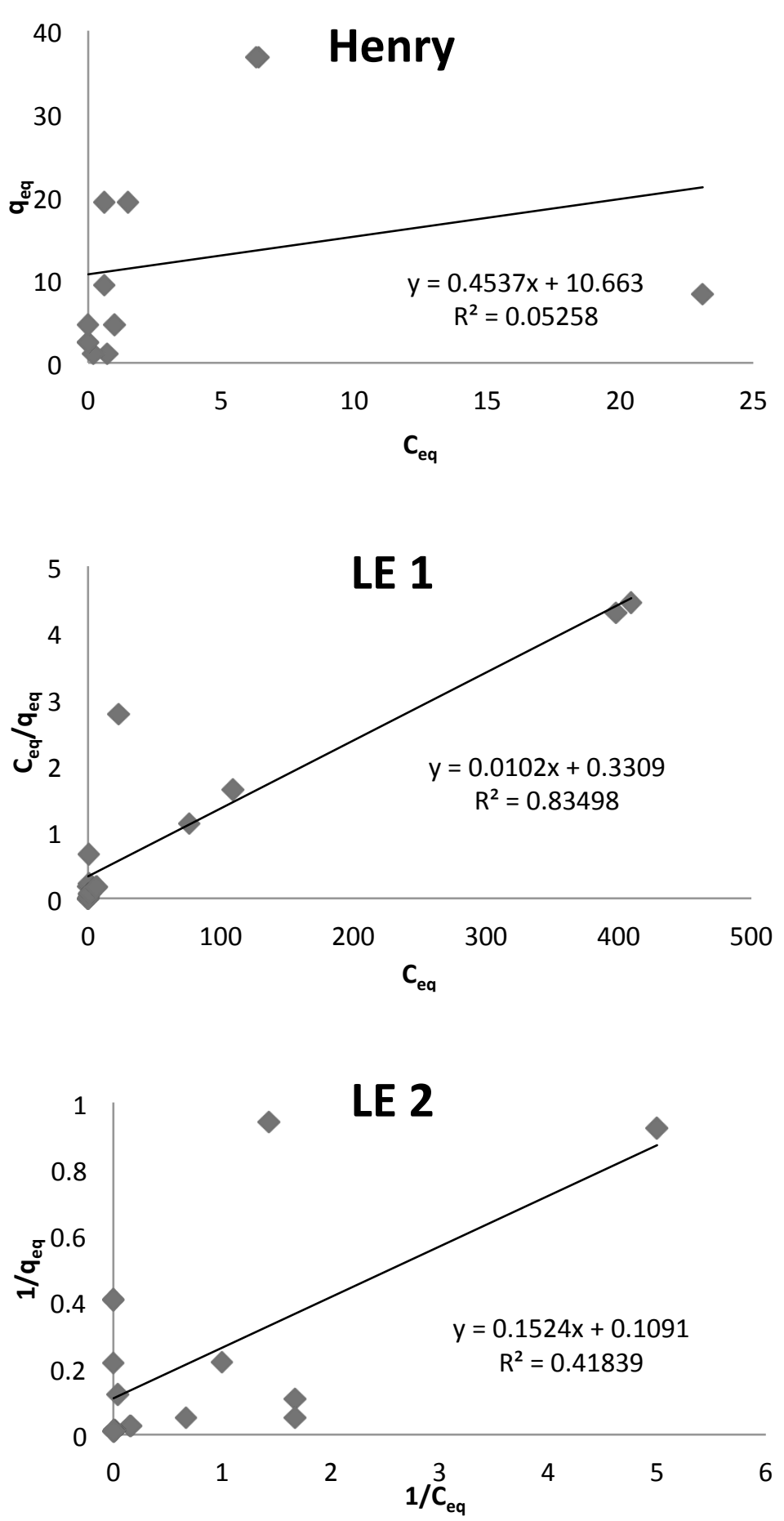

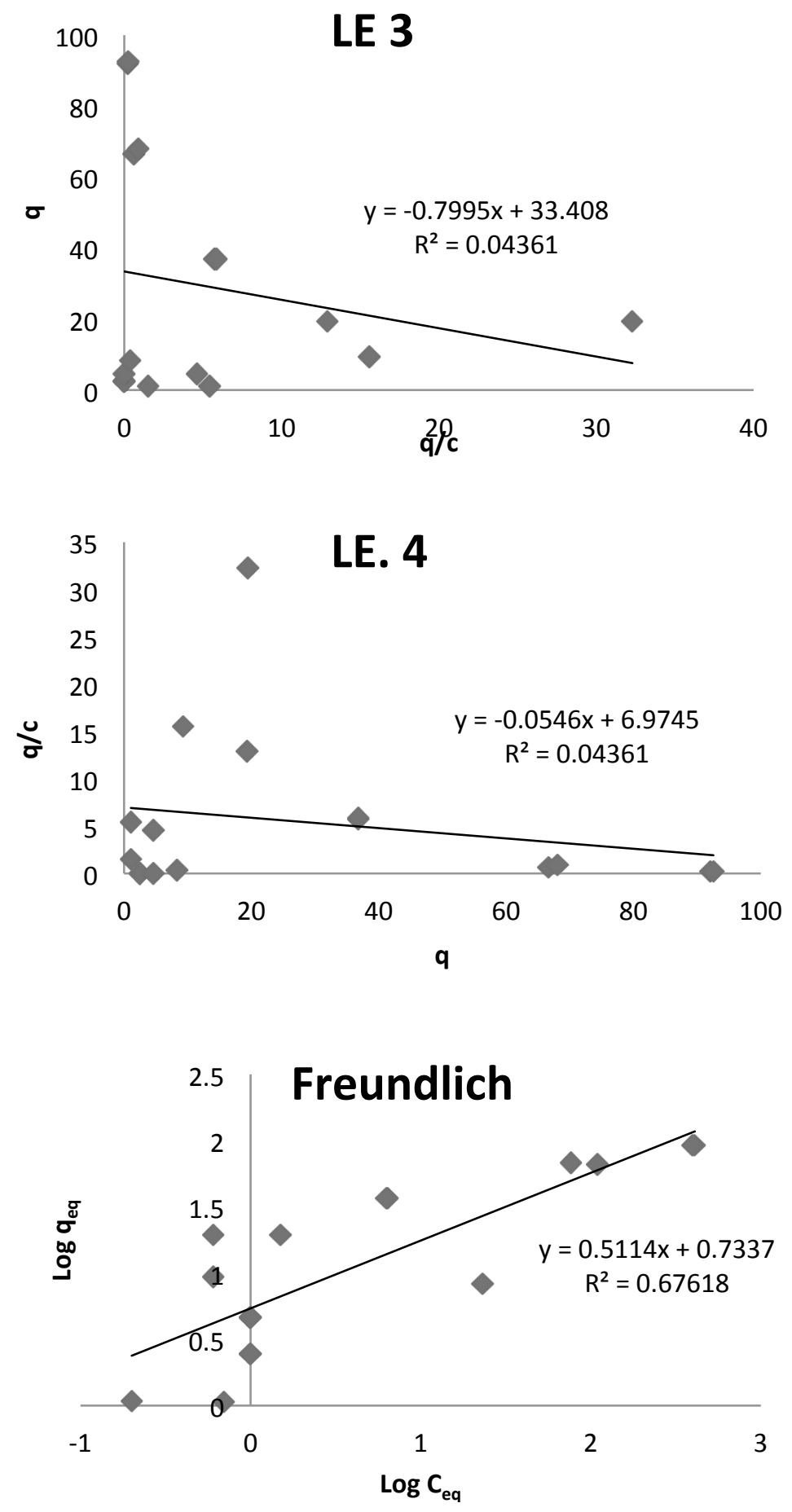

Figure 17 - Linear regression plots for lead equilibrium data 


\section{APPENDIX C: KINETIC LINEAR REGRESSION}

\section{Ladybug Sand}

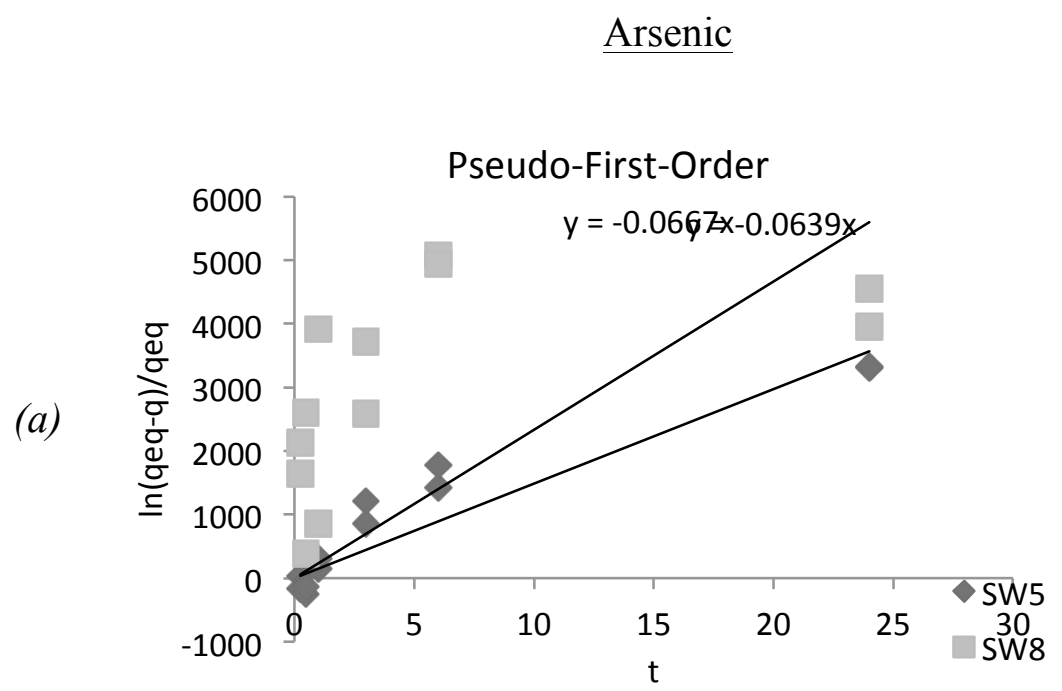

(b)

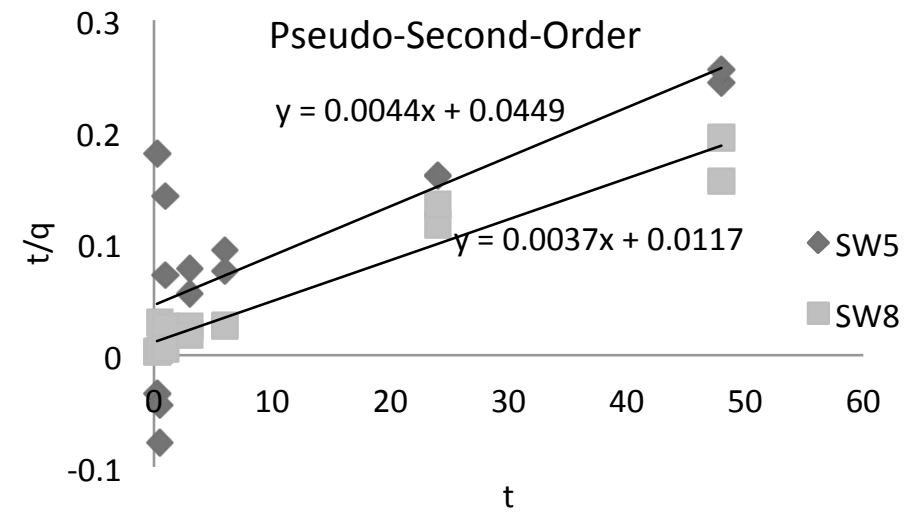

Figure 18 - (a) Pseudo-first-order and (b) pseudo-second-order models applied to arsenic kinetic batch data. 


\section{$\underline{\text { Cadmium }}$}
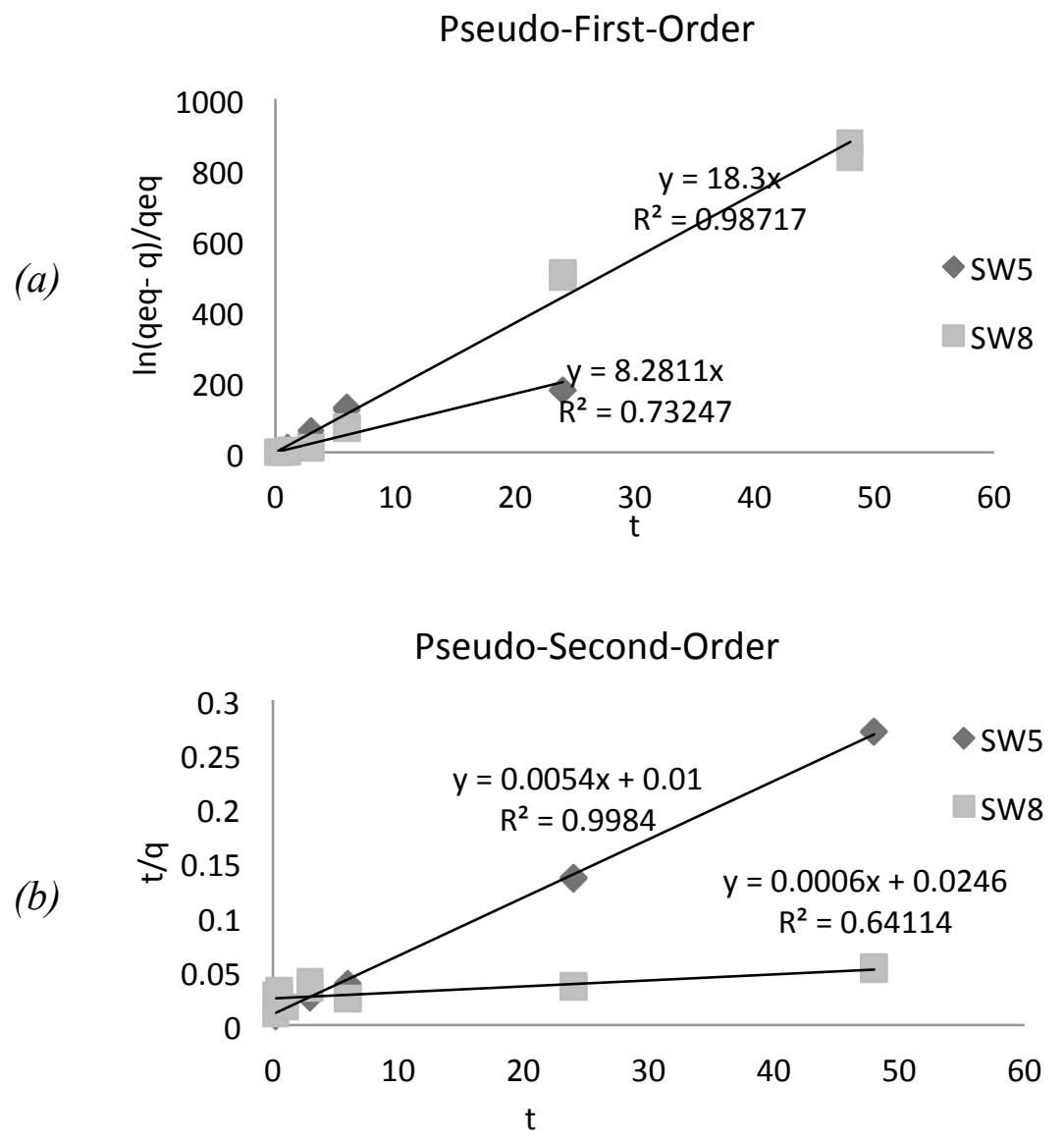

Figure 19 - (a) Pseudo-first-order and (b) pseudo-second-order models applied to cadmium kinetic batch data. 


\section{Lead}

(a)
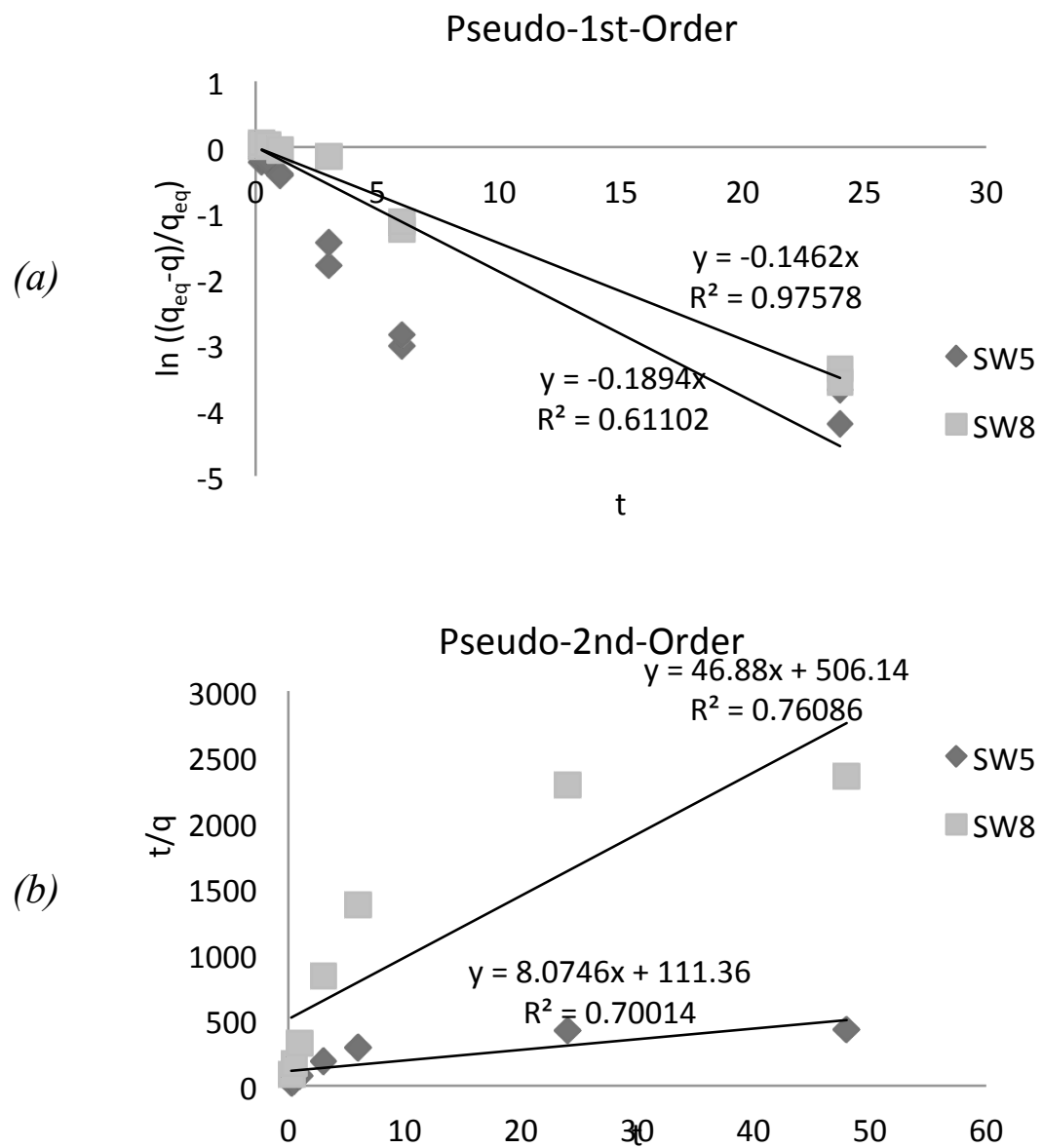

Figure 20-(a) Pseudo-first-order and (b) pseudo-second-order models applied to lead kinetic batch data. 


\section{GREEN SAND}
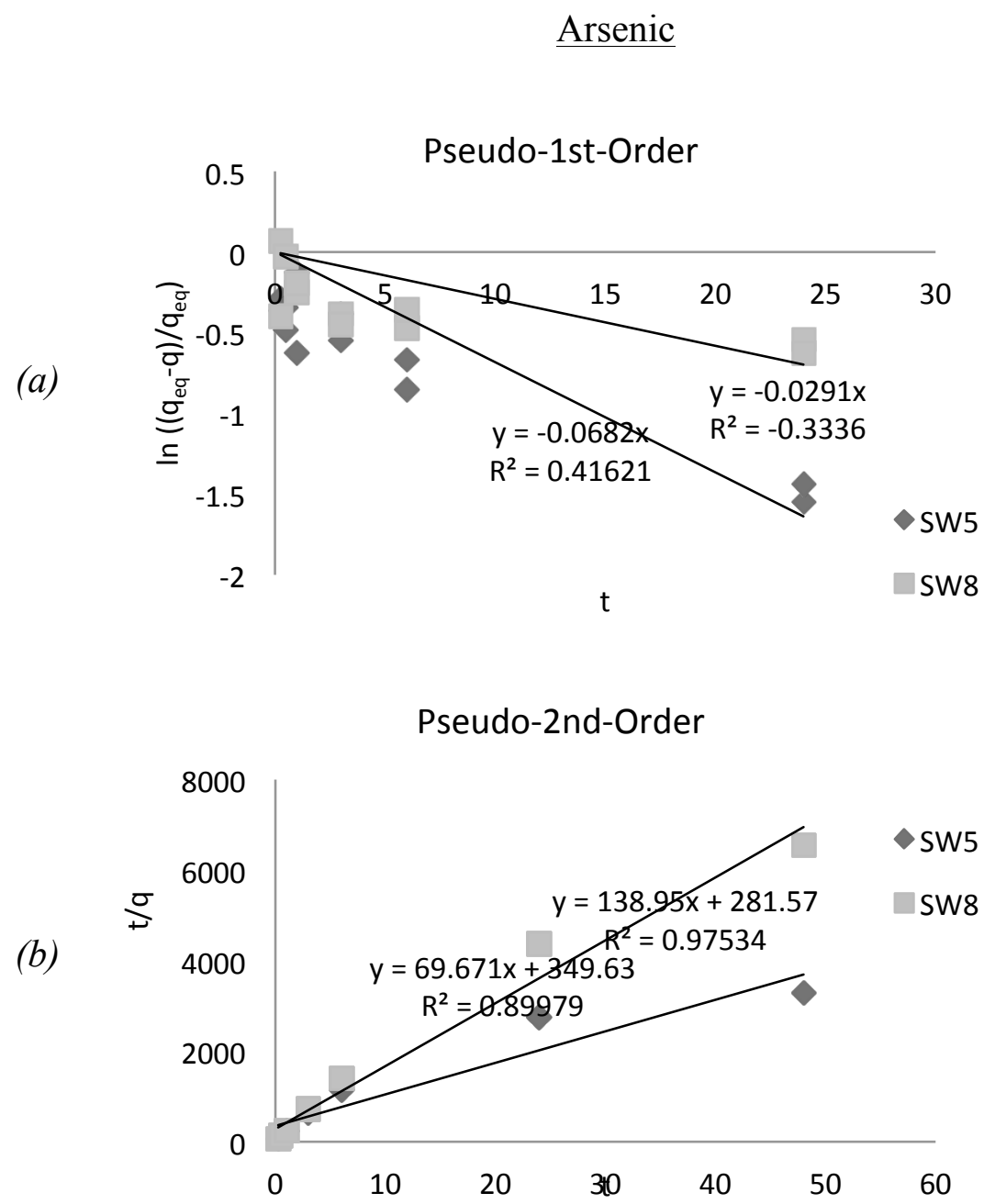

Figure 21 - (a) Pseudo-first-order and (b) pseudo-second-order models applied to arsenic kinetic batch data. 


\section{Lead}
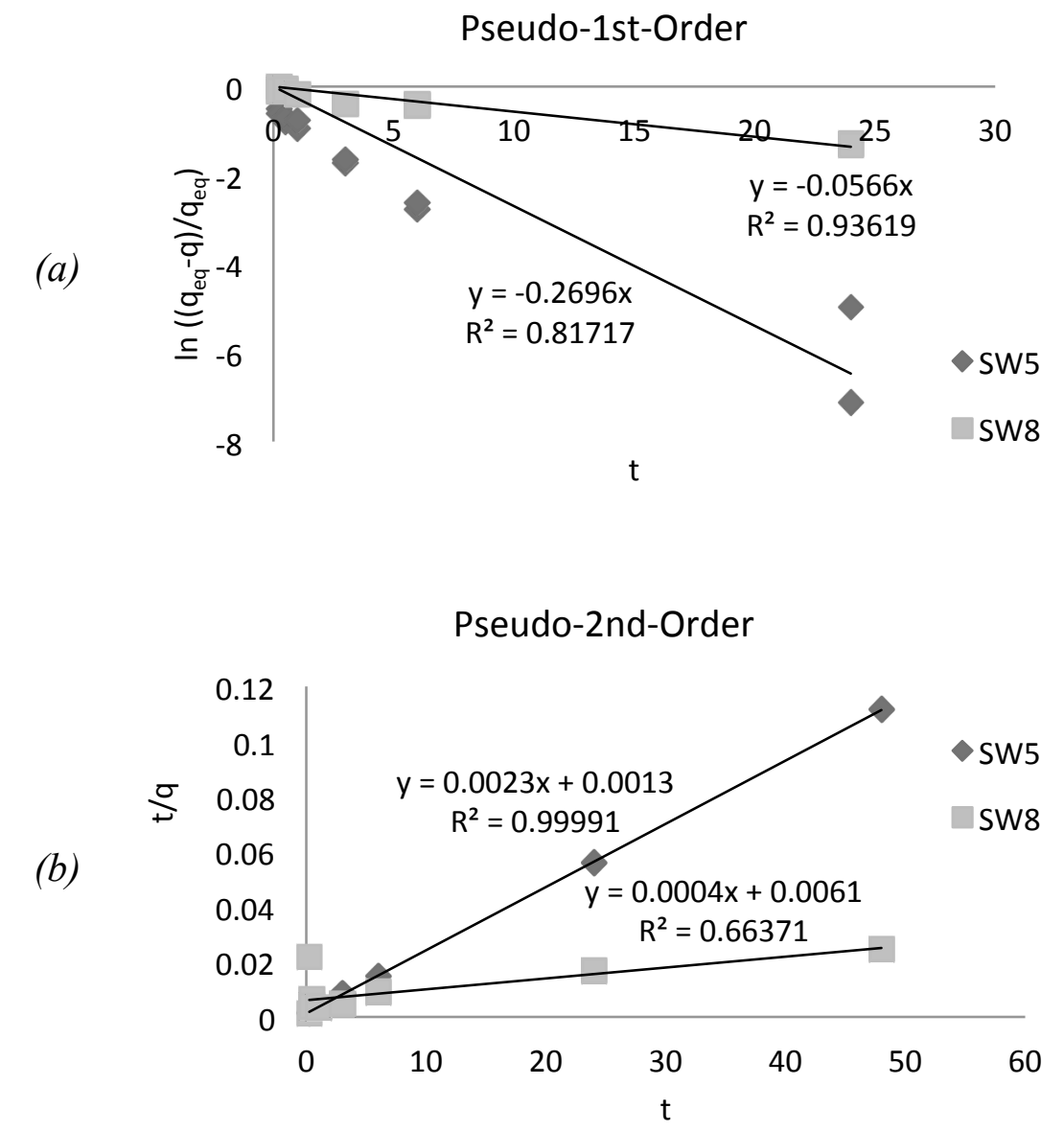

Figure 22 - (a) Pseudo-first-order and (b) pseudo-second-order models applied to Lead kinetic batch data. 


\section{APPENDIX D: SPECTRAL ANALYSIS OF SANDS (ICP-ES)}

Table 31 - Spectral analysis of sands (ICP-ES)

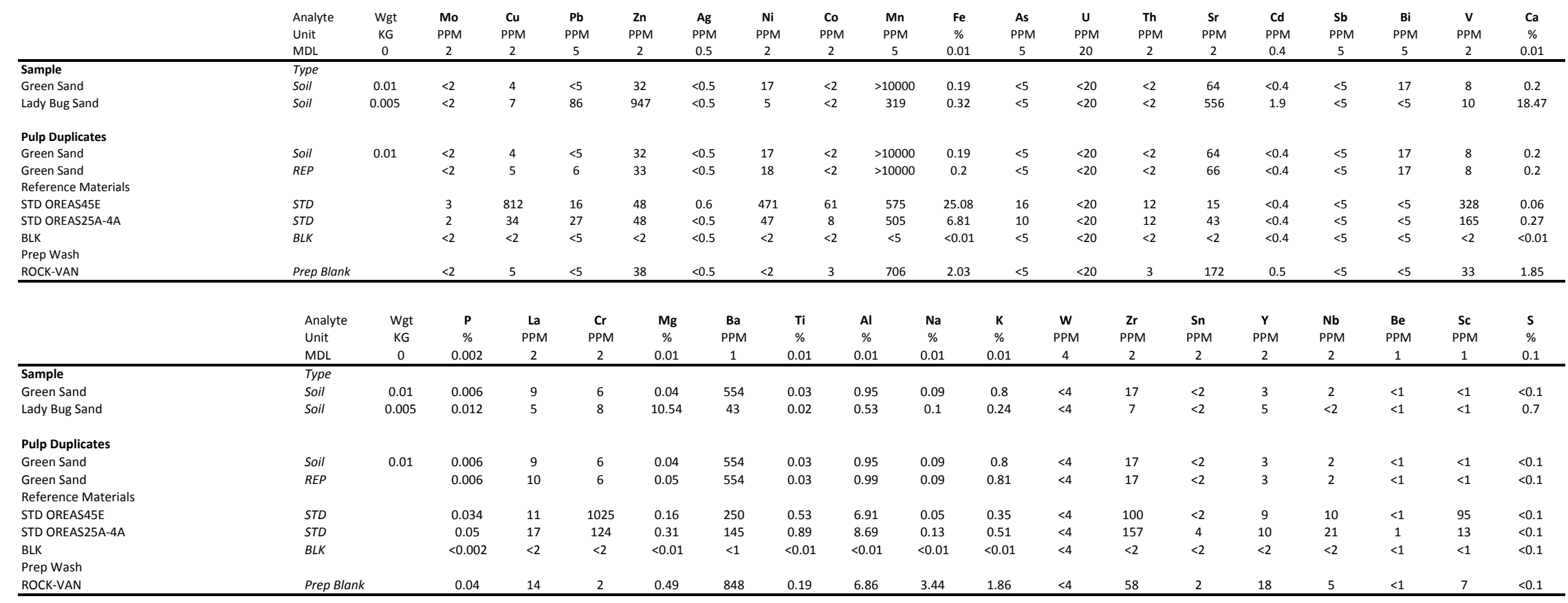


APPENDIX E: EH-PH DIAGRAMS

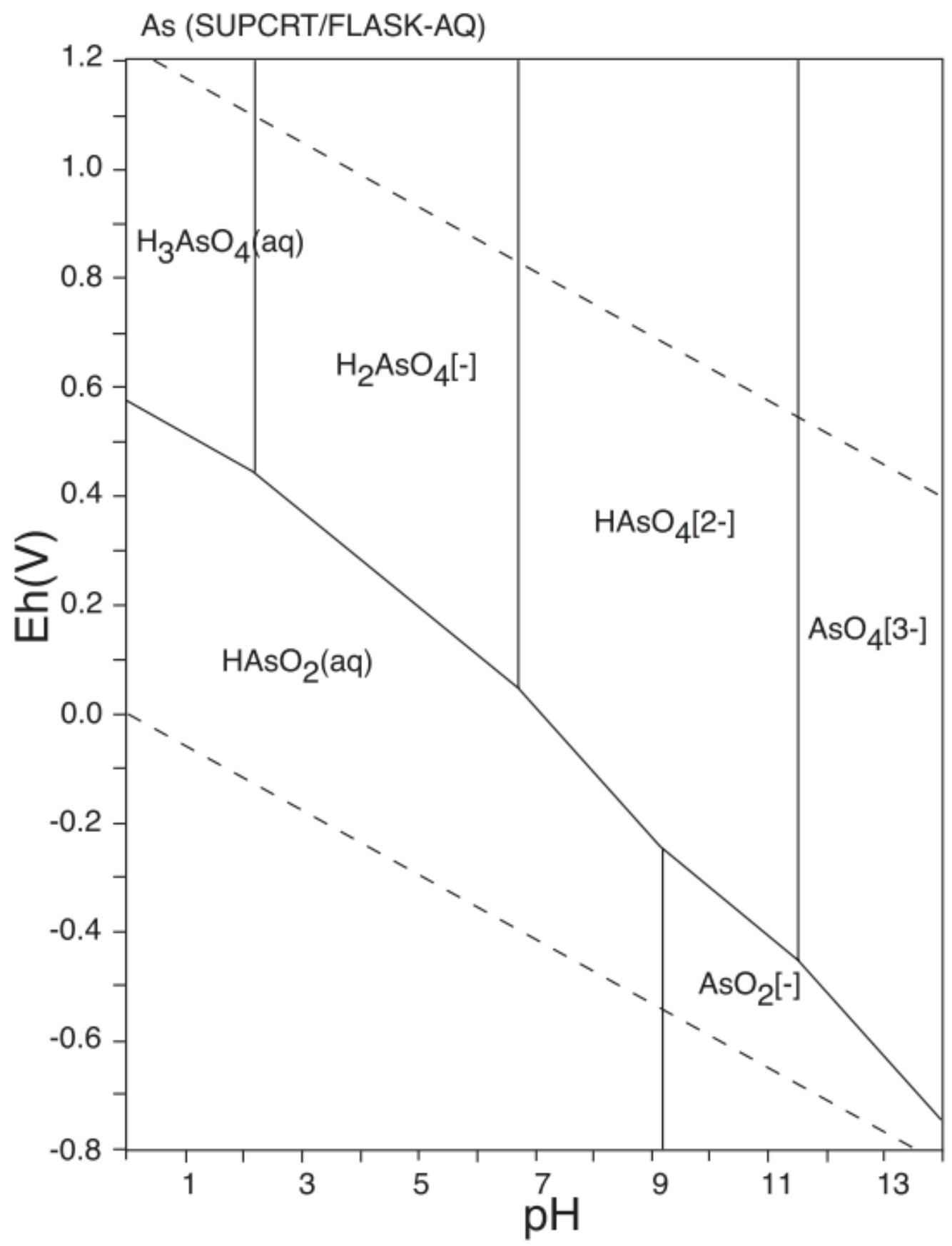

Figure 23 - Eh-pH diagram for arsenic (Takeno 2005) 


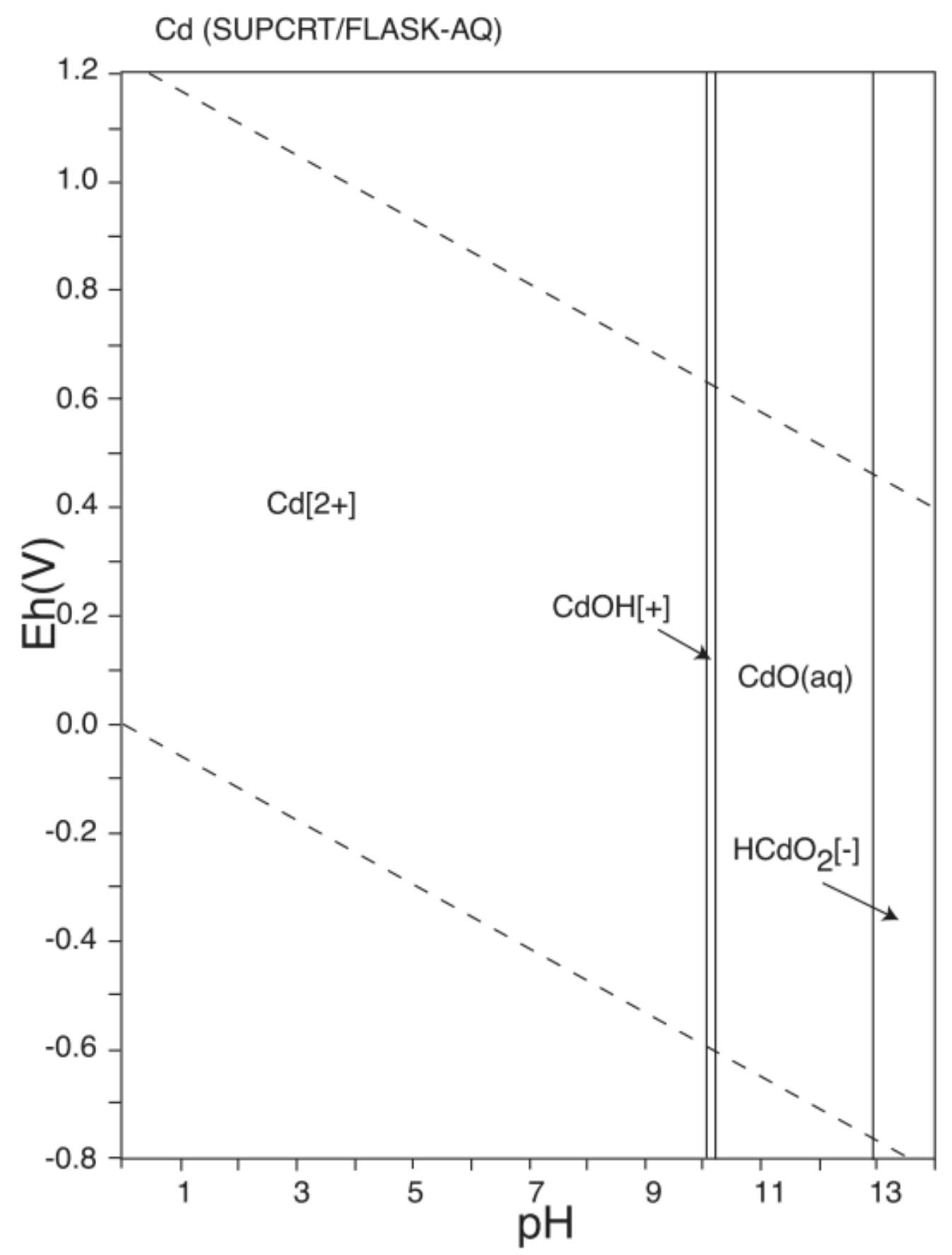

Figure 24 - Eh-pH diagram for cadmium (Takeno 2005) 


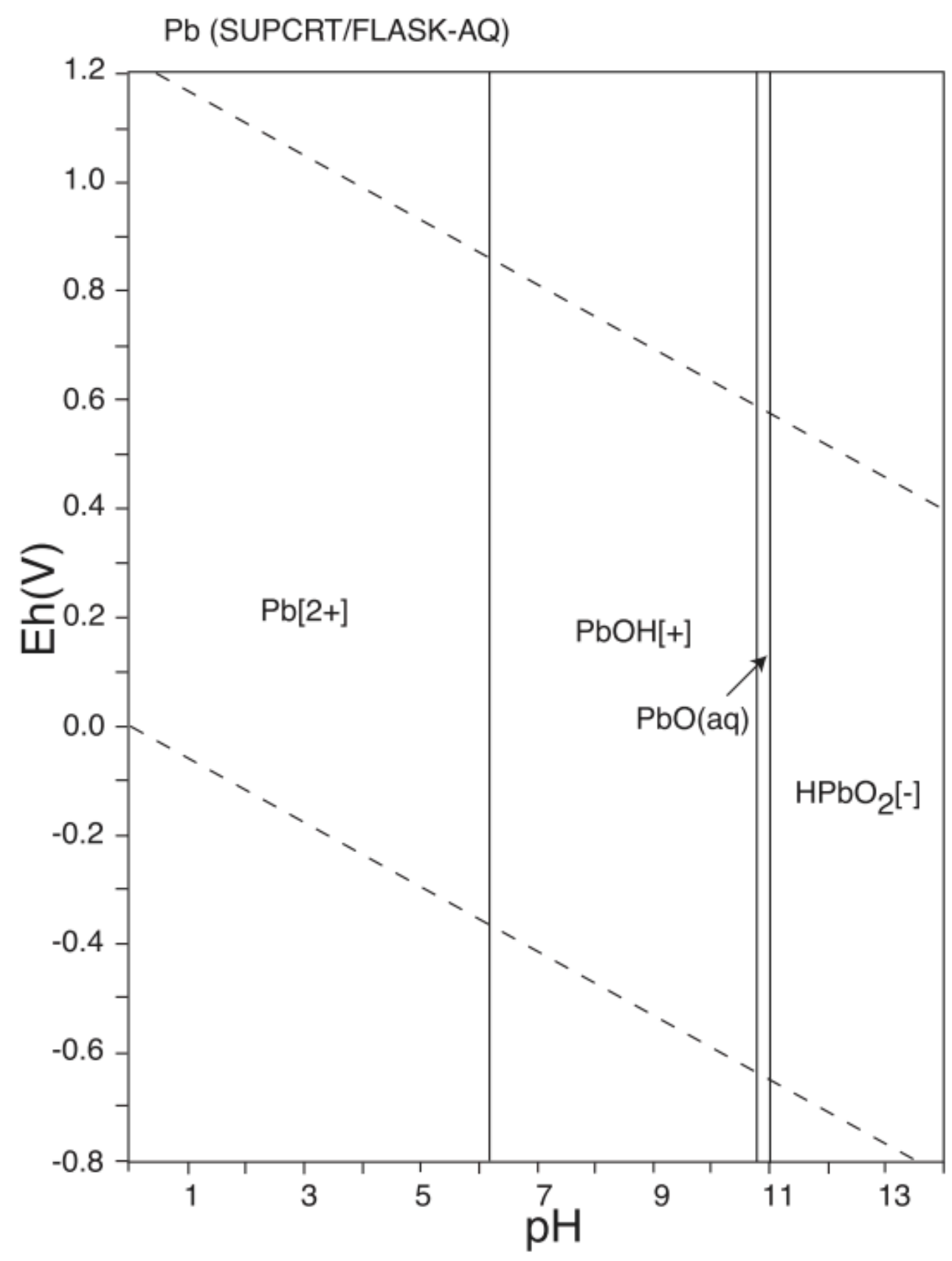

Figure 25 - Eh-pH diagram for lead (Takeno 2005) 


\section{REFERENCES}

Ali I, Gupta VK. 2006. Advances in water treatment by adsorption technology. Nat. Protoc. 1:2661-2667. doi:10.1038/nprot.2006.370.

American Association of State Highway and Transportation Officials. 2013. AASHTO T 88 Standard Method of Test for Particle Size Analysis of Soils.

Amrhar O, Nassali H, Elyoubi MS. 2015. Application of nonlinear regression analysis to select the optimum absorption isotherm for Methylene Blue adsorption onto Natural Illitic Clay. Bull. la Société R. des Sci. Liège 84:116-130.

April E. 2011. Soil, Ground Water and Sediment Standards for Use Under Part XV . 1 of the Environmental Protection Act.

Argun ME, Dursun S, Ozdemir C, Karatas M. 2007. Heavy metal adsorption by modified oak sawdust: Thermodynamics and kinetics. J. Hazard. Mater. 141:77-85. doi:10.1016/j.jhazmat.2006.06.095.

Arias F, Sen TK. 2009. Removal of zinc metal ion $(\mathrm{Zn} 2+)$ from its aqueous solution by kaolin clay mineral: A kinetic and equilibrium study. Colloids Surfaces A Physicochem. Eng. Asp. 348:100-108. doi:10.1016/j.colsurfa.2009.06.036.

Azizian S. 2004. Kinetic models of sorption: A theoretical analysis. J. Colloid Interface Sci. 276:47-52. doi:10.1016/j.jcis.2004.03.048.

Bolster CH, Hornberger GM. 2007. On the Use of Linearized Langmuir Equations. Soil Sci. Soc. 
Am. J. 71:1796-1806. doi:10.2136/sssaj2006.0304er.

Boulinguiez B, Cloirec P Le, Wolbert D. 2008. Revisiting the Determination of Langmuir Parameters s Application to Tetrahydrothiophene Adsorption onto Activated Carbon. 24:64206424. doi:10.1021/1a800725s.

Bradford A, Gharabaghi B. 2004. Evolution of Ontario's stormwater management planning and design guidance. Water Qual. Res. J. Canada 39:343-355.

City of Toronto. 2009. Design Criteria for Sewers and Watermains.

Clark SE, Pitt R. 2012. Targeting treatment technologies to address specific stormwater pollutants and numeric discharge limits. Water Res. 46:6715-6730.

doi:10.1016/j.watres.2012.07.009.

Cooney DO. 1999. Adsorption design for wastewater treatment. Lewis Publishers. [accessed 2017 May 3].

https://books.google.ca/books/about/Adsorption_Design_for_Wastewater_Treatme.html?id=jS3 BVK1T3iIC\&redir_esc $=\mathrm{y}$.

Echeverría JC, Morera MT, Mazkiarán C, Garrido JJ. 1998. Competitive sorption of heavy metal by soils. Isotherms and fractional factorial experiments. Environ. Pollut. 101:275-284. doi:10.1016/S0269-7491(98)00038-4.

El-Khaiary MI, Malash GF. 2011. Common data analysis errors in batch adsorption studies. Hydrometallurgy 105:314-320. doi:10.1016/j.hydromet.2010.11.005.

EPA. 2009. National Water Quality Inventory : Report to Congress 2004 Reporting Cycle. 
Water:43. doi:http://www.epa.gov/owow/305b/2004report/.

Foo KY, Hameed BH. 2010. Insights into the modeling of adsorption isotherm systems. Chem. Eng. J. 156:2-10. doi:10.1016/j.cej.2009.09.013.

Genç-Fuhrman H, Mikkelsen PS, Ledin A. 2007. Simultaneous removal of As, Cd, Cr, Cu, Ni and Zn from stormwater: Experimental comparison of 11 different sorbents. Water Res. 41:591602. doi:10.1016/j.watres.2006.10.024.

Gupta VK, Carrott PJM, Ribeiro Carrott MML, Suhas. 2009. Low-Cost Adsorbents: Growing Approach to Wastewater Treatment—a Review. Crit. Rev. Environ. Sci. Technol. 39:783-842. doi:10.1080/10643380801977610.

Hand DW, Crittenden JC, M. ASCE, Thacker WE. 1983. User-oriented batch reactor solutions to the homogeneous surface diffusion model for different activated carbon dosages. J. Environ. Eng. 109:82-101. doi:10.1016/j.watres.2009.01.028.

Ho Y-S. 2004a. Selection of optimum sorption isotherm. Carbon N. Y. 42:2115-2116. doi:10.1016/j.carbon.2004.03.019.

Ho Y-S. 2004b. Citation review of Lagergren kinetic rate equation on adsorption reactions. Scientometrics 59:171-177. doi:10.1023/B.

Ho Y-S. 2006. Isotherms for the Sorption of Lead Onto Peat: Comparison of Linear and NonLinear Methods. Polish J. Environ. Stud. 15:81-86.

Ho Y-S, McKay G. 1998. A comparison of chemisorption kinetic models applied to pollutant removal on various sorbents. Process Saf. Environ. Prot. 76:332-340. 
doi:10.1205/095758298529696.

Ho Y-S, McKay G. 1999. Pseudo-second order model for sorption processes. Process Biochem. 34:451-465. doi:10.1016/S0032-9592(98)00112-5.

Ho Y-S, Ng J. CY, McKay G. 2000. Kinetics of pollutant sorption by biosorbents: review. Sep. Purif. Methods 29:189-232. doi:10.1081/SPM-100100009.

Hungerford \& Terry Inc. 2003. Greensand process removes iron, manganese, arsenic from groundwater. Water Waste Dig. Mag. [accessed 2017 Sep 21]. https://www.wwdmag.com/arsenic/greensand-process-removes-iron-manganese-arsenicgroundwater.

Knaebel KSK. 2007. A How “To Guide” for Adsorber Design. Adsorpt. Res. Inc. Dublin, Ohio:23.

Koumoulas P. 2015. Review and decision support of options for the removal, treatment and disposal of stormwater sediments. Ryerson University.

Limousin G, Gaudet J-P, Charlet L, Szenknect S, Barthès V, Krimissa M. 2007. Sorption isotherms: A review on physical bases, modeling and measurement. Appl. Geochemistry 22:249-275. doi:10.1016/j.apgeochem.2006.09.010.

Ministry of the Environment. 2003. Stormwater Management Planning and Design Manual.

Plazinski W, Rudzinski W, Plazinska A. 2009. Theoretical models of sorption kinetics including a surface reaction mechanism: A review. Adv. Colloid Interface Sci. 152:2-13. doi:10.1016/j.cis.2009.07.009. 
Prahas D, Kartika Y, Indraswati N, Ismadji S. 2008. Activated carbon from jackfruit peel waste by $\mathrm{H} 3 \mathrm{PO} 4$ chemical activation: Pore structure and surface chemistry characterization. Chem. Eng. J. 140:32-42. doi:10.1016/j.cej.2007.08.032.

Qiu H, Lv L, Pan B, Zhang Q, Zhang W, Zhang Q. 2009. Critical review in adsorption kinetic models. J. Zhejiang Univ. Sci. A 10:716-724. doi:10.1631/jzus.A0820524.

Reddy KR, Xie T, Dastgheibi S. 2014. Adsoprtion of mixtures of nutrients and heavy metals in simulated urban stormwater by different filter materials. Water. Air. Soil Pollut. 225. doi:10.1007/s11270-013-1778-8.

Roy D, Wang G, Adrian DD. 1993. A Simplified Solution Technique For Carbon Adsorption Model. Water Resour. 27:1033-1040.

Simonin JP. 2016. On the comparison of pseudo-first order and pseudo-second order rate laws in the modeling of adsorption kinetics. Chem. Eng. J. 300:254-263. doi:10.1016/j.cej.2016.04.079.

Statistics Canada. 2007. Weather conditions in capital and major cities (Precipitation). [accessed 2017 Sep 14]. http://www.statcan.gc.ca/tables-tableaux/sum-som/101/cst01/phys08a-eng.htm.

Sukpreabprom H, Arquero O-A, Naksata W, Sooksamiti P, Janhom S. 2014. Isotherm, Kinetic and Thermodynamic Studies on the Adsorption of Cd (II) and Zn (II) ions from Aqueous Solutions onto Bottom Ash. Int. J. Environ. Sci. Dev. 5:165-170. doi:10.7763/IJESD.2014.V5.471.

Takeno N. 2005. Atlas of Eh-pH diagrams Intercomparison of thermodynamic databases. Natl. Inst. Adv. Ind. Sci. Technol. Tokyo:285. 
Toronto and Region Conservation Authority. 2005. Synthesis of Monitoring Studies Conducted Under the Stormwater Assessment Monitoring and Performance Program.

Tran H, You S-J, Hosseini-Bandegharaei A, Chao H-P. 2017. Mistakes and inconsistencies regarding adsorption of contaminants from aqueous solutions: A critical review. Water Res. 120:88-116. doi:10.1016/j.watres.2017.04.014.

Tuccillo ME. 2006. Size fractionation of metals in runoff from residential and highway storm sewers. Sci. Total Environ. 355:288-300. doi:10.1016/j.scitotenv.2005.03.003.

Vijayakumar G, Tamilarasan R, Dharmendirakumar M. 2012. Adsorption, kinetic, equilibrium and thermodynamic studies on the removal of basic dye Rhodamine-B from aqueous solution by the use of natural adsorbent perlite. J. Mater. Environ. Sci. 3:157-170.

Vollertsen J, Lange KH, Pedersen J, Hallager P, Brink-kjær A. 2009. Advanced stormwater treatment - comparison of technologies. In: Proceedings of the 11th Nordic/Nordiwa Wastewater Conference. p. 44-53.

Vollertsen J, Lange KH, Pedersen J, Hallager P, Bruus A, Laustsen A, Bundesen VW, Brix H, Nielsen a. H, Nielsen NH, et al. 2009. Monitoring the startup of a wet detention pond equipped with sand filters and sorption filters. Water Sci. Technol. 60:1071-1079. doi:10.2166/wst.2009.460.

Weber T, Chakravorti R. 1974. Pore and solid diffusion models for fixed bed adsorbers. Am. Inst. Chem. Eng. J. 20:229-238.

Weber WJ, Smith EH. 1987. Simulation and design models for adsorption processes. Environ. 
Sci. Technol. 21:1040-1050.

Wium-Andersen T, Nielsen AH, Hvitved-Jacobsen T, Kristensen NK, Brix H, Arias CA, Vollertsen J. 2012. Sorption media for stormwater treatment - a laboratory evaluation of five low-cost media for their ability to remove metals and phosphorus from artificial stormwater. Water Environ. Res. 84:605-616. doi:10.2175/106143012X13373550426832.

Worch E. 2008. Fixed-bed adsorption in drinking water treatment: A critical review on models and parameter estimation. J. Water Supply Res. Technol. - AQUA 57:171-183. doi:10.2166/aqua.2008.100.

Worch E. 2012. Adsorption Technology in Water Treatment: Fundamentals, Processes, and Modeling.

Wu P, Zhou YS. 2009. Simultaneous removal of coexistent heavy metals from simulated urban stormwater using four sorbents: A porous iron sorbent and its mixtures with zeolite and crystal gravel. J. Hazard. Mater. 168:674-680. doi:10.1016/j.jhazmat.2009.02.093.

Zhang Q, Crittenden JC, Hristovski K, Hand D, Westerhoff P. 2009. User-oriented batch reactor solutions to the homogeneous surface diffusion model for different activated carbon dosages. Water Res. 43:1859-1866. doi:10.1016/j.watres.2009.01.028. 


\section{GLOSSARY}

$\mathrm{SWAMP}=$ Stormwater Assessment and Management Program

TRCA $=$ Toronto and Region Conservation Authority

$\mathrm{MOE}=$ Ministry of the Environment

$\mathrm{EPA}=$ Environmental Protection Agency

PWQO $=$ Provincial Water Quality Objectives

$\mathrm{BMP}=$ best management practices

TSS $=$ total suspended solids

$\mathrm{q}=$ adsorbent loading

$\mathrm{C}=$ concentration

$\mathrm{D}_{\mathrm{s}}=$ surface diffusion coefficient

$\mathrm{k}_{1}=$ pseudo-first-order reaction coefficient

$\mathrm{k}_{2}=$ pseudo-second-order reaction coefficient

HSDM $=$ homogenous surface diffusion model

$\mathrm{BTC}=$ Breakthrough Curve 